Cochrane Database of Systematic Reviews

\title{
Adrenaline and vasopressin for cardiac arrest (Review)
}

Finn J, Jacobs I, Williams TA, Gates S, Perkins GD

Finn J, Jacobs I, Williams TA, Gates S, Perkins GD.

Adrenaline and vasopressin for cardiac arrest.

Cochrane Database of Systematic Reviews 2019, Issue 1. Art. No.: CD003179.

DOI: 10.1002/14651858.CD003179.pub2. 
TABLE OF CONTENTS

HEADER 1

ABSTRACT

PLAIN LANGUAGE SUMMARY

SUMMARY OF FINDINGS

BACKGROUND

OBJECTIVES

METHODS

RESULTS

Figure 1.

Figure 2.

Figure 3.

Figure 4.

Figure 5.

DISCUSSION

AUTHORS' CONCLUSIONS

ACKNOWLEDGEMENTS

REFERENCES

CHARACTERISTICS OF STUDIES

DATA AND ANALYSES

Analysis 1.1. Comparison 1 Standard dose adrenaline (SDA) versus placebo, Outcome 1 Survival to hospital discharge. ..........

Analysis 1.2. Comparison 1 Standard dose adrenaline (SDA) versus placebo, Outcome 2 Survival to hospital admission. ........

Analysis 1.3. Comparison 1 Standard dose adrenaline (SDA) versus placebo, Outcome 3 Neurological outcome. ....................

Analysis 1.4. Comparison 1 Standard dose adrenaline (SDA) versus placebo, Outcome 4 ROSC.

Analysis 2.1. Comparison 2 Standard dose adrenaline (SDA) versus high dose adrenaline (HDA), Outcome 1 Survival to hospital discharge.

Analysis 2.2. Comparison 2 Standard dose adrenaline (SDA) versus high dose adrenaline (HDA), Outcome 2 Survival to hospital discharge (adult vs child).

Analysis 2.3. Comparison 2 Standard dose adrenaline (SDA) versus high dose adrenaline (HDA), Outcome 3 Survival to hospital discharge (OHCA vs IHCA).

Analysis 2.4. Comparison 2 Standard dose adrenaline (SDA) versus high dose adrenaline (HDA), Outcome 4 Survival to hospital admission.

Analysis 2.5. Comparison 2 Standard dose adrenaline (SDA) versus high dose adrenaline (HDA), Outcome 5 24-hour survival. .. Analysis 2.6. Comparison 2 Standard dose adrenaline (SDA) versus high dose adrenaline (HDA), Outcome 6 Neurological outcome.

Analysis 2.7. Comparison 2 Standard dose adrenaline (SDA) versus high dose adrenaline (HDA), Outcome 7 ROSC (OHCA vs IHCA).

Analysis 2.8. Comparison 2 Standard dose adrenaline (SDA) versus high dose adrenaline (HDA), Outcome 8 ROSC (adults vs children).

Analysis 3.1. Comparison 3 Standard dose adrenaline (SDA) versus vasopressin, Outcome 1 Survival to hospital discharge. .... Analysis 3.2. Comparison 3 Standard dose adrenaline (SDA) versus vasopressin, Outcome 2 Survival to hospital discharge (OHCA vs IHCA).

Analysis 3.3. Comparison 3 Standard dose adrenaline (SDA) versus vasopressin, Outcome 3 Survival to hospital admission. ... Analysis 3.4. Comparison 3 Standard dose adrenaline (SDA) versus vasopressin, Outcome 4 Neurological Outcome.

Analysis 3.5. Comparison 3 Standard dose adrenaline (SDA) versus vasopressin, Outcome 5 ROSC.

Analysis 3.6. Comparison 3 Standard dose adrenaline (SDA) versus vasopressin, Outcome 6 ROSC (OHCA vs IHCA). ................. Analysis 4.1. Comparison 4 Standard dose adrenaline (SDA) versus [adrenaline and vasopressin], Outcome 1 Survival to hospital discharge.

Analysis 4.2. Comparison 4 Standard dose adrenaline (SDA) versus [adrenaline and vasopressin], Outcome 2 Survival to hospital admission.

Analysis 4.3. Comparison 4 Standard dose adrenaline (SDA) versus [adrenaline and vasopressin], Outcome 3 Neurological Outcome.

Analysis 4.4. Comparison 4 Standard dose adrenaline (SDA) versus [adrenaline and vasopressin], Outcome 4 ROSC. .............. APPENDICES

2

4

10

11

11

13

14

18

19

21

22

25

29

29

30

37

72

73

73

74 
[Intervention Review]

\section{Adrenaline and vasopressin for cardiac arrest}

Judith Finn 1,2 , Ian Jacobs $1,2 a$, Teresa A Williams ${ }^{3}$, Simon Gates ${ }^{4}$, Gavin D Perkins 5

1Prehospital, Resuscitation and Emergency Care Research Unit (PRECRU), Curtin University, Bentley, Australia. ${ }^{2}$ St John Ambulance Western Australia, Belmont, Australia. ${ }^{3}$ Royal Perth Hospital, Perth, Australia. ${ }^{4}$ Cancer Research UK Clinical Trials Unit, School of Cancer Sciences, Institute of Cancer and Genomic Sciences, University of Birmingham, Birmingham, UK. 5 Warwick Medical School and University Hospitals Birmingham, University of Warwick, Coventry, UK

a Deceased

Contact address: Judith Finn, Prehospital, Resuscitation and Emergency Care Research Unit (PRECRU), Curtin University, Kent Street, Bentley, Western Australia, 6102, Australia.judith.finn@curtin.edu.au.

Editorial group: Cochrane Heart Group.

Publication status and date: New, published in Issue 1, 2019.

Citation: Finn J, Jacobs I, Williams TA, Gates S, Perkins GD. Adrenaline and vasopressin for cardiac arrest. Cochrane Database of Systematic Reviews 2019, Issue 1. Art. No.: CD003179. DOI: 10.1002/14651858.CD003179.pub2.

Copyright ( 2019 The Cochrane Collaboration. Published by John Wiley \& Sons, Ltd.

\section{A B S T R A C T}

\section{Background}

Adrenaline and vasopressin are widely used to treat people with cardiac arrest, but there is uncertainty about the safety, effectiveness and the optimal dose.

\section{Objectives}

To determine whether adrenaline or vasopressin, or both, administered during cardiac arrest, afford any survival benefit.

\section{Search methods}

We searched the Cochrane Central Register of Controlled Trials, MEDLINE, Embase and DARE from their inception to 8 May 2018 , and the International Liaison Committee on Resuscitation 2015 Advanced Life Support Consensus on Science and Treatment Recommendations. We also searched four trial registers on 5 September 2018 and checked the reference lists of the included studies and review papers to identify potential papers for review.

\section{Selection criteria}

Any randomised controlled trial comparing: standard-dose adrenaline versus placebo; standard-dose adrenaline versus high-dose adrenaline; and adrenaline versus vasopressin, in any setting, due to any cause of cardiac arrest, in adults and children. There were no language restrictions.

\section{Data collection and analysis}

Two review authors independently identified trials for review, assessed risks of bias and extracted data, resolving disagreements through re-examination of the trial reports and by discussion. We used risk ratios (RRs) with $95 \%$ confidence intervals (Cls) to compare dichotomous outcomes for clinical events. There were no continuous outcomes reported. We examined groups of trials for heterogeneity. We report the quality of evidence for each outcome, using the GRADE approach.

\section{Main results}

We included 26 studies (21,704 participants).

Moderate-quality evidence found that adrenaline increased survival to hospital discharge compared to placebo ( $R R$ 1.86; 2 studies, 8538 participants; an increase from 23 to 32 per $1000,95 \% \mathrm{Cl} 25$ to 42 ). We are uncertain about survival to hospital discharge 
for high-dose compared to standard-dose adrenaline (RR 1.10, 95\% Cl 0.75 to 1.62; participants $=6274$; studies = 10); an increase from 33 to 36 per $1000,95 \% \mathrm{Cl} 24$ to 53); standard-dose adrenaline versus vasopressin (RR 1.25, 95\% Cl 0.84 to $1.85 ; 6$ studies; 2511 participants; an increase from 72 to 90 per $1000,95 \% \mathrm{Cl} 60$ to 133); and standard-dose adrenaline versus vasopressin plus adrenaline (RR $0.76,95 \% \mathrm{Cl}$ 0.47 to 1.22 ; 3 studies; 3242 participants; a possible decrease from 24 to 18 per $1000,95 \% \mathrm{Cl} 11$ to 29 ), due to very low-quality evidence.

Moderate-quality evidence found that adrenaline compared with placebo increased survival to hospital admission ( $\mathrm{RR} 2.51,95 \% \mathrm{Cl} 1.67$ to 3.76; 2 studies, 8489 participants; an increase from 83 to 209 per 1000, 95\% Cl 139 to 313). We are uncertain about survival to hospital admission when comparing standard-dose with high-dose adrenaline, due to very low-quality evidence. Vasopressin may improve survival to hospital admission when compared with standard-dose adrenaline (RR 1.27, 95\% Cl 1.04 to 1.54; 3 studies, 1953 participants; low-quality evidence; an increase from 260 to 330 per $1000,95 \% \mathrm{Cl} 270$ to 400), and may make little or no difference when compared to standard-dose adrenaline plus vasopressin (RR $0.95,95 \% \mathrm{Cl} 0.83$ to 1.08 ; 3 studies; 3249 participants; low-quality evidence; a decrease from 218 to 207 per 1000 (95\% Cl 181 to 236).

There was no evidence that adrenaline (any dose) or vasopressin improved neurological outcomes.

The rate of return of spontaneous circulation (ROSC) was higher for standard-dose adrenaline versus placebo (RR 2.86, $95 \% \mathrm{Cl} 2.21$ to 3.71 ; participants = 8663; studies = 3); moderate-quality evidence; an increase from 115 to 329 per $1000,95 \% \mathrm{Cl} 254$ to 427 ). We are uncertain about the effect on ROSC for the comparison of standard-dose versus high-dose adrenaline and standard-does adrenaline compared to vasopressin, due to very low-quality evidence. Standard-dose adrenaline may make little or no difference to ROSC when compared to standard-dose adrenaline plus vasopressin (RR 0.97, 95\% Cl 0.87 to 1.08; 3 studies, 3249 participants; low-quality evidence; a possible decrease from 299 to 290 per $1000,95 \% \mathrm{Cl} 260$ to 323 ).

The source of funding was not stated in 11 of the 26 studies. The study drugs were provided by the manufacturer in four of the 26 studies, but neither drug represents a profitable commercial option. The other 11 studies were funded by organisations such as research foundations and government funding bodies.

\section{Authors' conclusions}

This review provides moderate-quality evidence that standard-dose adrenaline compared to placebo improves return of spontaneous circulation, survival to hospital admission and survival to hospital discharge, but low-quality evidence that it did not affect survival with a favourable neurological outcome. Very low -quality evidence found that high-dose adrenaline compared to standard-dose adrenaline improved return of spontaneous circulation and survival to admission. Vasopressin compared to standard dose adrenaline improved survival to admission but not return of spontaneous circulation, whilst the combination of adrenaline and vasopressin compared with adrenaline alone had no effect on these outcomes. Neither standard dose adrenaline, high-dose adrenaline,vasopressin nor a combination of adrenaline and vasopressin improved survival with a favourable neurological outcome. Many of these studies were conducted more than 20 years ago. Treatment has changed in recent years, so the findings from older studies may not reflect current practice.

\section{PLAIN LANGUAGE SUMMARY}

\section{Adrenaline and vasopressin for cardiac arrest}

\section{Review question}

Do the drugs adrenaline or vasopressin improve survival in cardiac arrest.

\section{Background}

Cardiac arrest occurs when someone's heart unexpectedly stops beating. Without any treatment, death occurs within minutes. Treatments that are proven to work in cardiac arrest include cardiopulmonary resuscitation and giving an electric shock (defibrillation). If these treatments do not work, drugs such as adrenaline and vasopressin are injected (usually into a vein) to try to restart the heart. The early scientific evidence which led to their use came largely from small studies in animals. Whilst some human studies have shown that these drugs can help restart the heart initially, research also suggests they may have harmful effects on the brain.

\section{Search date}

The last search was conducted on 8 May 2018.

\section{Study Characteristics}

We identified 26 randomised controlled trials, involving 21,704 participants, that examined the effect of adrenaline or vasopressin on survival after cardiac arrest that occurred in and out of hospital and in adults and children. Some studies compared adrenaline in standard doses with placebo (dummy medication); some examined standard-dose versus high-dose adrenaline; and others compared vasopressin alone or vasopressin plus adrenaline to standard doses of adrenaline.

\section{Study funding sources}


The source of funding was not stated in 11 of the 26 studies. The study drugs were provided by the manufacturer in four of the 26 studies, but neither drug represents a profitable commercial option. The other 11 studies were funded by organisations such as research foundations and government funding bodies.

\section{Key results}

The studies found evidence that adrenaline was effective at restarting the heart and helping people recover enough to go home from hospital. However, there was no evidence that any of the drugs improved survival with a good neurological outcome.

\section{Quality of the evidence}

The overall quality of evidence ranged from low to moderate (for studies comparing adrenaline to placebo), but mainly low or very low for the other comparisons, due to risks of bias within the studies. Many of these studies were conducted more than 20 years ago. Treatment has changed in recent years, so the findings from older studies may not reflect current practice. The studies examined the drugs in many different situations (in and outside of hospitals, at different dosages, and in both adults and children), which may make combining findings misleading. 
SUMMARY OF FINDINGS

Summary of findings for the main comparison. Standard-dose adrenaline (SDA) compared to placebo for cardiac arrest

Standard-dose adrenaline (SDA) compared to placebo for cardiac arrest

Patient or population: people suffering cardiac arrest

Setting: either outside of hospital (OHCA) or during hospitalisation (IHCA)

Intervention: standard-dose adrenaline (SDA)

Comparison: placebo

\begin{tabular}{|c|c|c|c|c|c|c|}
\hline \multirow[t]{2}{*}{ Outcomes } & \multicolumn{2}{|c|}{ Anticipated absolute effects ${ }^{\star}(95 \% \mathrm{CI})$} & \multirow{2}{*}{$\begin{array}{l}\text { Relative effect } \\
(95 \% \mathrm{Cl})\end{array}$} & \multirow{2}{*}{$\begin{array}{l}\text { № of partici- } \\
\text { pants } \\
\text { (studies) }\end{array}$} & \multirow{2}{*}{$\begin{array}{l}\text { Certainty of } \\
\text { the evidence } \\
\text { (GRADE) }\end{array}$} & \multirow[t]{2}{*}{ Comments } \\
\hline & $\begin{array}{l}\text { Risk with place- } \\
\text { bo }\end{array}$ & Risk with standard-dose adrenaline & & & & \\
\hline \multirow{2}{*}{$\begin{array}{l}\text { Survival to hospital } \\
\text { discharge }\end{array}$} & Study population & & \multirow{2}{*}{$\begin{array}{l}\text { RR } 1.44 \\
\text { (1.11 to } 1.86)\end{array}$} & \multirow{2}{*}{$\begin{array}{l}8538 \\
(2 \mathrm{RCTs})\end{array}$} & \multirow{2}{*}{$\begin{array}{l}\oplus \oplus \oplus \odot \\
\text { MODERATE } a\end{array}$} & \multirow[t]{2}{*}{ OHCA only } \\
\hline & 23 per 1000 & $\begin{array}{l}32 \text { per } 1000 \\
(25 \text { to } 42)\end{array}$ & & & & \\
\hline \multirow{2}{*}{$\begin{array}{l}\text { Survival to hospital ad- } \\
\text { mission }\end{array}$} & Study population & & \multirow{2}{*}{$\begin{array}{l}\text { RR } 2.51 \\
\text { (1.67 to } 3.76)\end{array}$} & \multirow{2}{*}{$\begin{array}{l}8489 \\
(2 \mathrm{RCTs})\end{array}$} & \multirow{2}{*}{$\begin{array}{l}\oplus \oplus \oplus \ominus \\
\text { MODERATE } a\end{array}$} & \multirow[t]{2}{*}{ OHCA only } \\
\hline & 83 per 1000 & $\begin{array}{l}209 \text { per } 1000 \\
(139 \text { to } 313)\end{array}$ & & & & \\
\hline \multirow{3}{*}{$\begin{array}{l}\text { Favourable neurologi- } \\
\text { cal outcomes }\end{array}$} & Study population & & \multirow{3}{*}{$\begin{array}{l}\text { RR } 1.21 \\
\text { (0.90 to } 1.62)\end{array}$} & \multirow{3}{*}{$\begin{array}{l}8535 \\
\text { (2 RCTs) }\end{array}$} & \multirow{3}{*}{$\begin{array}{l}\oplus \oplus \Theta \Theta \\
\text { LOWa,b }\end{array}$} & \multirow{3}{*}{$\begin{array}{l}\text { Favourable neuro- } \\
\text { logical outcomes } \\
\text { were defined as a } \\
\mathrm{CPC} \text { score of }<3 \text { or } \\
\mathrm{mRS}<4 \\
\text { OHCA only }\end{array}$} \\
\hline & 19 per 1000 & $\begin{array}{l}22 \text { per } 1000 \\
\text { (17 to } 30)\end{array}$ & & & & \\
\hline & & & & & & \\
\hline \multirow{2}{*}{$\begin{array}{l}\text { Return of spontaneous } \\
\text { circulation }\end{array}$} & Study population & & \multirow{2}{*}{$\begin{array}{l}\text { RR } 2.86 \\
\text { ( } 2.21 \text { to } 3.71 \text { ) }\end{array}$} & \multirow{2}{*}{$\begin{array}{l}8663 \\
\text { (3 RCTs) }\end{array}$} & \multirow{2}{*}{$\begin{array}{l}\oplus \oplus \oplus \ominus \\
\text { MODERATEC }\end{array}$} & \multirow[t]{2}{*}{$\mathrm{OHCA}$ and IHCA } \\
\hline & 115 per 1000 & $\begin{array}{l}329 \text { per } 1000 \\
(254 \text { to } 427)\end{array}$ & & & & \\
\hline
\end{tabular}

*The risk in the intervention group (and its $95 \%$ confidence interval) is based on the assumed risk in the comparison group and the relative effect of the intervention (and its $95 \% \mathrm{Cl}$ ).

CI: Confidence interval; RR: Risk ratio; CPC: cerebral performance category; mRs: modified Rankin score 
GRADE Working Group grades of evidence

High certainty: We are very confident that the true effect lies close to that of the estimate of the effect

Moderate certainty: We are moderately confident in the effect estimate: The true effect is likely to be close to the estimate of the effect, but there is a possibility that it is substantially different

Low certainty: Our confidence in the effect estimate is limited: The true effect may be substantially different from the estimate of the effect

Very low certainty: We have very little confidence in the effect estimate: The true effect is likely to be substantially different from the estimate of effect

aDowngraded one level as one study at high risk of bias for incomplete outcome data

$b$ Downgraded by one level for imprecision. The $\mathrm{Cl}$ crosses the clinical decision threshold.

'Downgraded one level as two studies at high risk of bias for incomplete outcome data

\section{Summary of findings 2. Standard-dose adrenaline (SDA) compared to high-dose adrenaline (HDA) for cardiac arrest}

Standard-dose adrenaline (SDA) compared to high-dose adrenaline (HDA) for cardiac arrest

Patient or population: people suffering cardiac arrest

Setting: either outside of hospital (OHCA) or during hospitalisation (IHCA)

Intervention: High-dose adrenaline (HDA)

Comparison: Standard-dose adrenaline (SDA)

\begin{tabular}{|c|c|c|c|c|c|c|}
\hline \multirow[t]{2}{*}{ Outcomes } & \multicolumn{2}{|c|}{ Anticipated absolute effects ${ }^{\star}(95 \% \mathrm{CI})$} & \multirow{2}{*}{$\begin{array}{l}\text { Relative effect } \\
(95 \% \mathrm{Cl})\end{array}$} & \multirow{2}{*}{$\begin{array}{l}\text { № of partici- } \\
\text { pants } \\
\text { (studies) }\end{array}$} & \multirow{2}{*}{$\begin{array}{l}\text { Certainty of } \\
\text { the evidence } \\
\text { (GRADE) }\end{array}$} & \multirow[t]{2}{*}{ Comments } \\
\hline & $\begin{array}{l}\text { Risk with stan- } \\
\text { dard-dose } \\
\text { adrenaline (SDA) }\end{array}$ & $\begin{array}{l}\text { Risk with high-dose } \\
\text { adrenaline (HDA) }\end{array}$ & & & & \\
\hline \multirow{2}{*}{$\begin{array}{l}\text { Survival to hos- } \\
\text { pital discharge }\end{array}$} & \multicolumn{2}{|l|}{ Study population } & \multirow{2}{*}{$\begin{array}{l}\text { RR } 1.10 \\
\text { (0.75 to } 1.62)\end{array}$} & \multirow{2}{*}{$\begin{array}{l}6274 \\
\text { (10 RCTs) }\end{array}$} & \multirow{2}{*}{$\begin{array}{l}\oplus \odot \Theta \odot \\
\text { VERY } \\
\text { LOWa,b,c,d }\end{array}$} & \multirow{2}{*}{$\begin{array}{l}\text { Two more studies }(\mathrm{N}=245) \text { reported no sur- } \\
\text { vivors in either arm, but could not be added } \\
\text { to the meta-analysis due to zero events. } \\
\text { OHCA and IHCA }\end{array}$} \\
\hline & 33 per 1000 & $\begin{array}{l}36 \text { per } 1000 \\
(24 \text { to } 53)\end{array}$ & & & & \\
\hline \multirow{2}{*}{$\begin{array}{l}\text { Survival to hos- } \\
\text { pital admission }\end{array}$} & \multicolumn{2}{|l|}{ Study population } & \multirow{2}{*}{$\begin{array}{l}\text { RR } 1.13 \\
\text { (1.03 to } 1.24)\end{array}$} & \multirow{2}{*}{$\begin{array}{l}5764 \\
\text { (5 RCTs) }\end{array}$} & \multirow{2}{*}{$\begin{array}{l}\oplus \odot \odot \odot \\
\text { VERY LOWc,e }\end{array}$} & \multirow[t]{2}{*}{ OHCA only } \\
\hline & 213 per 1000 & $\begin{array}{l}241 \text { per } 1000 \\
\text { (220 to } 264)\end{array}$ & & & & \\
\hline \multirow{2}{*}{$\begin{array}{l}\text { Favourable neu- } \\
\text { rological out- } \\
\text { comes }\end{array}$} & Study population & & \multirow{2}{*}{$\begin{array}{l}\text { RR } 0.91 \\
\text { (0.65 to } 1.26)\end{array}$} & \multirow{2}{*}{$\begin{array}{l}5803 \\
\text { (4 RCTs) }\end{array}$} & \multirow{2}{*}{$\begin{array}{l}\oplus \ominus \ominus \ominus \\
\text { VERY LOWc,d,f,g }\end{array}$} & \multirow{2}{*}{$\begin{array}{l}\text { Favourable neurological outcomes were de- } \\
\text { fined as a CPC score of }<3 \text { in two studies; CPC } \\
<2 \text { in one study and CPC }<4 \text { in one study. } \\
\text { OHCA and IHCA }\end{array}$} \\
\hline & 26 per 1000 & $\begin{array}{l}23 \text { per } 1000 \\
\text { (17 to } 32)\end{array}$ & & & & \\
\hline
\end{tabular}




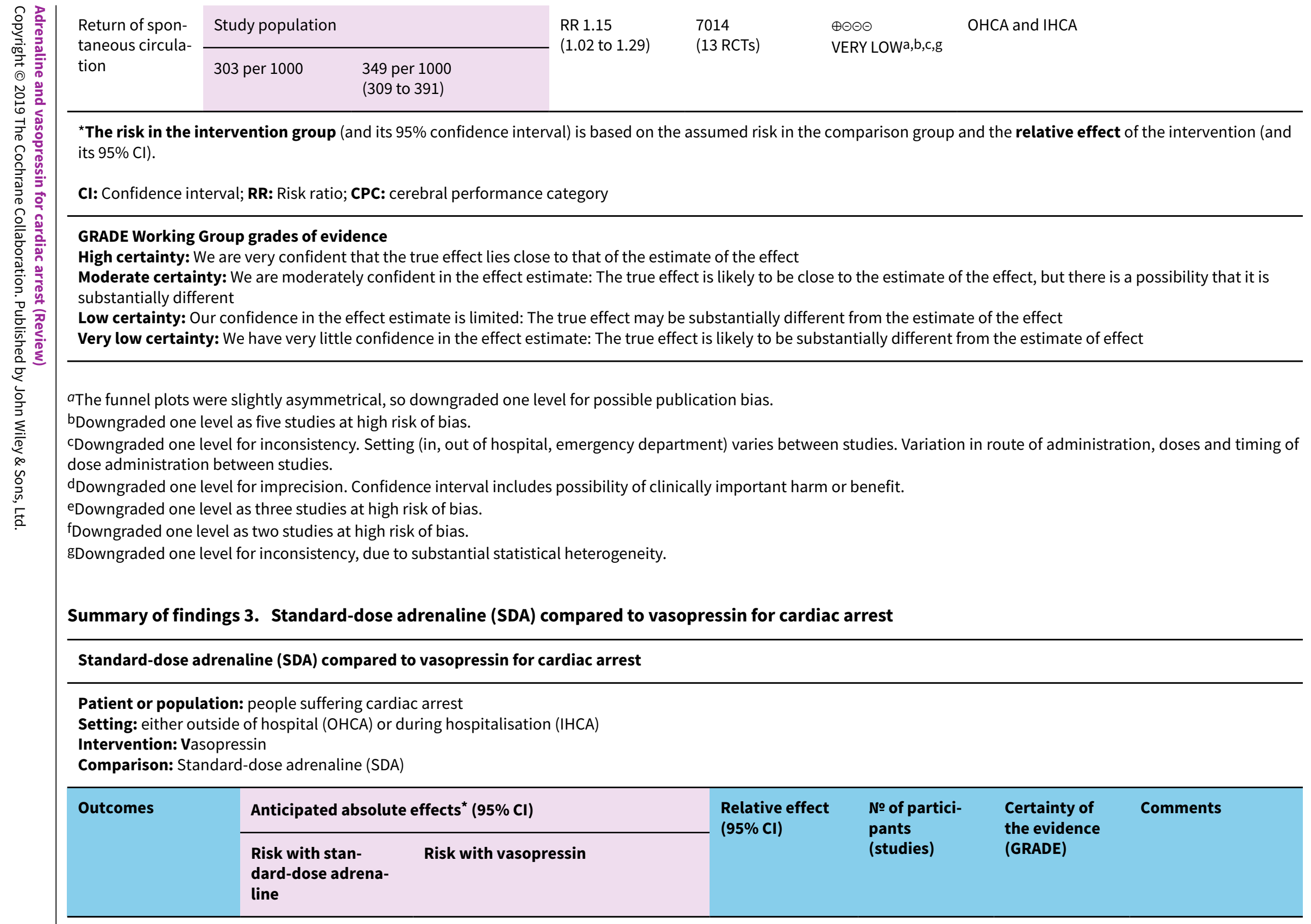




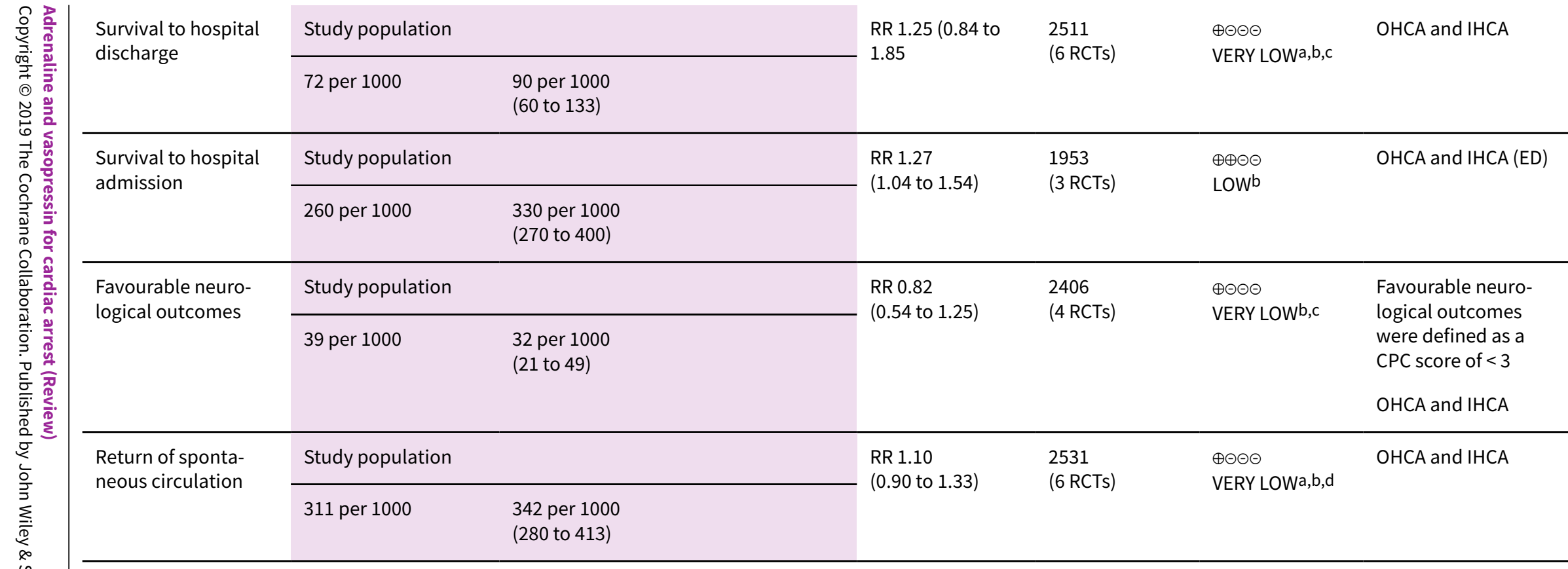

${ }^{*}$ The risk in the intervention group (and its 95\% confidence interval) is based on the assumed risk in the comparison group and the relative effect of the intervention (and its $95 \% \mathrm{Cl})$.

CI: Confidence interval; RR: Risk ratio; CPC: cerebral performance category

\section{GRADE Working Group grades of evidence}

High certainty: We are very confident that the true effect lies close to that of the estimate of the effect

Moderate certainty: We are moderately confident in the effect estimate: The true effect is likely to be close to the estimate of the effect, but there is a possibility that it is substantially different

Low certainty: Our confidence in the effect estimate is limited: The true effect may be substantially different from the estimate of the effect

Very low certainty: We have very little confidence in the effect estimate: The true effect is likely to be substantially different from the estimate of effect

aDowngraded one level as two studies at high risk of bias.

bDowngraded two levels for inconsistency. Studies included in- and out-of-hospital cardiac arrest and cardiac arrests in the emergency department. Inclusion criteria varied between studies, with inconsistencies in interventions given.

cDowngraded two levels for imprecision. Events less than 300, upper and lower Cl limits include both meaningful benefit and harm.

dDowngraded one level for imprecision. Upper and lower $\mathrm{Cl}$ limits include both meaningful benefit and harm. 


\begin{tabular}{|c|c|c|c|c|c|c|}
\hline \multicolumn{7}{|c|}{ Standard-dose adrenaline (SDA) compared to SDA plus vasopressin for cardiac arrest } \\
\hline \multicolumn{7}{|c|}{$\begin{array}{l}\text { Patient or population: people suffering cardiac arrest } \\
\text { Setting: either outside of hospital (OHCA) or during hospitalisation (IHCA) } \\
\text { Intervention: SDA plus vasopressin } \\
\text { Comparison: Standard-dose adrenaline (SDA) }\end{array}$} \\
\hline \multirow[t]{2}{*}{ Outcomes } & \multicolumn{2}{|c|}{ Anticipated absolute effects ${ }^{*}(95 \% \mathrm{Cl})$} & \multirow{2}{*}{$\begin{array}{l}\text { Relative effect } \\
(95 \% \mathrm{CI})\end{array}$} & \multirow{2}{*}{$\begin{array}{l}\text { № of partici- } \\
\text { pants } \\
\text { (studies) }\end{array}$} & \multirow{2}{*}{$\begin{array}{l}\text { Certainty of } \\
\text { the evidence } \\
\text { (GRADE) }\end{array}$} & \multirow[t]{2}{*}{ Comments } \\
\hline & $\begin{array}{l}\text { Risk with stan- } \\
\text { dard-dose adrenaline } \\
\text { (SDA) }\end{array}$ & Risk with SDA plus vasopressin & & & & \\
\hline \multirow{2}{*}{$\begin{array}{l}\text { Survival to hospital } \\
\text { discharge }\end{array}$} & \multicolumn{2}{|l|}{ Study population } & \multirow{2}{*}{$\begin{array}{l}\text { RR } 0.76 \\
\text { (0.47 to } 1.22)\end{array}$} & \multirow{2}{*}{$\begin{array}{l}3242 \\
(3 \mathrm{RCTs})^{a}\end{array}$} & \multirow{2}{*}{$\begin{array}{l}\oplus \odot \Theta \odot \\
\text { VERY LOWa,b }\end{array}$} & \multirow{2}{*}{ OHCA only } \\
\hline & 24 per 1000 & $\begin{array}{l}18 \text { per } 1000 \\
(11 \text { to } 29)\end{array}$ & & & & \\
\hline \multirow{2}{*}{$\begin{array}{l}\text { Survival to hospital ad- } \\
\text { mission }\end{array}$} & \multicolumn{2}{|l|}{ Study population } & \multirow{2}{*}{$\begin{array}{l}\text { RR } 0.95 \\
\text { (0.83 to } 1.08 \text { ) }\end{array}$} & \multirow{2}{*}{$\begin{array}{l}3249 \\
(3 \mathrm{RCTs})\end{array}$} & \multirow{2}{*}{$\begin{array}{l}\oplus \oplus \oplus \ominus \\
\text { LOWa,c }\end{array}$} & \multirow[t]{2}{*}{-OHCA only } \\
\hline & 218 per 1000 & $\begin{array}{l}207 \text { per } 1000 \\
\text { (181 to } 236)\end{array}$ & & & & \\
\hline \multirow{3}{*}{$\begin{array}{l}\text { Favourable neurologi- } \\
\text { cal outcomes }\end{array}$} & \multicolumn{2}{|l|}{ Study population } & \multirow{3}{*}{$\begin{array}{l}\text { RR } 0.65 \\
(0.33 \text { to } 1.31)\end{array}$} & \multirow{3}{*}{$\begin{array}{l}2887 \\
(1 \mathrm{RCT})\end{array}$} & \multirow{3}{*}{$\begin{array}{l}\oplus \odot \odot \odot \\
\text { VERY LOWa,b }\end{array}$} & \multirow{3}{*}{$\begin{array}{l}\text { Favourable neu- } \\
\text { rological out- } \\
\text { comes was de- } \\
\text { fined as a CPC } \\
\text { score of < } 3 \\
\text { OHCA only }\end{array}$} \\
\hline & 14 per 1000 & $\begin{array}{l}\text { 9per } 1000 \\
(5 \text { to } 18)\end{array}$ & & & & \\
\hline & & & & & & \\
\hline \multirow{2}{*}{$\begin{array}{l}\text { Return of spontaneous } \\
\text { circulation }\end{array}$} & Study population & & \multirow{2}{*}{$\begin{array}{l}\text { RR } 0.97 \\
\text { (0.87 to } 1.08 \text { ) }\end{array}$} & \multirow{2}{*}{$\begin{array}{l}3249 \\
\text { (3 RCTs) }\end{array}$} & \multirow{2}{*}{$\begin{array}{l}\oplus \oplus \oplus \ominus \\
\text { LOWa,c }\end{array}$} & \multirow[t]{2}{*}{ OHCA only } \\
\hline & 299 per 1000 & $\begin{array}{l}290 \text { per } 1000 \\
(260 \text { to } 323)\end{array}$ & & & & \\
\hline
\end{tabular}

${ }^{\star}$ The risk in the intervention group (and its $95 \%$ confidence interval) is based on the assumed risk in the comparison group and the relative effect of the intervention (and its $95 \% \mathrm{Cl}$ ).

CI: Confidence interval; RR: Risk ratio; CPC: cerebral performance category

\section{GRADE Working Group grades of evidence}

High certainty: We are very confident that the true effect lies close to that of the estimate of the effect 
Moderate certainty: We are moderately confident in the effect estimate: The true effect is likely to be close to the estimate of the effect, but there is a possibility that it is substantially different

Low certainty: Our confidence in the effect estimate is limited: The true effect may be substantially different from the estimate of the effect

Very low certainty: We have very little confidence in the effect estimate: The true effect is likely to be substantially different from the estimate of effect

aDowngraded two levels for imprecision. Event rate less than 300 and confidence interval includes possibility of clinically important harm or benefit.

Downgraded one level for inconsistency. Setting (in, out of hospital, emergency department) varies between studies. Variation in route of administration, doses and timing of

dose administration between studies.

'Downgraded one level for imprecision. Confidence interval includes possibility of clinically important harm or benefit. 


\section{B A C K G R O U N D}

\section{Description of the condition}

Sudden cardiac arrest is defined by the absence of signs of circulation (Utstein 2015). Each year, globally, hundreds of thousands of people sustain a cardiac arrest from which fewer then one in ten survive if the arrest occurs outside a hospital (Beck 2018; Daya 2015; Grasner 2016; PAROS 2015) and around one in five if the arrest occurs inside a hospital (Girotra 2014; Nolan 2014). Key treatments associated with survival are high-quality cardiopulmonary resuscitation (CPR) (Hasselqvist-Ax 2015; Sasson 2010; Wik 2016) and early defibrillation (Sandroni 2007; Sasson 2010).

The initial goal of resuscitation is to restart the heart, described as achieving return of spontaneous circulation (ROSC). However amongst those people in whom ROSC is achieved, only about $25 \%$ to $50 \%$ survive to go home from hospital. The main causes of hospital deaths are severe brain injury and multi-organ failure (Laver 2004). Thus overall survival rates to hospital discharge are low, in the range of $0.6 \%$ to $25 \%$ (Berdowski 2010).

A significant proportion of those who survive to leave hospital are left with significant brain damage (Corrada 2013; Kim 2016; Scales 2016). Even those with apparently good overall recovery may be left with subtle cognitive impairment (Nolan 2015a).

\section{Description of the intervention}

Pharmacological agents were a central part of early resuscitation algorithms, but the evidence for whether or not they are effective has been questioned for nearly two decades (Lundin 2016; Nolan 2002; Perkins 2014). Adrenaline has been used over a range of doses ( $0.5 \mathrm{mg}$ to more than $10 \mathrm{mg}$ ) through intracardiac, intravenous, endobronchial and intraosseous routes.

Vasopressin was explored as an adjunct or alternative to adrenaline in the late 1990s. Early experimental and animal studies suggested that vasopressin was superior to adrenaline, particularly during prolonged resuscitation (Wenzel 2000). However, evaluation in subsequent randomised controlled trials in humans produced equivocal results (Layek 2014). Vasopressin was recommended in American Heart Association guidelines from 2000 through to 2015, when its routine use was no longer recommended (Link 2015).

\section{How the intervention might work}

The proposed mechanism of action for adrenaline in cardiac arrest has been described previously (Nolan 2013). Stimulation of a-receptors located on vascular smooth muscle causes vasoconstriction which increases aortic diastolic pressure and coronary perfusion pressure, which optimises the chances of achieving return of spontaneous circulation (ROSC) (Paradis 1990). Potentially harmful effects arise from deleterious changes in cerebral microvascular blood flow leading to worsening of cerebral injury (Burnett 2012; Ristagno 2009), increased cardiac instability after ROSC and adverse metabolic and immunomodulatory effects (Nolan 2013; Wiedermann 2015). The potentially deleterious effects of adrenaline led to the search for alternative vasopressors. Vasopressin is a naturally-occurring antidiuretic hormone. In high doses it acts as a potent vasoconstrictor via V1a receptors located on smooth muscle cells, resulting in increased systemic vascular resistance which raises coronary perfusion pressure
(Lindner 1995). Previous laboratory data suggest that vasopressin is superior to adrenaline in improving vital organ perfusion during CPR, post-ROSC survival leading to better neurological outcome (Mentzelopoulos 2012).

\section{Why it is important to do this review}

Observational studies allow large amounts of data to be collected but are often limited by bias and confounding. Statistical techniques can be used to adjust for differences in measured confounding variables, but unknown confounders may still lead to biased results.

An early evaluation of the effect of vasopressors for cardiac arrest was presented by the Ontario Prehospital Advanced Life Support (OPALS) group. This prospective, observational study tested the incremental effect on the rate of survival after out-ofhospital cardiac arrest of adding a programme of advanced life support (ALS, endotracheal intubation and intravenous drugs) to a programme of rapid defibrillation in the late 1990s. The ALS interventions produced no increase in survival (odds ratio (OR) 1.1, $95 \%$ confidence interval $(\mathrm{Cl}) 0.8$ to 1.5 ), raising uncertainty about the role of drugs and advanced airway management in cardiac arrest. (Stiell 2004).

One of the first large prospective evaluations to raise concern about adrenaline in cardiac arrest was a propensity-matched observational study from Japan (Hagihara 2012), which enrolled 417,188 participants with out-of-hospital cardiac arrest. The study found that those who received adrenaline had improved rates of return of spontaneous circulation (adjusted (Adj) OR 2.51, 95\% CI 2.24 to 2.80), but fewer participants were alive at 30 days (Adj OR $0.54,95 \% \mathrm{Cl} 0.43$ to 0.68 ) and the neurological outcome was worse (Adj OR 0.21, 95\% Cl 0.10 to 0.44) (Hagihara 2012). The effect of unmeasured confounders and the challenges this presents in interpreting observational studies is highlighted by a subsequent analysis (Nakahara 2013). In this study researchers used a different propensity-matched scoring algorithm to analyse data from the same registry used by Hagihara 2012, which mitigated the signal of harm shown by Hagihara 2012 and suggested marginally better outcomes in participants with non-shockable rhythms/Nakahara 2013). This may explain in part the high levels of heterogeneity noted in meta-analyses of observational studies of vasopressors in cardiac arrest (Loomba 2015).

Vasoactive drugs have been an established treatment for cardiac arrest throughout the world, even though there was no evidence that they were beneficial for long-term outcomes (Nolan 2015b). Recent evidence from observational studies shows a consistent pattern of benefit on short-term outcomes (return of spontaneous circulation and survival to hospital admission), but a reduction in survival to hospital discharge and the proportion of participants surviving with a favourable neurological outcome (Perkins 2014). However, such studies are limited by unmeasured confounders, not least the fact that those with the best prognosis (i.e. with a rapid return of spontaneous circulation after defibrillation or other resuscitation measures) are less likely to receive adrenaline.

In 2015 the International Liaison Committee on Resuscitation (ILCOR) synthesised the available evidence and concluded that there is insufficient evidence to know if adrenaline or other vasoactive drugs had beneficial or harmful effects on survival to discharge from hospital and on neurological outcome (Nolan 
2015b). ILCOR called for placebo-controlled trials to evaluate the use of any vasopressor in adult and paediatric cardiac arrest (Kleinman 2018).

Against this background, we set out to complete a comprehensive review of randomised controlled trials examining the effectiveness of vasoactive drugs during the resuscitation of adults and children in cardiac arrest. This review considers and pools evidence from randomised controlled trials of the two most commonly used vasoactive drugs (adrenaline and vasopressin) and considers the effect of drug dose and whether they work best singly or in combination. It extends previous systematic reviews through rigorous assessment of bias, by focusing only on randomised controlled trials, including adult and paediatric studies and from both an out-of-hospital and in-hospital settings (Larabee 2012; Soar 2015).

\section{OB JECTIVES}

To determine whether adrenaline or vasopressin or both administered during a cardiac arrest, afford any survival benefit.

\section{METHODS}

\section{Criteria for considering studies for this review Types of studies}

Any randomised controlled trial comparing (1) standard-dose (or high-dose) adrenaline versus placebo; (2) standard-dose adrenaline versus high-dose adrenaline; or (3) adrenaline versus vasopressin (alone or in combination with adrenaline). We include non-English articles (Li 1999; Zhu 2000), conference abstracts (Sanchez-Mendiola 1998) and letters to the editor of peer-reviewed journals (Polglase 1994; Schmidbauer 2000) in this review. We exclude animal studies. We include data from all papers for the same study population as one study, e.g. Ong 2012.

\section{Types of participants}

We include all participants of any age suffering cardiac arrest from any cause. Trials could enrol participants suffering cardiac arrest either outside of hospital (OHCA) or during hospitalisation (IHCA).

\section{Types of interventions}

We include trials that compared intravenous adrenaline versus placebo, high-dose adrenaline or vasopressin. Optimal administration of adrenaline is intravenous (IV), with a freeflowing saline infusion, although flushing intravenous lines with 20 to $30 \mathrm{mls}$ of IV fluid is commonly practised. We also include the intra-osseous route. We accepted adrenaline administered by an endotracheal tube, although this demonstrates different pharmacodynamic and pharmacokinetic properties. Intracardiac adrenaline administration has essentially been abandoned for more than a decade, and we do not include it in this review. The comparisons of interest were:

- Standard-dose adrenaline versus placebo

- Standard-dose adrenaline versus high-dose adrenaline

- Standard-dose adrenaline versus vasopressin

- Standard-dose adrenaline versus vasopressin plus adrenaline

The standard dosages of adrenaline and vasopressin that are commonly used in clinical studies are $1 \mathrm{mg}$ and $40 \mathrm{IU}$, respectively.

\section{Types of outcome measures}

\section{Primary outcomes}

We initially proposed the following outcomes, but we have not covered the last three in the results of this review because they were rarely reported in the included studies.

- Survival to hospital discharge.

- Survival to hospital admission.

- Neurological outcome, assessed using either the Glasgow Outcome Scale (Jennett 1975; Teasdale 1998) or Cerebral Performance Category (Jennett 1975) or modified Rankin scale (Quinn 2009).

\section{Secondary outcomes}

- Return of spontaneous circulation (ROSC)

- All-cause mortality

- Return of non-perfusing cardiac rhythm

- Admission to intensive care unit (ICU) (not reported)

\section{Search methods for identification of studies}

\section{Electronic searches}

We searched the following electronic databases from their inception to 8 May 2018, using the MeSH and text terms shown in Appendix 1:

- Cochrane Central Register of Controlled Trials (CENTRAL), Issue 4 of 12, 2018 (Cochrane Library)

- Database of Abstracts of Reviews of Effects (DARE), Issue 2 of 4 , 2015 (Cochrane Library) (No longer updated)

- Epub Ahead of Print, In-Process and Other Non-Indexed Citations, MEDLINE Daily and MEDLINE (Ovid, 1946 to 08 May 2018)

- Embase Classic and Embase (Ovid, 1947 to 2018 May 07)

The RCT filter for MEDLINE is the Cochrane sensitivity-maximising RCT filter. For Embase, we applied the terms as recommended in the Cochrane Handbook for Systematic Reviews of Interventions (Lefebvre 2011).

\section{Searching other resources}

We checked the reference lists of all included studies and relevant systematic reviews (e.g. Lin 2014), for additional references to randomised trials.

We also searched the International Liaison Committee on Resuscitation (ILCOR) 2015 Advanced Life Support Consensus on Science and Treatment Recommendations (CoSTR) (Soar 2015).

We searched for ongoing trials on 5 September 2018, using various combinations of keywords such as 'adrenaline, epinephrine, vasopressin, cardiac arrest, heart arrest, resuscitation', on the following trials registers:

- ClinicalTrials.gov (www.clinicaltrials.gov).

- International standardised randomised controlled trials number (ISRCTN) registry (www.isrctn.com/).

- World Health Organization (WHO) International Clinical Trials Registry Platform (ICTRP) (www.who.int/ictrp/en/). 
- NHS Clinical Trials and Medical Research (www.nhs.uk/ Conditions/Clinical-trials/Pages/clinical-trial-details.aspx? Trialld= ).

\section{Data collection and analysis}

\section{Selection of studies}

Two review authors (JF and IJ initially; JF and TW in subsequent searches) independently read the titles and abstracts of relevant papers retrieved by the search strategy described above, to identify potentially suitable studies. If in doubt about whether a title was relevant, we read the full article. We retrieved full publications of all potentially-relevant studies and stored them electronically in an Endnote library. Two review authors (TW and JF) determined trial eligibility independently, using a standardised inclusion form, and excluding studies that did not meet the inclusion criteria. We did not apply any language restrictions. We resolved any disagreements by discussion with the other two review authors (GP and SG). We detail the excluded studies and reasons for their exclusion in the Characteristics of excluded studies table.

\section{Data extraction and management}

We recorded data initially on paper, and then on electronic data extraction forms (which we had piloted) and entered them into Review Manager 5. We recorded all clinically relevant outcomes, including adverse events. We resolved differences through reexamination of the study report and further discussion, consulting with a third review author (IJ/GP) if we could not achieve consensus.

We sought the following data items from each study:

\section{Study characteristics}

- Location of study

- In-hospital cardiac arrest (IHCA) or out-of-hospital cardiac arrest (OHCA), or both

- Type of emergency medical system (EMS) (OHCA)

- Study design: RCT or quasi-RCT

- Blinding

Participant characteristics in each arm of the study

- Age (mean, standard deviation (SD), range)

- Male \%

- Ventricular fibrillation (VF)/ventricular tachycardia (VT) \%

- Witnessed (OHCA) \%

- Cardiac aetiology \%

- EMS witnessed (OHCA) \%

- Bystander cardiopulmonary resuscitation (CPR) (OHCA)\%

- Initial rhythm \%

- Study inclusion/exclusion criteria

Number of participants in each study arm

- Number eligible

- Excluded pre-randomisation

- Numbers randomised

- Lost to follow-up

- Number analysed

\section{Details of intervention/comparison groups}

- Study drug, control 'drug', dose, route, frequency, maximum dose, time frames

- Other interventions, e.g. IV flushing agent

- Other specific protocols for resuscitation

\section{Outcomes:}

- Event numbers and denominator numbers for each study arm

- Return of spontaneous circulation (ROSC)

- Survival to hospital admission (OHCA only)

- Admission to ICU

- Discharged from hospital alive (or in-hospital mortality)

- Neurological outcome on discharge from hospital (and tool used to measure)

One of the included studies was only available in Chinese. The data extraction for this paper was undertaken by a translator (native Chinese speaker), and the data were double-checked against the English abstract (TW and JF).

\section{Assessment of risk of bias in included studies}

Two review authors (TW, JF) independently assessed risks of bias, using the Cochrane 'Risk of bias' tool. This involves judgements across a series of domains of bias, as described in Chapter 8 of the Cochrane Handbook (Higgins 2017).

Three independent investigators (TW, GDP and SG) reviewed papers co-authored by authors of this systematic review (e.g. Jacobs 2011), using the criteria recommended by the Cochrane Heart Group. Similarly, TW (who was not a co-investigator on the study or a co-author of the paper) assessed risks of bias for the Perkins 2018 study.

\section{Measures of treatment effect}

We used risk ratios (RRs) with 95\% confidence intervals (Cls) to compare dichotomous outcomes. We had planned to analyse continuous outcomes as mean differences (MDs), but none were reported. We dichotomised neurological outcomes reported as Cerebral Performance Category (Jennett 1975) scores (1 to 5) as follows: 1 - 2 'good' neurological outcome and 3 - 5 'poor' neurological outcome. Similarly, we rated a score of 3 or less on the modified Rankin scale, (Quinn 2009), which ranges from 0 (no symptoms) to 6 (death), as a 'favourable' neurologic outcome.

\section{Unit of analysis issues}

Whilst there was a potential problem with including five multi-arm studies (Callaham 1992; Ducros 2011; Li 1999; Polglase 1994; Zhu 2000), we avoided an issue with unit of analysis by treating each dose as a separate analysis, so that the same control group was not used twice within the same analysis.

\section{Dealing with missing data}

We made no attempt to impute missing data values. We tried to contact the authors of Lee 2000 but there was no reply. We did not attempt to contact other trial authors to identify missing data because many of the studies are quite old. 


\section{Assessment of heterogeneity}

We examined groups of trials for clinical and statistical heterogeneity; the former involved assessment of whether we judged the participants, interventions, comparisons and outcomes to be sufficiently similar to ensure an answer that is clinically meaningful, while the latter involved the use of the $\mathrm{Chi}^{2}$ and $\mathrm{I}^{2}$ statistics and visual inspection of the forest plots. As in the Cochrane Handbook (Chapter 9) (Higgins 2017), we consider an $\left.\right|^{2}$ statistic greater than $50 \%$ to represent substantial heterogeneity.

\section{Assessment of reporting biases}

To establish the potential influence of small-trial effects and possible publication bias, we constructed funnel plots for each outcome where we had included more than 10 studies in the metaanalysis.

\section{Data synthesis}

Where we deemed clinical and statistical heterogeneity to be acceptable, we conducted meta-analyses using Review Manager 5 to combine results for each outcome across studies. We used a random-effects model to calculate a weighted average of MantelHaenszel risk ratios across studies for all outcomes. We did not assume that all studies measured the same underlying true effect (i.e. fixed-effect across studies).

\section{Subgroup analysis and investigation of heterogeneity}

The a priori subgroup analyses were: (1) adult participants and paediatric participants; (2) OHCA and IHCA events. Both are considered potential effect modifiers, due to known differences in cardiac arrest aetiology in the subgroups.

\section{Sensitivity analysis}

To determine whether the findings of the systematic review were influenced by specific studies, we performed sensitivity analyses restricting the analysis to a subset of the studies, by excluding those at high risk of bias (as shown in red in Figure 2) in any domain.
We performed sensitivity analyses for the following comparisons: (1) high-dose versus standard-dose adrenaline; (2) vasopressin versus vasopressin plus adrenaline.

\section{'Summary of findings' tables}

We used the GRADE approach (www.gradepro.org ) to construct a 'Summary of findings' table for each outcome for the primary comparison, where possible. The five GRADE considerations (study limitations, consistency of effect, imprecision, indirectness and publication bias) are used to assess the quality of the body of evidence for each outcome.

\section{RES U L T S}

\section{Description of studies}

\section{Results of the search}

The search found 2056 papers, reduced to 1808 after deduplication. We excluded 1730 of these on the basis of title and abstract not meeting the study criteria. A recently published RCT (Perkins 2018) of SDE versus placebo was included. We also identified: a potential study (Ghafourian 2015) from a recent systematic review (Belletti 2018), which was subsequently excluded based on non-randomisation of the 'controls' and uncertainty about the random allocation of treatment arms of the study. Two ongoing studies (Andersen 2018; Raymond 2008) were also excluded, resulting in 80 papers for full-text review. We excluded 48 papers at this stage, because they did not meet the study inclusion criteria after review of the text; see Figure 1 . We included 26 studies reported in 32 papers (Brown 1992; Callaham 1992; Callaway 2006; Choux 1995; Ducros 2011; Gueugniaud 1998; Gueugniaud 2008; Jacobs 2011; Li 1999; Lindner 1991a; Lindner 1997; Lipman 1993; Mukoyama 2009; Ong 2012; Patterson 2005; Perkins 2018; Perondi 2004; Polglase 1994; Sanchez-Mendiola 1998; Schmidbauer 2000; Sherman 1997; Stiell 1992; Stiell 2001; Wenzel 2004; Woodhouse 1995; Zhu 2000), as shown in the Characteristics of included studies table. 
Figure 1. Selection process

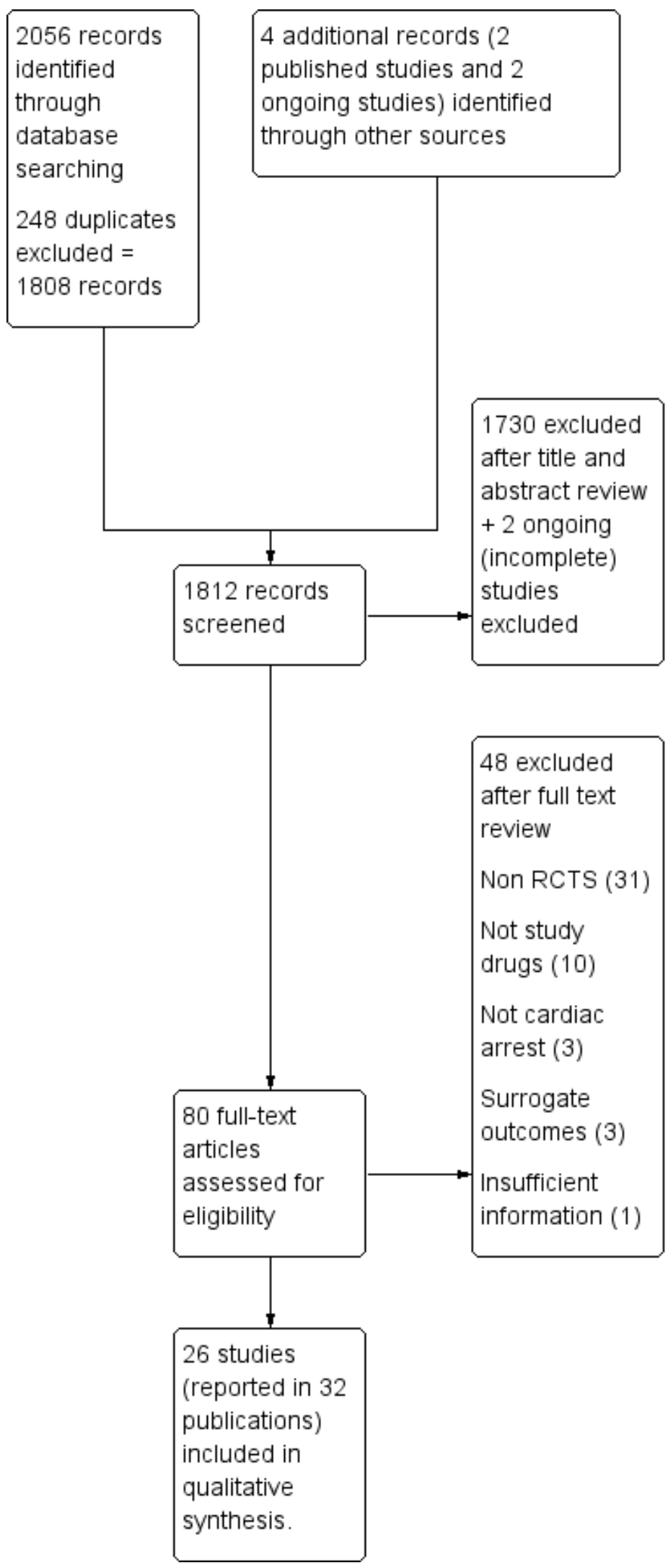


The papers were published between 1992 and 2018, 13 of them before 2000 (Brown 1992; Callaham 1992; Choux 1995; Gueugniaud 1998; Li 1999; Lindner 1991a; Lindner 1997; Lipman 1993; Polglase 1994; Sanchez-Mendiola 1998; Sherman 1997; Stiell 1992; Woodhouse 1995), five from 2000 up to 2005 (Perondi 2004; Schmidbauer 2000; Stiell 2001; Wenzel 2004; Zhu 2000), four from 2005 up to 2010 (Callaway 2006; Gueugniaud 2008; Mukoyama 2009; Patterson 2005), and four from 2010 onwards (Ducros 2011; Jacobs 2011; Ong 2012; Perkins 2018). A total of 21,704 participants were included in the analyses. Two Chinese papers (Li 1999; Zhu 2000) and one Japanese paper (Nishizawa 1993) were translated into English. Three studies were specifically from paediatric populations (Patterson 2005; Perondi 2004; SanchezMendiola 1998).

There was substantial variation between studies in the number of participants included. In the three RCTs of adrenaline versus placebo the sample sizes varied from 194 (Woodhouse 1995) to 534 (Jacobs 2011) and 8104 (Perkins 2018). Considering studies of high-dose adrenaline versus standard-dose adrenaline, the sample sizes ranged from 43 (Li 1999; Zhu 2000) to 3907 participants (Gueugniaud 1998), and for vasopressin versus standard-dose adrenaline the sample sizes ranged from 30 (Ducros 2011) to 1186 participants (Wenzel 2004).

\section{Included studies}

Most of the studies (16/26) were of people who suffered OHCAs (Brown 1992; Callaham 1992; Callaway 2006; Choux 1995; Ducros 2011; Gueugniaud 1998; Gueugniaud 2008; Jacobs 2011; Lindner 1997; Mukoyama 2009; Patterson 2005; Perkins 2018; Polglase 1994; Schmidbauer 2000; Sherman 1997; Wenzel 2004), including one paediatric study (Patterson 2005). In-hospital cardiac arrests (IHCAs) included cardiac arrests in the Emergency Department (ED) and intensive care unit (ICU). Four studies (Lindner 1991a; Ong 2012; Stiell 1992; Woodhouse 1995) included both out-of-hospital and in-hospital cardiac arrest, one which was OHCA and ED (Ong 2012), and six in-hospital (Li 1999; Lipman 1993; Perondi 2004; Sanchez-Mendiola 1998; Stiell 2001; Zhu 2000), two of which were paediatric studies (Perondi 2004; Sanchez-Mendiola 1998).

Of the 26 studies included in this review, three studies compared adrenaline to placebo (Jacobs 2011; Perkins 2018; Woodhouse 1995). Fifteen studies compared standard-dose adrenaline (SDA) with high-dose adrenaline (HDA), ranging from $2 \mathrm{mg}$ to $10 \mathrm{mg}$ doses (Brown 1992; Callaham 1992; Choux 1995; Gueugniaud 1998; Lindner 1991a; Li 1999; Lipman 1993; Patterson 2005; Perondi 2004; Polglase 1994; Sanchez-Mendiola 1998; Schmidbauer 2000; Sherman 1997; Stiell 1992; Zhu 2000); six studies compared SDA to vasopressin (Li 1999; Lindner 1997; Mukoyama 2009; Ong 2012; Stiell 2001; Wenzel 2004); three studies (Callaway 2006; Ducros 2011; Gueugniaud 2008) examined the effect of SDA and vasopressin combined with SDA. Note that Li 1999 is included in the SDA versus HDA analysis and the SDA versus vasopressin analysis.

Five studies had more than one intervention group. Li 1999 reported results from the control group (SDA) compared to three intervention groups: HDA, standard-dose vasopressin and highdose vasopressin. Zhu 2000 compared administration of SDA to 2 $\mathrm{mg}$ adrenaline every three minutes and also with increasing doses of adrenaline ( $1 \mathrm{mg}$ adrenaline initially and then progressively increased dosage to $2 \mathrm{mg}$ every three minutes). Polglase 1994 compared two different doses of adrenaline $(5 \mathrm{mg}$ and $10 \mathrm{mg}$ ) to SDA. Two studies compared SDA to HDA and noradrenaline (Callaham 1992) or HDA administered with nitroglycerine (Ducros 2011). We discarded the results from the noradrenaline arm and the HDA with nitroglycerine arm, because they did not meet the selection criteria.

Most studies reported intravenous administration of the study drug. One study (Schmidbauer 2000) administered the study drug through the endobronchial route and three used a combination of routes: intravenous or by the endotracheal tube (Gueugniaud 1998; Stiell 1992); intravenous or intra-osseous (Perkins 2018); and intravenous, endobronchial or intra-osseous (Patterson 2005).

\section{Baseline characteristics}

Baseline characteristics were similar between groups for most of the studies, but the characteristics that were reported varied between studies. One study did not report baseline characteristics (Schmidbauer 2000). Differences in baseline characteristics between groups were evident in seven studies (Choux 1995; Gueugniaud 1998; Jacobs 2011; Lipman 1993; Ong 2012; Sherman 1997; Stiell 1992). Choux 1995 reported similar baseline characteristics in standard-dose or placebo and high-dose adrenaline groups, except for the time from Basic Life Support to Advanced Cardiac Life Support $(P=0.04)$, which was longer for the high-dose adrenaline group. There were fewer men in the standard-dose adrenaline group compared to the adrenaline plus vasopressin group in Gueugniaud 2008, at $72 \%$ versus $75 \%$ ( $P=$ 0.03). Lipman 1993 found no difference in age, sex or the number of days in ICU, but the Acute Physiology Score 24 hours before the cardiac arrest and the dose of dobutamine administered were higher in the high-dose adrenaline group. A higher proportion of participants with a medical history in the vasopressin group was reported by Ong 2012, but the only significant history was higher hyperlipidaemia in the standard-dose adrenaline group. Stiell 1992 reported that the prevalence of ischaemic heart disease was lower in the low-dose adrenaline group. Jacobs 2011 reported a marginal difference in the proportion of participants whose cardiac arrest was witnessed by a bystander ( $53 \%$ placebo versus $44 \%$ adrenaline, $P=0.05)$.

The mean age was 62 years for the control and intervention groups in the adult studies that reported age (Brown 1992; Callaway 2006; Choux 1995; Ducros 2011; Gueugniaud 1998; Gueugniaud 2008; Jacobs 2011; Li 1999; Lindner 1991a; Lindner 1997; Lipman 1993; Mukoyama 2009; Ong 2012; Polglase 1994; Sherman 1997; Stiell 1992; Stiell 2001; Wenzel 2004; Woodhouse 1995; Zhu 2000). Callaham 1992 reported a median age of 67 years for both groups and Perkins 2018 reported a mean age in both groups of 70 years. There were a similar proportion of adult men, around $66 \%$ in both groups. Two paediatric studies (Patterson 2005; Perondi 2004) reported the mean age as 4.7 years in the control group and 4.5 years in the intervention group, and a similar proportion of boys in both group (56\% versus $57 \%$ ).

The initial cardiac arrest rhythm was reported by all but four studies (Li 1999; Polglase 1994; Schmidbauer 2000; Zhu 2000); and was generally categorised as a shockable rhythm, i.e. ventricular fibrillation or (pulseless) ventricular tachycardia (VF/pVT) or a non-shockable rhythm, i.e. asystole or pulseless electrical activity (PEA). PEA is characterised by "presence of spontaneous organized cardiac electric activity in the absence of blood flow sufficient to maintain consciousness" (Myerburg 2013). The proportion 
of participants with an initial rhythm of ventricular fibrillation (VF), asystole and pulseless electrical activity (PEA) were similar between control and intervention groups, but varied widely between studies (Appendix 2). This included one study (Lindner 1997) that only included people with ventricular fibrillation, two studies (Lipman 1993; Sanchez-Mendiola 1998) that only included people with asystole and one study that only enrolled participants with asystole or PEA (Lindner 1991a). Patterson 2005 reported that $95 \%$ of the children overall had asystole.

The proportion of arrests witnessed by a bystander was reported in 15 studies (Brown 1992; Callaham 1992; Callaway 2006; Gueugniaud 1998; Gueugniaud 2008; Jacobs 2011; Lindner 1991a; Lindner 1997; Mukoyama 2009; Ong 2012; Patterson 2005; Perkins 2018; Sherman 1997; Stiell 1992; Stiell 2001), with bystanderwitnessed arrests ranging from 24\% (Patterson 2005) to close to $80 \%$ (Stiell 2001). Witnessed EMS (paramedic-witnessed) cardiac arrests were reported in three studies (Callaway 2006; Jacobs 2011; Perkins 2018), in $12 \%$ or fewer of participants.

There were 14 studies that reported the proportion of participants that received bystander CPR (Brown 1992; Callaham 1992; Callaway 2006; Gueugniaud 1998; Gueugniaud 2008; Jacobs 2011; Lindner 1997; Mukoyama 2009; Ong 2012; Patterson 2005; Perkins 2018; Stiell 1992; Wenzel 2004; Woodhouse 1995). Whilst the percentage of bystander CPR was similar in the intervention and control groups, there was considerable variation between studies, ranging from around 15\% (Ong 2012) to almost 60\% (Perkins 2018).

The number of doses of study drug administered to a participant also varied between studies. A single dose of study drug was administered in four studies (Brown 1992; Lindner 1997; Ong 2012; Stiell 2001), up to two doses in two studies (Gueugniaud 2008; Wenzel 2004), three doses in three studies (Callaway 2006; Ducros 2011; Lipman 1993), four doses in one study (Sherman 1997), and five doses in three studies (Jacobs 2011, Stiell 1992; Perkins 2018). The protocol for both of the standard-dose adrenaline versus placebo controlled trials allowed up to 10 doses (Jacobs 2011; Perkins 2018), and up to 15 doses in two studies (Choux 1995; Gueugniaud 1998). Studies were permitted to use open-label adrenaline after the maximum doses of study drug.

\section{Outcomes}

Several survival endpoints were used. Return of spontaneous circulation (ROSC) was the most common, although the actual definition was often not specified. Survival time to hospital discharge (STHD) was also often reported and survival to hospital admission (STHA) reported less often. Other endpoints included survival to one hour (Stiell 2001), to 12 hours (Lindner 1991a; Lipman 1993), to 24 hours (Gueugniaud 1998; Lindner 1997; Lipman 1993; Mukoyama 2009; Patterson 2005; Perondi 2004), to three, eight, 15 and 21 days (Choux 1995), to 30 days (Callaway 2006; Stiell 2001; Perkins 2018 ), to six months (Choux 1995), to one year (Gueugniaud 2008) and, in an ICU study, ICU survival (Lipman 1993). Neuological outcomes were measured using various tools, as described under 'Neurological outcomes' below in Effects of interventions.

We used the ' $\mathrm{N}$ ' randomised as the denominator for analyses as far as possible. However, we used the available ' $n$ ' where this was not clear, or where there was a large discrepancy between ' $n$ ' randomised and ' $n$ ' analysed, eg Gueugniaud 1998. Similarly, we chose to use the amended denominator where loss to follow up for different outcomes (e.g. neurological ones) was described (eg Perkins 2018; Wenzel 2004). There is therefore some discrepancy in the denominators across different outcomes within the same study.

Different methods and time points were used to assess neurological outcome. Cerebral Performance Category (CPC) scores were used in 11 studies (Brown 1992; Callaham 1992; Gueugniaud 1998; Gueugniaud 2008; Jacobs 2011; Mukoyama 2009; Ong 2012; Perondi 2004; Stiell 1992; Stiell 2001; Wenzel 2004), making it the most common measure of neurological outcome used. CPC was recorded most often at hospital discharge, but others recorded CPC at 96 hours (and at discharge) (Stiell 1992) or at six months (Wenzel 2004). CPC scores were most often dichotomised into scores of less than three (i.e. 'good') and three to five (i.e. 'poor'). However, Brown 1992 dichotimised good outcomes as CPC one to three and poor outcomes as four and five according to whether the participant was conscious or unconscious, and Stiell 1992 reported the 'best category of cerebral performance', i.e. $\mathrm{CPC}=1$. Perkins 2018 measured neurological outcomes at hospital discharge and at three months using the modified Rankin scale (Quinn 2009). Survival with a favourable neurological outcome was defined as a score of three or less on the modified Rankin scale (which ranges from 0 (no symptoms) to 6 (death)). One study (Patterson 2005) used the Glasgow Outcome Scale (Jennett 1975), which has five categories: death, persistent vegetative state, severe disability, moderate disability, and good recovery.

The Glasgow Coma Scale (GCS) (Teasdale 1998) was also used to assess neurological outcome (Choux 1995; Gueugniaud 1998; Lindner 1997; Stiell 1992), albeit at different time points and using different summary measures. Stiell 1992 reported the highest GCS at hospital discharge; Lindner 1997 reported the mean GCS at hospital discharge; Gueugniaud 1998 reported the highest GCS at the time of admission and at one week; and Choux 1995 reported GCS at day 3 and day 21 after the OHCA. Sherman 1997 assessed GCS at different time points, but there were no survivors for assessment at hospital discharge.

Two studies (Stiell 1992; Stiell 2001) reported the median MiniMental State Examination (MMSE) scores (Teng 1987) of OHCA survivors at hospital discharge.

The two Chinese studies described neurological outcome as "discharged from hospital with 'normal' status" (Li 1999; Zhu 2000). However, it is unclear whether only survivors with 'normal' status were included in the assessment of STHD.

Hospital length of stay was only reported by two studies (Callaham 1992; Perkins 2018) and neither study found a difference between the respective treatment groups.

\section{Funding}

The source of funding was not stated in 11 of the 26 studies. The study drugs were provided or funded by the manufacturer in four out of 26 studies, but neither drug represents a profitable commercial option. The other 11 studies were funded by organisations such as research foundations and government funding bodies. 


\section{Excluded studies}

Studies were excluded because they were non-cardiac arrest papers (McCrirrick 1992; McCrirrick 1994, Quadrel 1995), reviews (Aung 2005; Larabee 2012; Mentzelopoulos 2012; Meyer 2011; Sillberg 2008; Xiaoli 2010; Zwingmann 2012), narratives (Pellegrino 2006; Berthier 1987; Cohen 1975), editorials (Mclntyre 2004) or critiques (Worster 2005), before-and-after studies (Carvolth 1996), cohort studies (Dieckmann 1995), other non-RCTs (Morris 1997; Niemann 2000; Ohshige 2005) or used surrogate measures not included in our systematic review's selection criteria (Paradis 1991; Quinton 1987; Woodhouse 1992). Eight RCTs were excluded because they were of drugs not included in this systematic review's selection criteria (Mentzelopoulos 2007; Mentzelopoulos 2009; Olasveengen 2009; Olson 1989; Patrick 1995; Song 1997; Turner 1988; Weaver 1990). For example, Mentzelopoulos (Mentzelopoulos 2007; Mentzelopoulos 2009) included methylprednisolone with vasopressin and adrenaline to compare the effect on outcomes with standard-dose adrenaline. The study found increased ROSC and STHD in the combination group, but it is unclear whether the results were related to methylprednisolone or a combination of the drugs used (Mentzelopoulos 2009). We excluded Olasveengen 2009 because the study included all intravenous drugs and was not limited to the drugs included in our systematic review, i.e. adrenaline, vasopressin (or terlipressin). Lee 2000 was excluded because it was a pilot study of 10 participants from a larger RCT in progress, of which few details were provided in the conference report, no record of the study could be found, and we were unsuccessful in contacting the authors. Ghafourian 2015), identified from a recent systematic review (Belletti 2018), was excluded based on non-randomisation of the 'controls' and uncertainty about the random allocation of treatment arms of the study. The two ongoing studies (Andersen 2018; Raymond 2008), the details of which can be found in Characteristics of ongoing studies, are not included in the analysis because of lack of data.

\section{Risk of bias in included studies}

The results of our assessment of risks of bias in the included studies can be seen in the Description of studies table and are summarised in Figure 2 and Figure 3. 
Figure 2. Risk of bias summary: review authors' judgements about each risk of bias item for each included study.

\begin{tabular}{|c|c|c|c|c|c|c|c|}
\hline & 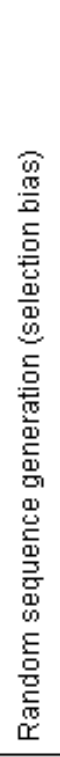 & 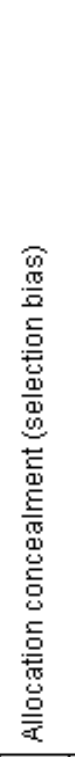 & 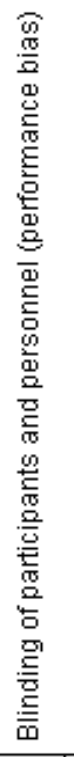 & 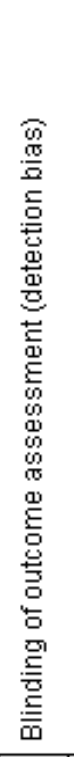 & 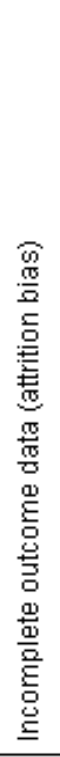 & 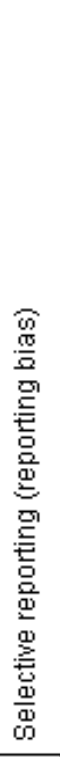 & 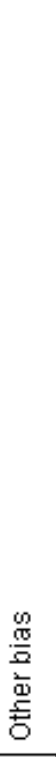 \\
\hline Brown 1992 & $?$ & $\odot$ & + & $\odot$ & $\odot$ & $?$ & $?$ \\
\hline Callaham 1992 & $\odot$ & $\odot$ & $\odot$ & + & $?$ & $?$ & $?$ \\
\hline Callaway 2006 & 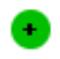 & + & $\odot$ & + & $\oplus$ & $?$ & $?$ \\
\hline Choux 1995 & $?$ & + & + & + & $\odot$ & $\odot$ & $?$ \\
\hline Ducros 2011 & + & + & + & + & $\oplus$ & $?$ & $?$ \\
\hline Gueugniaud 1998 & $\oplus$ & $\odot$ & $\oplus$ & $\odot$ & $\odot$ & $?$ & $\odot$ \\
\hline Gueugniaud 2008 & + & + & + & + & $\odot$ & $?$ & $?$ \\
\hline Jacobs 2011 & 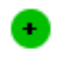 & + & $\oplus$ & + & $\odot$ & $\odot$ & $?$ \\
\hline Li 1999 & $?$ & $\Theta$ & $?$ & $?$ & $\odot$ & $?$ & $?$ \\
\hline Lindner 1991a & $?$ & $\odot$ & $\odot$ & $\odot$ & $\odot$ & $?$ & $?$ \\
\hline Lindner 1997 & + & + & 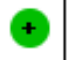 & 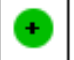 & $\odot$ & $?$ & $?$ \\
\hline Lipman 1993 & + & + & $?$ & $?$ & + & $?$ & $?$ \\
\hline Mukoyama 2009 & $?$ & $?$ & $?$ & $?$ & $\odot$ & $?$ & $?$ \\
\hline Ong 2012 & $\odot$ & + & $\oplus$ & $\odot$ & $\odot$ & $?$ & $?$ \\
\hline Patterson 2005 & $\odot$ & $?$ & $\odot$ & $?$ & 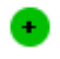 & $?$ & $?$ \\
\hline Perkins 2018 & $\odot$ & $\odot$ & $\odot$ & $\odot$ & $\odot$ & $\odot$ & $?$ \\
\hline Perondi 2004 & + & + & + & + & $?$ & $?$ & $?$ \\
\hline Polglase 1994 & $?$ & $\odot$ & $\odot$ & $?$ & $\odot$ & $?$ & $?$ \\
\hline Sanchez-Mendiola 1998 & $?$ & $\odot$ & $\odot$ & $?$ & 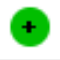 & $?$ & 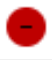 \\
\hline Schmidbauer 2000 & $?$ & $?$ & $?$ & $?$ & $?$ & $\odot$ & $?$ \\
\hline
\end{tabular}


Figure 2. (Continued)

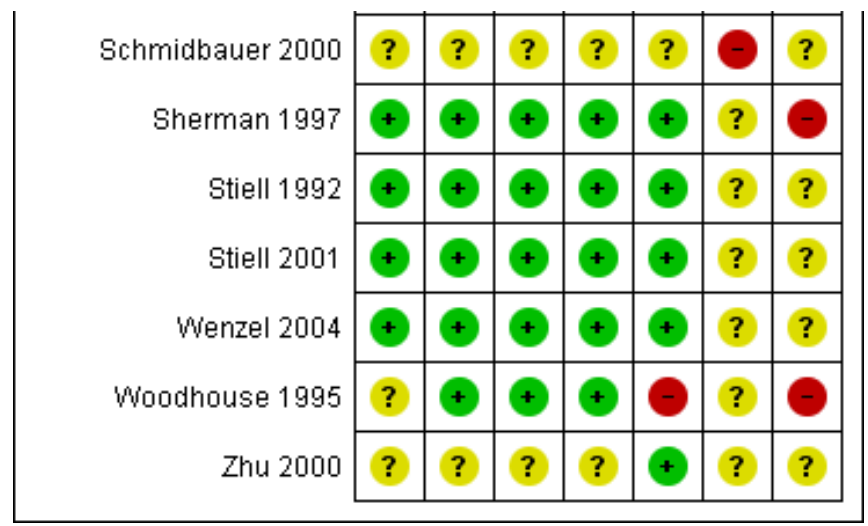

Figure 3. Risk of bias graph: review authors' judgements about each risk of bias item presented as percentages across all included studies.

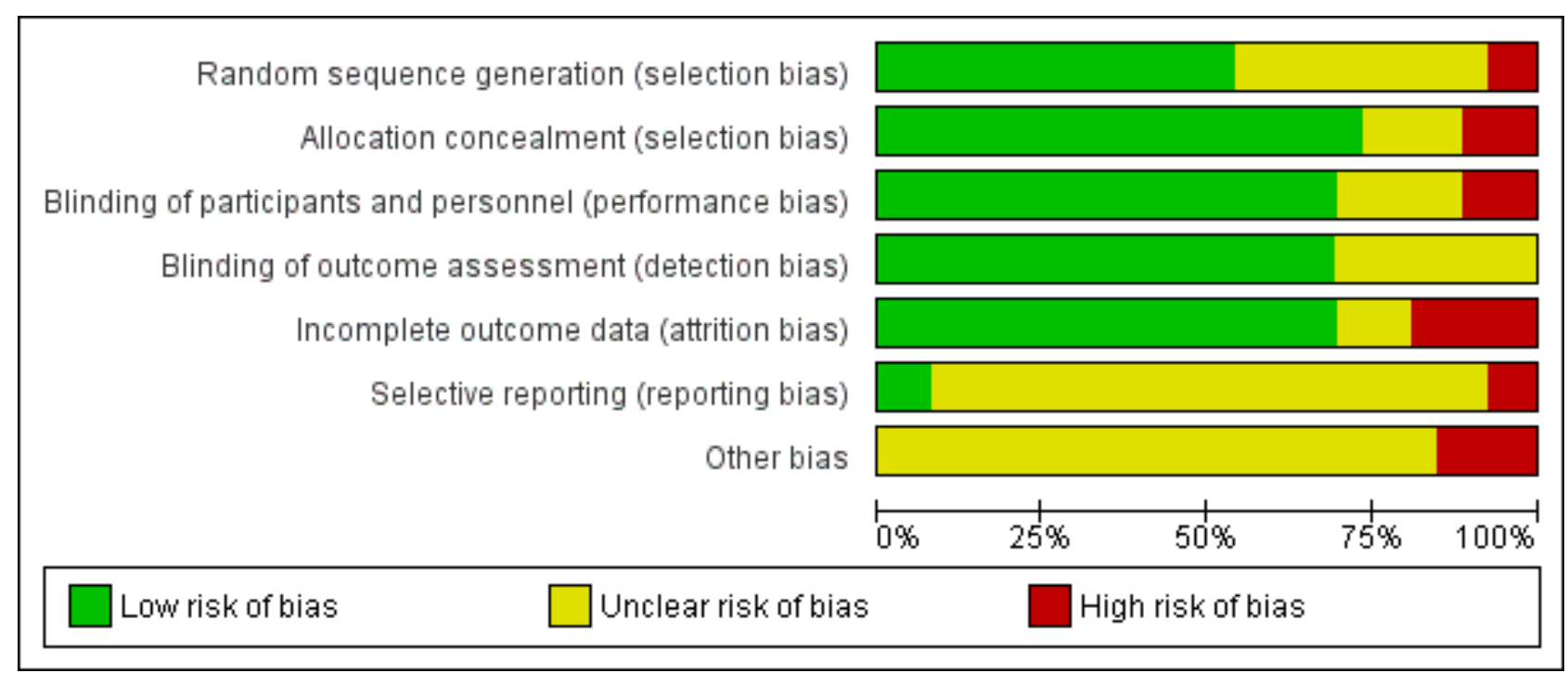

\section{Allocation}

\section{Random sequence generation}

All studies were randomised with the exception of one quasirandomised trial (Callaham 1992). Eleven studies reported a computer-generated randomisation sequence (Callaway 2006; Ducros 2011; Jacobs 2011; Lindner 1997; Lipman 1993; Ong 2012; Perkins 2018; Perondi 2004; Sherman 1997; Stiell 2001; Wenzel 2004). Three studies used a central randomisation schedule (Gueugniaud 1998; Gueugniaud 2008; Stiell 1992). We rated these 14 studies at low risk of bias. Ten studies (Brown 1992; Choux 1995; Li 1999; Lindner 1991a; Mukoyama 2009; Polglase 1994; Sanchez-Mendiola 1998; Schmidbauer 2000; Woodhouse 1995; Zhu 2000) stated that the study was "randomised" but did not report the method used for randomisation. We rated these 10 studies as unclear riskWe judged two studies (Patterson 2005; Callaham 1992) to be at high risk for bias. In a paediatric study of OHCA, Patterson 2005 used computer-generated randomisation for six centres, while the other centre assigned participants to the study group if their medical record number ended in an odd number and to the standard-dose group if their medical record number ended in an even number. Quasi-randomisation using alternation, in which the study drug and dose were changed for the entire city on Wednesdays, was used by Callaham 1992.

\section{Allocation concealment}

Nineteen studies described allocation concealment (Brown 1992; Callaham 1992; Callaway 2006; Choux 1995; Ducros 2011; Gueugniaud 1998; Gueugniaud 2008; Jacobs 2011; Lindner 1991a; Lindner 1997; Lipman 1993; Ong 2012; Perkins 2018; Perondi 2004; Sherman 1997; Stiell 1992; Stiell 2001; Wenzel 2004; Woodhouse 1995) and were considered as low risk. In Patterson 2005 it was uncertain whether the opaque envelopes were tamper-proof, and we rated the study as being at unclear risk of bias. Paramedics could have altered the dose given in Polglase 1994, and we considered the study to be at high risk; as we did so for Li 1999; and SanchezMendiola 1998. Three studies did not report any information about allocation concealment (Mukoyama 2009; Schmidbauer 2000; Zhu 2000) and were rated at unclear risk of bias. 


\section{Blinding}

\section{Blinding (performance bias and detection bias): survival outcomes}

Blinding was described in 18 studies (Brown 1992; Callaham 1992; Callaway 2006; Choux 1995; Ducros 2011; Gueugniaud 1998; Gueugniaud 2008; Jacobs 2011; Lindner 1991a; Lindner 1997; Ong 2012; Perkins 2018; Perondi 2004; Sherman 1997; Stiell 1992; Stiell 2001; Wenzel 2004; Woodhouse 1995). We rated three studies (Patterson 2005; Polglase 1994; Sanchez-Mendiola 1998) at high risk of bias. Blinding was only used in two of the seven centres because of technical difficulty in Patterson 2005. The other two studies (Polglase 1994; Sanchez-Mendiola 1998) were unblinded to the drug dose administered. Blinding was unknown in five studies (Li 1999; Lipman 1993; Mukoyama 2009; Schmidbauer 2000; Zhu 2000) and we rated them at unclear risk of bias.

\section{Blinding (performance bias and detection bias): neurological outcome}

Four studies were blinded to group allocation for neurological outcome (Jacobs 2011; Ong 2012; Stiell 1992; Perkins 2018) and we rated them at low risk, but for most studies it was unclear whether the assessor was aware of the allocation group (Brown 1992; Callaham 1992; Gueugniaud 1998; Gueugniaud 2008; Lindner 1997; Mukoyama 2009; Patterson 2005; Perondi 2004; Sherman 1997; Stiell 2001; Wenzel 2004) and we rated them at unclear risk of bias. Blinding was not reported in Choux 1995, but the Glasgow Coma Score (GCS) and electroencephalogram (EEG) are susceptible to bias because of the small sample size, with neurological assessments not being performed systematically, but were "made by different physicians" and "particular therapies given in the different hospitals could not be controlled". Sanchez-Mendiola 1998 did not blind caregivers to the drug dose administered which we rated at a high risk of bias. No neurological outcomes were reported in nine studies (Callaway 2006; Ducros 2011; Li 1999; Lindner 1991a; Lipman 1993; Polglase 1994; Schmidbauer 2000; Woodhouse 1995; Zhu 2000).

\section{Incomplete outcome data}

Most studies accounted for all their outcome data and we rated them at low risk (Brown 1992; Callaway 2006; Choux 1995; Ducros 2011; Gueugniaud 2008; Li 1999; Lindner 1991a; Lindner 1997; Lipman 1993; Ong 2012; Patterson 2005; Perkins 2018; SanchezMendiola 1998; Sherman 1997; Stiell 1992; Stiell 2001; Wenzel 2004; Zhu 2000).

Many studies (Ducros 2011; Gueugniaud 1998; Gueugniaud 2008; Jacobs 2011; Lindner 1997; Patterson 2005; Perkins 2018; Perond 2004; Stiell 2001; Wenzel 2004) claimed to perform intention-totreat analysis, i.e. including all randomised cases in the analysis, but some were 'per protocol' analyses because they did not include those participants who were randomised but later excluded, e.g. because of not meeting selection criteria, missing data, or unclear group allocation.

We assessed five studies as high risk of attrition bias. Jacobs 2011 planned to enrol 5000 participants. Enrolment issues, withdrawal of participating centres, and lack of willingness of paramedics to participate in a trial involving a placebo were responsible for enrolment being restricted to 601 participants $(12 \%$ of the original sample size), of whom 534 had their data analysed. We therefore assessed this study at high risk for incomplete outcome reporting. Mukoyama 2009 excluded 37\% of cases after randomisation and Polglase 1994 excluded 35\% because of "irregularities in dosing or incomplete documentation". Woodhouse 1995 excluded 10 participants for protocol violations, 7 for inadequate records and 145 participants received open-label $1 \mathrm{mg}$ adrenaline instead of study drug. Gueugniaud 1998 exclude 580 participants (15\% of the total) from the final analysis, for various reasons.

Lipman 1993 had more than $10 \%$ of the randomised cohort excluded from the study but was rated at low risk. Wenzel 2004 had $20 \%$ of participants who survived to hospital discharge but were lost to follow-up for neurological outcome. Three studies were rated as unclear risk of attrition bias (Callaham 1992; Perondi 2004; Schmidbauer 2000)

\section{Selective reporting}

We reviewed the published papers for details of the outcomes that were assessed. All but four studies were assessed as unclear for this domain. Choux 1995 listed STHD as an outcome measure but it was not reported, so this study was assessed as being at high risk of bias. Schmidbauer 2000 was assessed as being at high risk of reporting bias because only ROSC was reported for VF and Asystole patients. Perkins 2018 and Jacobs 2011 were assessed as being at low risk of selective reporting.

\section{Other potential sources of bias}

All but four studies (Gueugniaud 1998; Sanchez-Mendiola 1998; Sherman 1997; Woodhouse 1995) were assessed unclear risk of other bias. No study compared post-resuscitation care in the study groups. We considered Gueugniaud 1998 to be at high risk of other bias due to presenting baseline characteristics and some outcomes for the intervention group only. Sanchez-Mendiola 1998 was only available as a conference abstract so was also considered to be at high risk of 'other' bias. We rated Sherman 1997 at high risk of bias in the 'Other bias' section: enrolment was discontinued before reaching the recruitment target because of "geographic relocation of investigators, concerns re deferred consent, intercurrent results of recent trials, similar trials". In addition, intention-to-treat was not stated and participants who received the study drug but did not meet the entrance requirement were excluded from data analysis.We also rated the Woodhouse 1995 study as being at high risk of other bias as the supervising physician was stated to treat patients differently depending on their allocated group.

Sanchez-Mendiola 1998 and Schmidbauer 2000 provided insufficient detail in several categories in the 'Risk of bias' assessment, and we rated them at high risk of potential bias overall.

\section{Publication bias}

Funnel plots for high-dose adrenaline versus standard-dose adrenaline are shown in Figure 4 for ROSC and Figure 5 for STHD. We did not produce funnel plots for other outcomes or comparisons, due to limited studies (fewer then 10). Visual analysis of the funnel plots revealed that they were roughly not symmetrical, suggesting the possibility of publication bias. The funnel plot for ROSC (Figure 4) suggests a lack of small studies with an RR of less than about 1.1 (the point estimate for the biggest studies), which could be due to publication bias. The funnel plot for survival (Figure 5) looks less asymmetrical, but there is still only one small study on the left side of the plot versus several on the right. 
Figure 4. Funnel plot of comparison: 2 Standard dose adrenaline (SDA) versus high dose adrenaline (HDA), outcome: 2.8 ROSC (adults vs children).

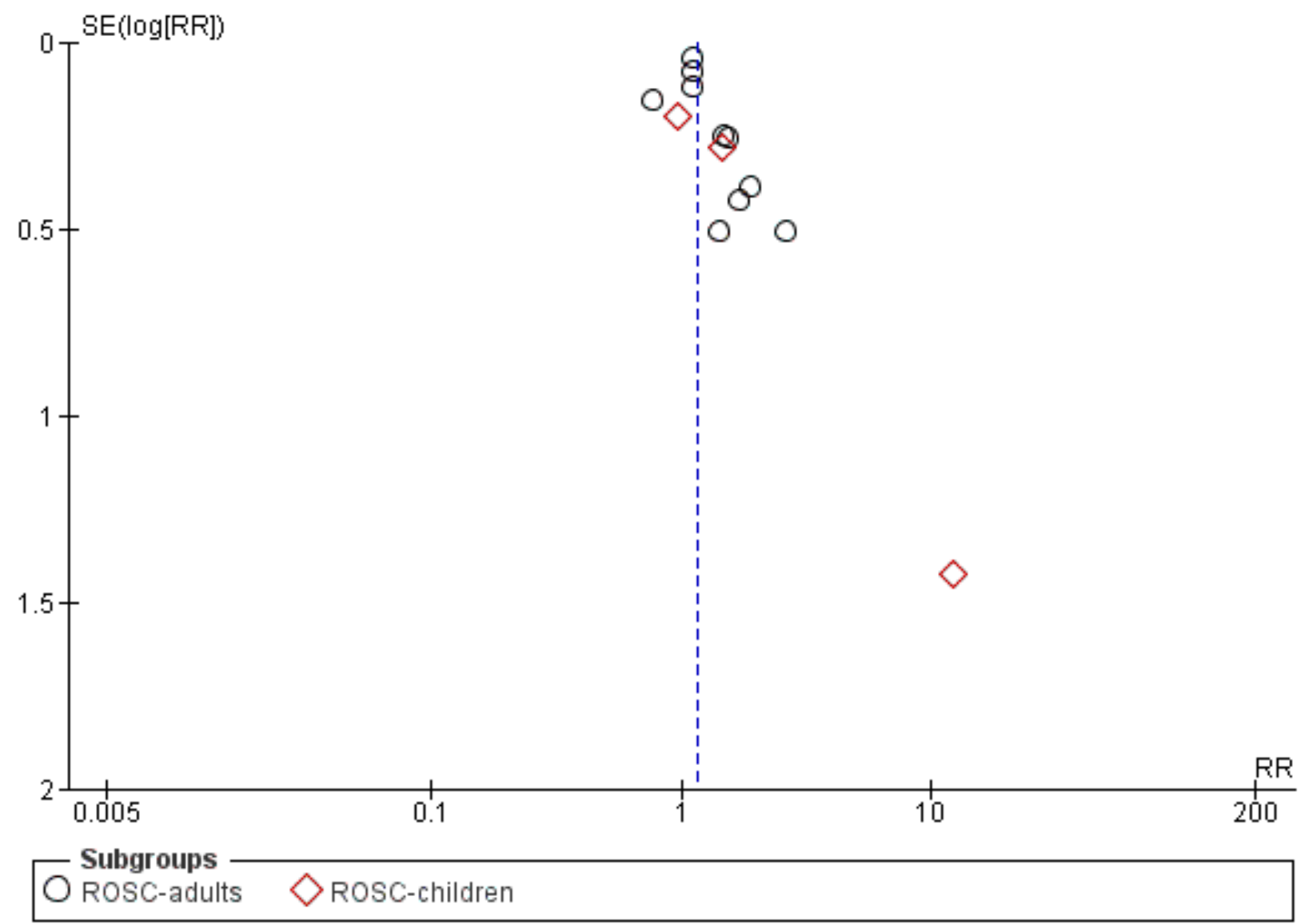


Figure 5. Funnel plot of comparison: 2 Standard dose adrenaline (SDA) versus high dose adrenaline (HDA), outcome: 2.1 Survival to hospital discharge.

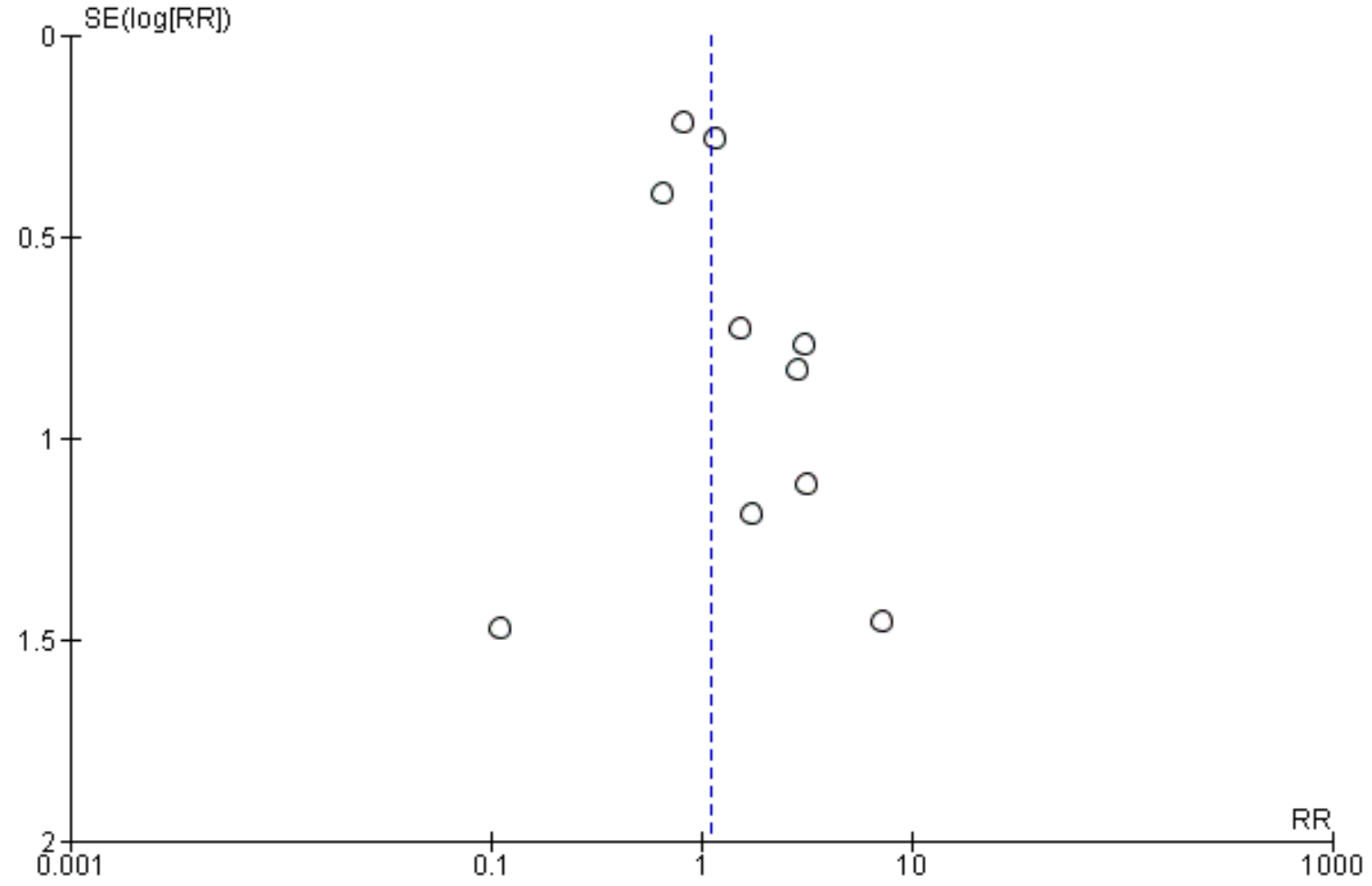

\section{Effects of interventions}

See: Summary of findings for the main comparison Standarddose adrenaline (SDA) compared to placebo for cardiac arrest; Summary of findings 2 Standard-dose adrenaline (SDA) compared to high-dose adrenaline (HDA) for cardiac arrest; Summary of findings 3 Standard-dose adrenaline (SDA) compared to vasopressin for cardiac arrest; Summary of findings 4 Standarddose adrenaline (SDA) compared to SDA plus vasopressin for cardiac arrest

\section{Survival to hospital discharge (STHD)}

\section{STHD: Adrenaline versus placebo}

Two studies compared standard-dose adrenaline (multiple doses) versus placebo (Jacobs 2011; Perkins 2018), and one smaller study (Woodhouse 1995) compared high-dose adrenaline (2 x $10 \mathrm{mg}$ doses) versus placebo before reverting back to standard (1 mg) doses of adrenaline. In the Woodhouse 1995 study there were no survivors to hospital discharge in either the high-dose adrenaline or placebo groups, and hence the pooled RR for adrenaline versus placebo is calculated from the two studies with events (Jacobs 2011; Perkins 2018). Jacobs 2011 (standard-dose adrenaline versus placebo) reported limited evidence of a difference in STHD, with the effect estimate suggesting a possible two-fold increase but the confidence interval indicating great uncertainty that could include either a small decrease or a very large increase (risk ratio (RR) 2.12, $95 \%$ confidence interval ( $\mathrm{Cl}) 0.75$ to 6.02 ; 534 participants).
The larger Perkins 2018 study reported an increase in STHD for participants in the intervention (adrenaline) group compared to the placebo group (RR $1.40,95 \% \mathrm{Cl} 1.08$ to $1.83 ; 8004$ participants). The pooled estimate for standard-dose adrenaline versus placebo showed an increase in STHD in favour of adrenaline: RR $1.44,95 \% \mathrm{Cl}$ 1.11 to 1.86 ; 2 studies; 8538 participants; $\left.\right|^{2}=0 \%$; moderate-quality evidence; Analysis 1.1 .

\section{STHD: Standard-dose adrenaline (SDA) versus high-dose adrenaline (HDA)}

Nine adult studies (Brown 1992; Callaham 1992; Gueugniaud 1998; Li 1999; Lindner 1991a; Polglase 1994; Sherman 1997; Stiell 1992; Zhu 2000) and three paediatric studies (Patterson 2005; Perondi 2004; Sanchez-Mendiola 1998) reported STHD for the comparison of high-dose adrenaline (HDA) versus standarddose adrenaline (SDA). There was considerable variation between studies in unadjusted STHD, ranging from $0 \%$ to $14 \%$ in the HDA group and $0 \%$ to $5 \%$ in the SDA group for adults; $0 \%$ to $20 \%$ in the HDA group to $0 \%$ to $12 \%$ in the SDA group for paediatric studies. Two of the studies comparing SDA versus HDA and reporting STHD had zero events in both arms of the study (Polglase 1994; Sherman 1997), meaning that we did not include these two studies in our calculation of the pooled RR for Analysis 2.1, nor in the subgroup analyses in Analysis 2.2 and Analysis 2.3. There was no evidence of a statistically significant difference in the pooled estimate for STHD in HDA versus SDA: RR 1.10, 95\% Cl 0.75 to 1.62; participants $=6274$; studies $=10 ; 1^{2}=24 \%$; very low-quality evidence; Analysis 2.1. Choux 
1995 did not report STHD, but did report 21-day survival. Including Choux 1995 in the pooled analysis (i.e. equating 21-day survival with STHD) only slightly affected the effect estimate and the 95\% confidence intervals, but not the conclusion of no effect.(RR 1.17, $95 \% \mathrm{Cl} 0.80$ to 1.71 ; participants $=6810$; studies $\left.=11 ;\left.\right|^{2}=25 \%\right)$ The very low-quality of the evidence for these two analyses means that we are uncertain of the effect of SDA compared with HDA on survival to hospital discharge.

We conducted two predefined subgroup analyses: (1) adults and children; and (2) IHCA and OHCA events.

(1) Three paediatric studies, one of OHCA (Patterson 2005), and two of IHCA (Perondi 2004; Sanchez-Mendiola 1998) compared highdose to standard-dose adrenaline. Whilst there was no evidence of a statistically significant difference in STHD (RR 1.54, 95\% Cl $0.17,13.66$; 3 studies; 317 participants), there was high clinical and statistical heterogeneity $\left(I^{2}=61 \%\right.$; Analysis 2.2$)$. There was no evidence of subgroup difference in STHD for adults versus children: Test for subgroup differences: $\mathrm{Chi}^{2}=0.17, \mathrm{df}=1(\mathrm{P}=0.68), \mathrm{I}=0.0 \%$.

(2) Six of the studies were OHCA (Brown 1992; Callaham 1992; Gueugniaud 1998; Patterson 2005; Polglase 1994 (not included in the meta-analysis) ; and Sherman 1997 (not included in the metaanalysis); four were IHCA (Li 1999; Perondi 2004; Sanchez-Mendiola 1998; Zhu 2000). Two studies (Lindner 1991a; Stiell 1992) included both IHCA and OHCA (adult) participants. The Lindner 1991a was excluded from the $\mathrm{IHCA} / \mathrm{OHCA}$ subgroup analysis, as it was not possible to distinguish results for the IHCA/OHCA groups. There was no evidence of subgroup difference in STHD for SDA compared to HDA in OHCA studies versus IHCA studies: Test for subgroup differences: $\mathrm{Chi}^{2}=0.30, \mathrm{df}=1(\mathrm{P}=0.58), \mathrm{I}^{2}=0 \%$; Analysis 2.3 .

\section{STHD: Standard-dose adrenaline versus vasopressin}

The pooled estimate for the six studies (Li 1999; Lindner 1997; Mukoyama 2009; Ong 2012; Stiell 2001; Wenzel 2004) that compared SDA to vasopressin showed no evidence of a statistically significant difference in STHD among 2511 participants: RR 1.25, 95\% Cl 0.84 to $1.85 ; I^{2}=29 \%$; very low-quality evidence; Analysis 3.1 . The very low quality of evidence means that we are uncertain of the effect of SDA versus vasopressin on STHD. Considering STHD for the three OHCA studies only (Lindner 1997; Mukoyama 2009; Wenzel 2004), there was no evidence of a statistically significant difference in the pooled results: RR $1.26,95 \% \mathrm{Cl} 0.76$ to $2.07 ; 1542$ participants, $\mathrm{I}^{2}=$ $29 \%$; Analysis 3.2). Similarly, there was no evidence of a statistically significant difference in STHD between SDA versus vasopressin for IHCA participants (Li 1999; Stiell 2001): RR 2.21, 95\% Cl 0.29 to 17.06; 242 participants, but heterogeneity was very high $(12=77 \%$; $P=$ $0.04)$. There was no evidence of OHCA/IHCA subgroup difference in STHD: Test for subgroup differences: $\mathrm{Chi}^{2}=0.28, \mathrm{df}=1(\mathrm{P}=0.60), \mathrm{I}^{2}$ $=0 \%$; Analysis 3.2 .

\section{STHD: Standard-dose adrenaline versus vasopressin plus adrenaline}

Three studies (Callaway 2006; Ducros 2011; Gueugniaud 2008) compared SDA to SDA plus vasopressin. Gueugniaud 2008 found no evidence of a statistically significant difference between the SDAplus-vasopressin group compared to the SDA (and placebo) group for STHD after OHCA: RR $0.73,95 \% \mathrm{Cl} 0.43$ to $1.23 ; 2887$ participants. Callaway 2006 compared vasopressin to placebo after both groups had received a dose of SDA and reported 30-day survival, not STHD.
There was no evidence of a statistically significant difference in 30-day survival between the groups: $\mathrm{RR} 1.18,95 \% \mathrm{Cl} 0.32$ to 4.32 ; 325 participants. In a small study ( $\mathrm{N}=30)$, Ducros 2011 compared up to three successive doses of SDA versus SDA plus vasopressin and found no evidence of a statistically significant difference in STHD: RR $0.23,95 \% \mathrm{Cl} 0.01$ to 4.36 . In a pooled analysis there was no evidence of a statistically significant difference in STHD/30-day survival, but the very low quality of the evidence means that we are uncertain of the effect on this outcome: RR $0.76,95 \% \mathrm{Cl} 0.47$ to 1.22 ; 3 studies; 3242 participants; $1^{2}=0 \%$; very low-quality evidence; Analysis 4.1.

\section{Survival to hospital admission (STHA)}

\section{STHA: Adrenaline versus placebo}

Both Jacobs 2011 and Perkins 2018 found a two to three-fold increase in STHA for adult participants who received SDA compared to placebo. The pooled estimate of the two studies showed an increase in STHA for participants in the intervention (adrenaline) group compared to placebo group: RR $2.51,95 \% \mathrm{Cl} 1.67$ to 3.76 ; 8489 participants; $1^{2}=77 \%$; moderate-quality evidence; Analysis 1.2. Woodhouse 1995 did not report STHA.

\section{STHA: Standard-dose adrenaline (SDA) versus high-dose adrenaline (HDA)}

Five studies in adults (Brown 1992; Callaham 1992; Choux 1995; Gueugniaud 1998; Polglase 1994) reported the proportion of people surviving to hospital admission among those who received HDA compared to SDA. The pooled estimate showed a $13 \%$ increase in STHA for the HDA group: RR 1.13, 95\% Cl 1.03 to 1.24; 5 studies; 5764 participants; $I^{2}=0 \%$; Analysis 2.4 . However, the very low quality of evidence suggests uncertainty in the effect for this outcome. No paediatric study reported STHA.

Survival to 24 hours was reported by five studies (Choux 1995; Gueugniaud 1998; Lipman 1993; Patterson 2005; Perondi 2004) that compared HDA to SDA. In the individual studies, there was no evidence of a difference in 24-hour survival between HDA and SDA in the three adult studies (Choux 1995; Gueugniaud 1998; Lipman 1993), nor the two paediatric studies (Patterson 2005; Perondi 2004). . The pooled estimate found no evidence of a statistically significant difference in 24-hour survival between HDA and SDA: (RR $1.04,95 \% \mathrm{Cl} 0.76$ to 1.43 ; participants $=4179$; studies $\left.=5 ; \mathrm{I}^{2}=39 \%\right)$; Analysis 2.5

\section{STHA: Standard-dose adrenaline versus vasopressin}

Administration of vasopressin was associated with increased STHA compared to SDA when we combined the results from the three studies (Ong 2012; Lindner 1997; Wenzel 2004) reporting this endpoint: RR $1.27,95 \% \mathrm{Cl} 1.04$ to $1.54 ; 3$ studies; 1953 participants; $\mathrm{I}^{2}=27 \%$; low-quality evidence; Analysis 3.3 .

\section{STHA: Standard-dose adrenaline versus vasopressin plus adrenaline}

A pooled estimate of the effect of vasopressin and adrenaline compared to SDA from three studies (Callaway 2006; Ducros 2011; Gueugniaud 2008) showed no effect on STHA: RR 0.95, 95\% Cl 0.83 to 1.08 ; 3 studies; 3249 participants; $\left.\right|^{2}=0 \%$; low-quality evidence; Analysis 4.2. 


\section{Neurological outcome}

\section{Neurological outcome: Adrenaline versus placebo}

In the Jacobs 2011 study, nine of the 11 survivors (3.1\% overall) in the SDA group had a favourable neurological outcome (CPC < 3) at hospital discharge, whilst all five of the surviving participants in the placebo group (1.9\% overall) had a favourable neurological outcome: RR $1.73,95 \% \mathrm{Cl} 0.59$ to $5.11 ; 534$ participants. In the Perkins 2018 study, there was no difference in the percentage of participants who had a favourable neurological outcome at hospital discharge (mRs $\leq 3)$ (or at three months after the OHCA) between the SDA (2.2\%) and placebo (1.9\%) groups: RR 1.17, 95\% Cl 0.86 to $1.59 ; 8001$ participants. The pooled estimate of SDA versus placebo showed no statistically significant difference in favourable neurological outcome between the SDA and placebo groups: RR $1.21,95 \% \mathrm{Cl} 0.90$ to $1.62 ; 2$ studies; 8535 participants; $12=0 \%$; lowquality evidence; Analysis 1.3. However, Perkins 2018 also showed that severe neurologic impairment at hospital discharge (a mRs of 4 or 5) was more frequent in the SDA group than in the placebo group (39 of 126 participants (31.0\%) versus 16 of 90 participants $(17.8 \%)$ ).

\section{Neurological outcome: Standard-dose adrenaline versus high- dose adrenaline}

Two studies (Callaham 1992; Gueugniaud 1998) reported CPC scores $<3$ for participants receiving SDA or HDA, with neither finding evidence of a difference in neurological outcome between the SDA and HDA groups. Stiell 1992 reported CPC scores category ' 1 ' and found no evidence of difference between the SDA and HDA groups (RR $0.63,95 \% \mathrm{Cl} 0.28$ to $1.42 ; 650$ participants). Brown 1992 recorded CPC score categories < 4, i.e. "conscious at time of hospital discharge" and reported $92 \%$ of participants in the SDA group who survived to hospital discharge and $94 \%$ in the HDA group had $\mathrm{CPC}<4$. Including this study with the others reporting CPC scores (i.e. Brown 1992; Callaham 1992; Gueugniaud 1998; Stiell 2001), there was no evidence of a statistically significant difference in the effect of SDA versus HDA on 'good' neurological outcomes: (RR $0.91,95 \% \mathrm{Cl} 0.65$ to 1.26 ; participants $=5803$; studies $=4$; $1^{2}=0 \%$ ); Analysis 2.6. The very low quality of evidence means that we are uncertain of the effect of SDA versus HDA on this outcome. Neurological outcome in the Li 1999 study was described as "discharged from hospital with pre-arrest conscious state, heart rate and respiratory rate status" - and was not included in the metaanalysis. The GCS neurological assessments in Choux 1995 at day 3 and day 21 were made by different physicians and (according to the authors) "were not systematically performed"; so we have not included these results in the meta-analysis. However, the authors reported that there was no evidence of difference in GCS between the intervention SDA and HDA groups (Choux 1995).

Three paediatric studies comparing SDA to HDA assessed neurological outcome (Perondi 2004; Patterson 2005; SanchezMendiola 1998). Given the small number of survivors in each study and the different assessment tools used, we provide a narrative summary. Perondi 2004 reported no survivors in the HDA group; in the SDA group, two children had a paediatric CPC score of ' 1 ' and the other two children (who were impaired before the hospital cardiac arrest) had the same neurological outcome after the IHCA. Patterson 2005 used an adapted Glasgow Outcome Scale (Jennett 1975) to assess neurological outcome at hospital discharge. In the HDA group two children had good, one had moderate and six children had a severe neurological outcome. Both surviving children in the SDA group had severe neurological outcome $(P=$ 0.51). Sanchez-Mendiola 1998 reported no survivors in the SDA group, and of the two survivors in the HDA group both had "neurologic damage" at hospital discharge.

\section{Neurological outcome: Standard-dose adrenaline versus vasopressin}

For the four studies (Mukoyama 2009; Ong 2012; Stiell 2001; Wenzel 2004) that reported neurological outcome as CPCs for the vasopressin versus SDA comparison, there was no evidence of a statistically significant difference in the pooled result: RR $0.82,95 \%$ $\mathrm{Cl} 0.54$ to 1.25 ; participants $=2406$; studies $=4 ; \mathrm{I}^{2}=0 \%$; Analysis 3.4. The very low quality of the evidence indicates uncertainty around this outcome. Ong 2012 followed up participants to one year and reported no evidence for a difference between the SDA and vasopressin groups at that time. Lindner 1997 reported no evidence of a difference in the mean(sd) Glasgow Coma Scale scores for the three STHD participants in the SDA group compared to the eight STHD participants in the vasopressin group (10.7 (3.8) versus 11.7 (1.6), $P=0.78$ ), but this was not included in the meta-analysis due to the use of a different neurologic assessment scale.

\section{Neurological outcome: Standard-dose adrenaline versus vasopressin plus adrenaline}

Gueugniaud 2008 compared CPC scores $<3$ between the SDA plus vasopressin group and the SDA with placebo group, and found no evidence of difference in CPC scores: RR $0.65,95 \% \mathrm{Cl} 0.33$ to 1.31 ; participants $=887$; studies $=1$; very low-quality evidence; Analysis 4.3 .

\section{Return of spontaneous circulation (ROSC)}

\section{ROSC: Adrenaline versus placebo}

Jacobs 2011 reported that pre-hospital ROSC in OHCA was significantly higher in the SDA group when compared to placebo: RR $2.80,95 \%$ CI 1.78 to 4.41; participants $=534$. Similarly, Perkins 2018 reported more than a tripling of the proportion of participants achieving pre-hospital ROSC in the SDA group (36.3\% versus $11.7 \%$; RR 3.10, $95 \% \mathrm{Cl} 2.82$ to 3.41 ; participants $=7935$ ). In the Woodhouse 1995 study, immediate survival, defined as "stable cardiac rhythm with palpable pulse at time cardiac arrest team left", was higher, but not significantly different in OHCA in the HDA group compared to placebo (RR 1.37, 95\% Cl 0.53 to 3.53; participants $=194$ ).

The pooled estimate for the three studies (Jacobs 2011; Perkins 2018; Woodhouse 1995) that compared the effect of adrenaline versus placebo on the proportion of participants who achieved ROSC was: RR $2.86,95 \% \mathrm{Cl} 2.21$ to 3.71 ; participants $=8663$; studies $=3 ; 1^{2}=33 \% ;$ Analysis 1.4 . Removal of the Woodhouse 1995 study, which had a high risk of bias (see Figure 2) and a different experimental intervention (HDA compared to placebo), had minimal effect on the pooled estimate (RR $3.09,95 \% \mathrm{Cl} 2.82$ to 3.39 ; participants $=8469 ;$ studies $=3 ; 1^{2}=0 \%$ ).

\section{ROSC: Standard-dose adrenaline versus high-dose adrenaline}

Of the 7014 participants (adults and children) in the 13 studies (Brown 1992; Callaham 1992; Choux 1995; Gueugniaud 1998; Li 1999; Patterson 2005; Perondi 2004; Polglase 1994; SanchezMendiola 1998; Schmidbauer 2000; Sherman 1997; Stiell 1992; Zhu 2000;) that compared ROSC in participants receiving HDA or SDA, there was a small increase in ROSC of $15 \%$ in the HDA group: RR 
$1.15,95 \% \mathrm{Cl} 1.02$ to $1.29 ; \mathrm{I}^{2}=34 \%$; Analysis 2.8 . The very low quality of evidence means there is uncertainty around this outcome. There was no substantial change in the estimate with the removal of Schmidbauer 2000 (excluded because of a high risk of bias).

Two studies also compared graded doses of adrenaline (Zhu 2000) or $5 \mathrm{mg}$ adrenaline (Polglase 1994) to SDA and found similar results to participants receiving HDA, as shown in the Characteristics of included studies table. The pooled estimate for the four studies ( $\mathrm{Li}$ 1999; Perondi 2004; Sanchez-Mendiola 1998; Zhu 2000) that were conducted in-hospital showed a slight increase in the relative risk of ROSC but the confidence interval also includes the possibility of no effect or even a small decrease: RR $1.78,95 \% \mathrm{Cl} 0.82$ to 3.88; participants $=190 ;$ Analysis 2.7. However there was a high level of heterogeneity $\left(I^{2}=68 \% ; P=0.02\right)$. There was no evidence of subgroup difference in ROSC for OHCA versus IHCA (test for subgroup differences: $\mathrm{Chi}^{2}=1.29, \mathrm{df}=1, \mathrm{P}=0.26, \mathrm{I}^{2}=22 \%$; Analysis 2.7).

Three paediatric studies (Patterson 2005; Perondi 2004; SanchezMendiola 1998) compared ROSC in SDA versus HDA in 258 children and found no evidence of a difference in ROSC, but with substantial heterogeneity: RR $1.3195 \% \mathrm{Cl} 0.67$ to $2.56 ; \mathrm{I}^{2}=63 \%$; Analysis 2.8 . Excluding one study (Sanchez-Mendiola 1998) because of a high risk of bias, there was no evidence of a difference in the effect estimate for ROSC (RR 1.13, 95\% Cl 0.73 to 1.73; participants = 222; studies = $\left.2 ; 1^{2}=41 \%\right)$. There was no evidence of subgroup difference in ROSC for adults versus children; test for subgroup differences: $\mathrm{Chi}^{2}=0.15$, $\mathrm{df}=1(\mathrm{P}=0.70), \mathrm{I}^{2}=0.0 \%$; Analysis 2.8 .

\section{ROSC: Standard-dose adrenaline versus vasopressin}

The pooled estimate for the six studies ( Li 1999; Lindner 1997; Mukoyama 2009; Ong 2012; Stiell 2001; Wenzel 2004) that compared SDA to vasopressin showed no evidence of a statistically significant difference in ROSC: RR $1.10,95 \% \mathrm{Cl} 0.90$ to 1.33 ; studies $=6$; participants $=2531 ; 1^{2}=61 \%$; very low-quality evidence; Analysis 3.5. There was no difference for participants who had an IHCA (RR $1.76,95 \% \mathrm{Cl} 0.40$ to 7.71 ; participants $=242$, studies $=2 ; \mathrm{I}^{2}=84 \%$ ) or an OHCA (RR 1.05, 95\% Cl 0.80 to 1.39; participants $=1562$; studies = $3 ;\left.\right|^{2}=56 \%$; Analysis 3.6). However, there was substantial statistical heterogeneity for the IHCA subgroup. There was no evidence of subgroup difference in ROSC in OHCA versus IHCA; test for subgroup differences: $\mathrm{Chi}^{2}=0.45, \mathrm{df}=1(\mathrm{P}=0.50), \mathrm{I}^{2}=0 \%$; Analysis 3.6.

\section{ROSC: Standard-dose adrenaline versus vasopressin plus adrenaline}

The pooled estimate of three studies (Callaway 2006; Ducros 2011; Gueugniaud 2008) that compared SDA versus vasopressin plus adrenaline showed no difference in ROSC: RR $0.97,95 \% \mathrm{Cl} 0.87$ to 1.08; participants $=3249 ;$ studies $=3 ; 1^{2}=0 \%$; low-quality evidence; Analysis 4.4.

\section{Other outcomes}

We prespecified three other outcomes in our protocol (Jacobs 2003), namely: all-cause mortality, return of non-perfusing rhythm, and admission to ICU, but we have not included them in the review for the following reasons.

Firstly, all-cause mortality is not reported in resuscitation research, since survival at specific time points (e.g. 'STHD') is the recommended outcome (Perkins 2015). Return of non-perfusing rhythm was not reported by any studies. Admission to ICU was reported as an outcome by several studies (Gueugniaud 1998; Lindner 1997; Ong 2012; Patterson 2005; Stiell 1992), but tended to be a surrogate for admission to hospital in OHCA. This outcome is not recommended in the Utstein guidelines (Perkins 2015), and we therefore have not analysed it separately.

\section{DISCUSSION}

\section{Summary of main results}

This systematic review and meta-analysis combines the results from 26 studies that reported the effect of administration of adrenaline or vasopressin or both on patient outcomes after cardiac arrest. We imposed no language or age limits, and the cardiac arrest could occur out of hospital (OHCA) or in the hospital (including ED or ICU) (IHCA). Because different aetiology is often involved in paediatric cardiac arrests (Reis 2002), we performed separate analyses for adults and children, and for IHCA and OHCA events.

A primary outcome was survival to hospital discharge (STHD). Timely restoration of cardiac rhythm and circulation (i.e. ROSC) is essential for short-term survival but STHD and the quality of survival are most important for patients, their families and caregivers (Haywood 2018). We found high-quality evidence from two randomised controlled trials (Jacobs 2011; Perkins 2018; 8538 participants in total) that showed that standard-dose adrenaline (1 mg repeated doses), compared to placebo, increased STHD. By contrast, we are uncertain about STHD in studies that compare high-dose adrenaline (HDA) and standard-dose adrenaline (SDA), vasopressin versus SDA or vasopressin/adrenaline versus SDA, due to very low-quality evidence. The information provided by subgroup analyses (adults versus children and IHCA versus OHCA) were limited by the small number of children and in-hospital cardiac arrests reported. Although the analyses performed showed no evidence of a difference in STHD (primary outcome), the confidence intervals were wide.

Survival to hospital admission (STHA) was reported less often than STHD. SDA compared to placebo more than doubled STHA. Although the analysis suggests that HDA increased STHA by $13 \%$ compared to SDA, we are uncertain about this effect, due to very low-quality evidence. Vasopressin increased STHA by $27 \%$ compared to SDA; but the pooled effect of SDA compared to vasopressin plus SDA found no evidence for a difference between the two groups.

Survival with a favourable neurological outcome is important for patients and their families (Haywood 2018), but several studies did not report neurological outcomes (Callaway 2006; Ducros 2011; Lindner 1991a; Lipman 1993; Polglase 1994; Schmidbauer 2000; Woodhouse 1995). Those that did used a range of methods: cerebral performance category (CPC) scores, Glasgow coma score (GCS), Glasgow outcome score, mini-mental state examination (MMSE) and electroencephalogram (EEG) (see Primary outcomes in the Included studies section for more details). In the comparison of SDA to placebo, the pooled estimate did not show evidence of a difference in survival with a favourable neurological outcome (Jacobs 2011; Perkins 2018); however, both studies reported more participants surviving with impaired neurological outcome in the adrenaline arm. Of the four studies that compared SDA to HDA 
(Brown 1992; Callaham 1992; Gueugniaud 1998; Stiell 1992) and reported CPC scores, the pooled analysis did not show any difference in neurologic outcome, but there is uncertainty around this result due to the very low quality of evidence. However. there was substantial heterogeneity $\left(I^{2}=62 \%\right)$, with small sample sizes and wide confidence intervals, and variation in the definition of 'good' CPC scores. The five studies (Mukoyama 2009; Ong 2012; Stiell 2001; Wenzel 2004;Gueugniaud 2008) that included vasopressin in the comparison found no evidence of improved neurological outcome, but again very low-quality evidence makes this uncertain. Hospital discharge was the most commonly collection time point for assessing neurological outcome, but longer follow-up is needed to assess the effects of the treatments received.

Whilst not a patient-centred outcome (Perkins 2015), return of spontaneous circulation (ROSC) is commonly reported as an initial survival outcome measure in resuscitation research. Despite the different operational definitions (as shown in the Characteristics of included studies table), we include ROSC as a secondary outcome. As has been widely reported elsewhere (Larabee 2012; Lin 2014), SDA increased ROSC compared to placebo. ROSC provides time to initiate therapies that may enable recovery, but the use of vasopressors could have negative effects on vital organs that may worsen neurological outcome (Ristagno 2009; Soar 2011). ROSC without good-quality survival is a poor outcome for patients.

\section{Overall completeness and applicability of evidence}

We conducted comprehensive searches using bibliographic databases, with no limits on language or date of publication. Two Chinese papers (Li 1999; Zhu 2000) and one Japanese paper (Nishizawa 1993) were translated into English. We also checked several systematic reviews (Aung 2005; Larabee 2012; Lin 2014; Mentzelopoulos 2012; Meyer 2011; Sillberg 2008; Wyer 2006), and included in our review all studies included in these reviews that met our selection criteria. While we included 26 studies with 28 comparisons in our review, there were several groups such as IHCA and cardiac arrests in children that had too few participants or had levels of heterogeneity across studies that precluded confidence in interpretation of the pooled results.

Furthermore, all studies in our review were conducted in relatively resource-rich countries, with well-established emergency medical responses, and as such may not be applicable to resource-limited settings. Out of the 26 studies only four used a placebo (Gueugniaud 2008; Jacobs 2011; Perkins 2018; Woodhouse 1995), and one of these (Gueugniaud 2008) administered adrenaline to both groups, i.e. placebo and adrenaline were administered in the control group and $1 \mathrm{mg}$ of adrenaline and $40 \mathrm{IU}$ of vasopressin in the experimental group. Two of the trials of placebo versus adrenaline were challenged by the "unwillingness of providers to randomise subjects to the placebo arm" (Jacobs 2011; Woodhouse 1995), and Perkins 2018 was subject to adverse media reporting during the conduct of the trial.

\section{Quality of the evidence}

We rated eight studies (Callaway 2006; Ducros 2011; Jacobs 2011; Lindner 1991a; Lindner 1997; Ong 2012; Perkins 2018; Stiell 1992) at low risk of bias for most categories. These include Ducros 2011, that was excluded in the Mentzelopoulos 2012 systematic review for high risk of bias, and Jacobs 2011, that was rated as "fair" by
Larabee 2012 because of the problems with recruitment to the study. In a sensitivity analysis, we excluded two studies (SanchezMendiola 1998; Schmidbauer 2000) for high risk of bias overall; the exclusion from pooled analyses reduced statistical heterogeneity but did not change the overall pooled result. Valid interpretation of the pooled estimate for the three paediatric studies (Patterson 2005; Perondi 2004; Sanchez-Mendiola 1998) was not possible, because of the substantial heterogeneity.

We sought to compare low- and high-dose adrenaline and adrenaline versus vasopressin, but study protocols varied. Some studies (Callaway 2006; Perondi 2004; Sherman 1997) required both groups to have an initial dose of SDA before administration of the study drug. The number of doses of study drug varied from one (Brown 1992; Lindner 1997; Ong 2012; Stiell 2001) to 15 (Choux 1995; Gueugniaud 1998). After the number of predefined study drug doses had been administered participants often received subsequent doses of SDA as required. Patterson 2005 permitted the administration of double doses of adrenaline for the second and subsequent doses, at the physician's discretion. SanchezMendiola 1998 allowed HDA to be administered after the initial dose of study drug. In Callaway 2006, which compared vasopressin to SDA, physicians were allowed to administer open-label vasopressin according to medical judgement. Adrenaline was used in all other studies that allowed vasopressors after the prescribed number of study drug doses had been administered, which varied considerably between studies.

Whilst many study protocols specified administration of the study drug as soon as practicable, in reality the time from onset of cardiac arrest to drug delivery varied widely. For example, in the large OHCA RCT of adrenaline vs placebo (Perkins 2018), with an average response time from emergency call to scene of around six minutes (comparable to many ambulance services worldwide), the median time from call to administration of the study agent was 21 minutes (interquartile range (IQR) 16 to 27 minutes). One OHCA study (Mukoyama 2009) did not allow vasopressor administration at all in the field, requiring instead that patients be randomly assigned to either vasopressin or SDA immediately after admission to the emergency room. This resulted in an interval of 30 minutes or more from call to drug administration. It is likely that the time interval from the arrest until drug administration is reduced in IHCA, since the response team is 'on site'. Stiell 2001 reported a mean time interval of 6.1 minutes to administration of study drug in their IHCA study. Similarly, Perondi 2004, the paediatric IHCA study where most participants were in intensive care unit or the emergency department, with $78 \%$ being monitored electrocardiographically, reported a mean time interval from call to drug administration of less than three minutes.

The differences in vasopressor administration timing and drug administration protocol can make interpretation of the specific effects of a therapy difficult when comparing outcomes between groups (Soar 2011). Similarly, differences in medical treatment and emergency medical services structure may affect outcomes in a RCT, e.g. the French OHCA studies (Choux 1995; Ducros 2011; Gueugniaud 1998; Gueugniaud 2008) used physician-staffed mobile ICUs. There was therefore heterogeneity in the settings, interventions and participant populations reported in this review. This in part explains why, despite the fact that we only included randomised controlled trials, the levels of evidence quality were 
very low and low, increasing to high only in the adrenaline-placebo trials.

This review was limited to reporting randomised controlled trials. Assessment of quality of the evidence for each outcome using GRADE identified at best moderate-quality evidence but mostly low or very low. For SDA compared to placebo, the quality of evidence was moderate for STHD, ROSC, and STHA, and low for favourable neurological outcomes (see Summary of findings for the main comparison). We rated the level of evidence for SDA compared to HDA as very low for all outcomes (see Summary of findings 2), with the quality of evidence downgraded for serious risk of bias, serious imprecision and serious inconsistency. We rated SDA versus vasopressin as very low quality of evidence for STHD, neurological outcome and ROSC, and low quality for STHA (see Summary of findings 3), with the quality of evidence downgraded for risk of bias, very serious inconsistency and imprecision. Finally, for SDA compared to vasopressin plus adrenaline, we judged the level of evidence to be low or very low (see Summary of findings 4), with the quality of evidence downgraded for serious risk of inconsistency and very serious risk of imprecision.

\section{Potential biases in the review process}

Although we performed an extensive search of the literature, we may have missed some papers reporting relevant studies. We included both OHCA and IHCA, and stratified some analyses to account for differences in outcomes because of the location of the cardiac arrest. Often only the sicker patients were included in studies, e.g. those in ventricular fibrillation (VF)/ pulseless ventricular tachycardia (VT) were randomised after initial defibrillation shocks were unsuccessful (Gueugniaud 2008; Jacobs 2011; Perkins 2018). Patients with a brief duration of VF and therefore a high likelihood of survival and subsequent good neurological recovery were not included in most studies. The selection of endpoints may not be the most suitable for people who suffer a cardiac arrest. Merely having ROSC and not surviving beyond a few hours may provide the opportunity to apply postresuscitation care that can affect survival, but it is not a good outcome for patients if survival is of poor quality.

Neurologic outcomes were most commonly assessed using the fivepoint Cerebral Performance Category. However, the 'cut point' to define a favourable neurologic outcome varied across studies.

Studies were published between 1991 (Lindner 1991a) and 2018 (Perkins 2018). It is difficult to account for variations in practice over time, as well as differences between hospitals and EMS providers, which could impact on patient outcomes.

We also cannot rule out the possibility that non-significant trials might be less likely to be published.

The source of funding was not stated in 11 of the 26 studies, The study drugs were provided and funded by the manufacturer in four of the 26 studies, but neither drug represents a profitable commercial option, given that they are 'off patent'.

\section{Agreements and disagreements with other studies or reviews}

Several systematic reviews (with and without meta-analyses) have been published in the last 15 years. Some were similar to ours in that they considered a range of interventions involving adrenaline, i.e. SDA versus placebo, HDA versus SDA, or vasopressin (alone or in combination with adrenaline) versus SDA (Larabee 2012; Lin 2014). Others restricted their reviews to comparisons of SDA versus vasopressin (alone or in combination with adrenaline) (Aung 2005; Mentzelopoulos 2012; Sillberg 2008; Wyer 2006; Xiao-li 2010). Our systematic review and meta-analysis provides a comprehensive report of the current literature of RCTs of OHCA and IHCA, adults and paediatric studies, and comparisons of adrenaline versus placebo, standard-dose adrenaline versus high-dose adrenaline, and adrenaline versus vasopressin (alone and in combination with adrenaline). The following provides an overview of the differences between our systematic review and those listed above.

Aung 2005 included five RCTs (Lee 2000; Li 1999; Lindner 1997; Stiell 2001; Wenzel 2004) that compared vasopressin to adrenaline. Our review excluded Lee 2000 because the conference abstract was a pilot study of 10 participants from a larger RCT in progress, for which few details were provided. We could find no record of the study, and were unsuccessful in contacting the authors. The methodological quality of three studies (Lindner 1997; Stiell 2001; Wenzel 2004) was rated as low risk, but Li 1999 was rated at high risk of bias, which differed from our assessment in which we did not rate the study as having a high risk overall. Aung 2005 concluded that there was no evidence of a difference in any of the outcomes (ROSC, STHA, STHD or neurological outcome) between the vasopressin and adrenaline groups.

Wyer 2006 compared vasopressin and adrenaline in cardiac arrest, but only included three RCTs (Lindner 1997; Stiell 2001; Wenzel 2004), which they regarded as "well-reported", and referred to the Aung 2005 systematic review. Wyer 2006 excluded two studies (Lee 2000; Li 1999), which were rated by Aung 2005 as "low quality". They stated that these two papers provided insufficient information about the study populations, treatment protocols, or the susceptibility to bias. We have also excluded Lee 2000, as explained above. We agree with Wyer's assessment that the inclusion of Lee 2000 in a pooled analysis "might distort the estimates in ways that the parsimoniously reported data does not allow an investigator to anticipate or assess". However, we did not exclude any study based on risk of bias, and we have therefore included Li 1999. Based on the three RCTs included in Wyer 2006, the authors concluded that "the evidence did not show a consistent benefit of vasopressin compared to adrenaline in increasing STHD or improving neurologic outcome".

Sillberg 2008 reported the results from three RCTs that compared the effect of vasopressin plus adrenaline versus repeated doses of SDA alone in OHCA (Callaway 2006; Wenzel 2004) and IHCA (Stiell 2001). Three excluded studies were not identified in the report. The authors did not conduct a meta-analysis because they believed that "the three studies were too dissimilar to allow pooling of results". However, they noted that only Wenzel 2004 showed improved outcomes (ROSC, admission to hospital and STHD) for the combination of vasopressin and epinephrine (adrenaline). Our review assigns these three studies to different comparison groups, i.e. Stiell 2001 and Wenzel 2004 to the 'SDA versus vasopressin' comparison, and Callaway 2006 to the 'SDA versus adrenaline and vasopressin' comparison.

Xiao-li 2010 compared the effect of vasopressin and adrenaline used together versus adrenaline alone in adults in cardiac arrest. They included six studies (Callaway 2006; Grmec 2006; Gueugniaud 2008; Lindner 1997; Stiell 2001; Wenzel 2004). One of the included 
studies (Grmec 2006) was an observational cohort study (not an RCT) and was therefore excluded from our review. The two studies that were excluded from the Xiao-li 2010 review due to methodological concerns were not identified. Outcomes assessed were ROSC, STHA, survival at 24 hours, STHD and neurological outcome. Xiao-li 2010 reported increased 24-hour survival for the vasopressin-plus-adrenaline group but no evidence of a difference for the other outcomes. As explained above, we separated the adrenaline-versus-vasopressin studies into two distinct comparisons based on whether or not the two drugs were co-administered.

Mentzelopoulos 2012 examined the effect of any vasopressin regimen versus adrenaline on outcomes from cardiac arrest. Eight studies (Callaway 2006; Ducros 2011; Gueugniaud 2008; Lindner 1997; Mentzelopoulos 2009; Mukoyama 2009; Stiell 2001; Wenzel 2004) were initially selected but two were excluded (Ducros 2011; Mukoyama 2009) because of a high risk of bias. Ducros 2011 was excluded because the risk of bias for blinding of long-term outcomes was unclear, i.e. there was a lack of explicit reporting of blinding for data collectors, outcome assessors and data analysts, the estimated sample size was not reached, and the frequency of bystander CPR differed between groups. Mukoyama 2009 was excluded because there was no blinding for short-term or longterm outcomes and there was no power calculation. We excluded neither of these studies from our review. Mentzelopoulos 2012 also included Mentzelopoulos 2009, which we excluded from our review because it did not allow the direct contribution of vasopressin on outcomes to be assessed. The conclusion drawn by Mentzelopoulos 2012 was that "Vasopressin use in the resuscitation of cardiac arrest patients is not associated with any overall benefit or harm".

Larabee 2012 examined the effect of vasopressors on outcomes in participants who suffered cardiac arrest. Unlike our review, Larabee 2012 included controlled trials, meta-analyses and case series, and is therefore not directly comparable with our review, which only includes RCTs. The only RCT included in Larabee 2012 that was not included in our review was Olasveengen 2009. This study compared the provision of advanced cardiac life support with and without intravenous drug administration, rather than comparing specific drugs. For this reason we excluded it from our review. Larabee 2012 concluded that "Epinephrine is associated with improvement in short term survival outcomes as compared to placebo, but no longterm survival benefit has been demonstrated".

In 2015 the International Liaison Committee for Resuscitation (ILCOR) conducted a number of systematic reviews of advanced life support interventions, including Epinephrine (adrenaline) versus placebo; Standard-dose epinephrine (SDE) versus highdose epinephrine (HDE); and Epinephrine versus vasopressin in combination with epinephrine (Soar 2015). These systematic reviews and meta-analyses were incorporated into a single publication (Lin 2014). The search strategy for Lin 2014 was undertaken up until July 2013, and hence does not include the recently-published Perkins 2018 study. The inclusion criteria of the Lin 2014 review also differ from ours by restricting analyses to adult participants, thus excluding the three paediatric studies in our review (Perondi 2004; Patterson 2005; Sanchez-Mendiola 1998). Studies were also excluded if it was not possible to separate outcomes amongst those sustaining in- and out-ofhospital cardiac arrests, thereby excluding Lindner 1991a; Lipman 1993 and Woodhouse 1992. We identified and translated two
Chinese studies (Li 1999; Zhu 2000) which were not included in the Lin 2014 review and also included Polglase 1994 (Research letter), Stiell 2001 (IHCA) and the recent Perkins 2018 study. The Lin 2014 review included 14 studies for the four comparisons as follows: (1) one study for adrenaline versus placebo (Jacobs 2011); (2) six studies for SDA versus HDA (Brown 1992; Callaham 1992; Choux 1995; Gueugniaud 1998; Sherman 1997; Stiell 1992); (3) six studies for SDA versus adrenaline plus vasopressin (Callaway 2006; Ducros 2011; Gueugniaud 2008; Lindner 1997; Ong 2012; Wenzel 2004); and (4) one study for SDA versus vasopressin alone (Mukoyama 2009). Our classification of studies that fell within the 'SDA vs vasopressin alone' and the 'SDA versus adrenaline plus vasopressin' comparisons differed from those in Lin 2014. In the 'SDA versus adrenaline plus vasopressin' comparison, we only included studies where the adrenaline and vasopressin were co-administered (Callaway 2006; Ducros 2011; Gueugniaud 2008), whereas Lin 2014 defined their comparison of 'Adrenaline and vasopressin combination' as "the use of both drugs concomitantly during resuscitation, regardless of the order of drug administration or specific trial intervention" (Lin 2014).

With respect to the pooled analyses for each of the four comparisons: (1) Lin 2014 only included one study (Jacobs 2011) for the 'SDA versus placebo' comparison and is therefore not comparable with our review, which now includes the substantial recent Perkins 2018 study; (2) As in our review, Lin 2014 reported a reduced risk of ROSC for SDA compared to HDA (RR 0.85, 95\% $\mathrm{Cl} 0.75$ to $0.97 ; 6$ studies; 6174 participants; $\left.\right|^{2}=48 \%$ ), and a small reduction in STHA for SDA compared to HDA (RR 0.87, 95\% Cl 0.76 to 1.00 ; 4 studies; 5699 participants; $\left.\right|^{2}=34 \%$ ), but no difference in STHD or neurological outcomes; (3) Lin 2014 reported no difference between SDA versus adrenaline plus vasopressin for any of the outcomes (ROSC, STHA, STHD, neurological outcome); and (4) only one study (Mukoyama 2009) was included in the Lin 2014 'SDA versus vasopressin alone' comparison. In contrast, (and possibly due to the difference in inclusion criteria and allocation of studies to specific comparisons) we found a small increase in STHA in favour of vasopressin compared to SDA in the pooled estimate (RR 1.27, $95 \% \mathrm{Cl} 1.04$ to $1.54 ; 3$ studies; 1953 participants; $12=27 \%$; Analysis 3.3). Lin 2014 concluded that there was "no clear advantage of SDA over placebo, HDA, adrenaline and vasopressin combination, or vasopressin alone, in STHD or neurological outcome in adults after OHCA."

Zhang 2017 is the most recently published review prior to our own. It was conducted to evaluate the efficacy of vasopressin and adrenaline combined, compared to adrenaline alone in people who suffered an OHCA, with a search current to Februrary 2017. They included nine studies in the review, five of which we also include in our review (Callaway 2006; Ducros 2011; Gueugniaud 2008; Ong 2012; Wenzel 2004), plus four Chinese studies that we did not identify in our searches (He 2010; Hu 2008; Xiao 2007; Yang 2012). We contacted the senior author of the Zhang 2017 review to clarify the citations for the four Chinese studies, who confirmed that reference 19 in this paper is incorrect, and should be He 2010. ROSC was the only outcome reported in Zhang 2017, with a pooled analysis that showed that vasopressin-epinephrine was associated with a higher rate of ROSC (OR 1.67, 95\% Cl 1.13 to 2.49; 9 studies; 5047 participants). In contrast, in our review we did not find that the ROSC rate was increased in either of the analyses that involved vasopressin (see Analysis 3.5; Analysis 4.4). However, unlike Zhang 2017, we distinguished between studies that compared vasopressin 
versus adrenaline (see Analysis 3.5) and those that compared vasopressin plus adrenaline versus adrenaline (see Analysis 4.4). It is therefore not surprising that there was very high heterogeneity $\left(I^{2}=83 \%\right)$ in the pooled estimate in the Zhang 2017 meta-analysis for ROSC.

As described in the Results (Outcomes) section above, we chose to use the amended denominator where loss to follow up for different outcomes (e.g. neurological status) was described (e.g. Perkins 2018; Wenzel 2004). There is therefore some discrepancy in the denominators used in analyses described in other systematic reviews. For example, similar to our review, the Mentzelopoulos 2012 review used 'adjusted' denominators, but this was not done in the Lin 2014 review.

\section{AUTHORS' CONCLUSIONS}

\section{Implications for practice}

Our review adds to the body of knowledge about the effect of vasopressors on survival and neurological outcomes from cardiac arrest. We included both adults and children, and we compared patient outcomes of in- and out-of-hospital cardiac arrests. However, most studies enrolled adult participants with out-ofhospital cardiac arrest, and this therefore limits the generalisability of our findings to in-hospital cardiac arrest and to paediatric cardiac arrest.

Compared to placebo, moderate-quality evidence showed that standard-dose adrenaline improved the return of spontaneous circulation, admission to hospital and survival to hospital discharge in people with out-of-hospital cardiac arrest. The effect on survival with a favourable neurological outcome at discharge is uncertain, as the evidence includes the possibility of benefit or harm.

The evidence for high-dose adrenaline compared to standarddose adrenaline was of very low quality, so we are uncertain of the effect on the return of spontaneous circulation, admission to hospital, survival to hospital discharge or survival with favourable neurological outcome.

Low-quality evidence showed that vasopressin compared to standard-dose adrenaline improved only survival to hospital admission, with uncertainty about the effect on other outcomes, due to very low-quality of evidence.

Vasopressin and adrenaline compared to standard-dose adrenaline alone (very low- and low-quality evidence) showed no significant effects for any of the prespecified outcomes.

Recommendations for the use of adrenaline should be informed by the findings of this review, taking into account the characteristics of the healthcare system (EMS and hospital facilities) and the values, preferences and priorities of the communities they serve.

\section{Implications for research}

- We defined only limited subgroup analyses in our protocol, as we anticipated (and experienced) difficulty in extracting relevant subgroup data from the index studies. Future studies should seek to report sufficiently granular information on subgroups of participants, to enable a better understanding of treatment effects in different groups of participants.

- There is a paucity of research relating to in-hospital cardiac arrest, and to in- and out-of-hospital cardiac arrest in children.

- Further research is required to better understand patients' prioritisation of outcomes following cardiac arrest, particularly their preferences about 'trade-offs' between survival and neurological outcome

- Further research is required to identify interventions that can sustain the large increase in return of spontaneous circulation and survival to hospital admission through to survival to hospital discharge with favourable neurological outcomes.

- Further research on time to drug administration is required, since this may influence outcomes.

- The cost effectiveness of vasopressors as a treatment for cardiac arrest needs to be considered, especially in relation to the survivor's long-term quality of life.

- Investigation is needed about dosing and mode of administration of adrenaline, e.g. the use of lower doses of adrenaline or as a continuous effusion, targeting physiological measurements of organ perfusion.

- The implications of vasopressor use for cardiac arrest on the rates of organ donation need to be considered.

\section{ACK N O WLEDGEMENTS}

Ian Jacobs was the lead author on this review until his untimely death in 2014

Thanks to Dr Tiew-Hwa Teng at the University of Western Australia for translating the two papers written in Chinese (Li 1999; Zhu 2000), and to Dr Hideo Tohira (now) at Curtin University Western Australia for translating the Japanese paper (Nishizawa 1993).

The review authors are grateful for the unwavering support and guidance provided by the Cochrane Heart Editorial team. In particular we would like to acknowledge and thank Nicole Martin (Managing Editor), Andrea Takeda (Systematic Review Specialist) and Charlene Bridges (Information Specialist) and the anonymous peer reviewers. 


\section{R E F E R E N C E S}

\section{References to studies included in this review}

Brown 1992 \{published data only\}

Brown CG, Martin DR, Pepe PE, Stueven H, Cummins RO, Gonzalez E, et al. A comparison of standard-dose and high-dose epinephrine in cardiac arrest outside the hospital. New England Journal of Medicine 1992;327(15):1051-5.

\section{Callaham 1992 \{published data only\}}

Callaham M, Madsen CD, Barton CW, Saunders CE, Pointer J. A randomized clinical trial of high-dose epinephrine and norepinephrine vs standard-dose epinephrine in prehospital cardiac arrest. JAMA 1992;268(19):2667-72.

\section{Callaway 2006 \{published data only\}}

Callaway CW, Hostler D, Doshi AA, Pinchalk M, Roth RN, Lubin J, et al. Usefulness of vasopressin administered with epinephrine during out-of-hospital cardiac arrest. American Journal of Cardiology 2006;98(10):1316-21.

\section{Choux 1995 \{published data only\}}

Choux C, Gueugniaud PY, Barbieux A, Pham E, Lae C, Dubien PY, et al. Standard doses versus repeated high doses of epinephrine in cardiac arrest outside the hospital. Resuscitation 1995;29(1):3-9.

\section{Ducros 2011 \{published data only\}}

Ducros L, Vicaut E, Soleil C, Le Guen M, Gueye P, Poussant T, et al. Effect of the addition of vasopressin or vasopressin plus nitroglycerin to epinephrine on arterial blood pressure during cardiopulmonary resuscitation in humans. Journal of Emergency Medicine 2011;41(5):453-9.

\section{Gueugniaud 1998 \{published data only\}}

Gueugniaud PY, Mols P, Goldstein P, Pham E, Dubien PY, Deweerdt C, et al. A comparison of repeated high doses and repeated standard doses of epinephrine for cardiac arrest outside the hospital. New England Journal of Medicine 1998; Vol. 339, issue 22:1595-601.

\section{Gueugniaud 2008 \{published data only\}}

Gueugniaud PY, David JS, Chanzy E, Hubert H, Dubien PY, Mauriaucourt $P$, et al. Vasopressin and epinephrine vs. epinephrine alone in cardiopulmonary resuscitation. New England Journal of Medicine 2008;359(1):21-30.

\section{Jacobs 2011 \{published data only\}}

Jacobs IG, Finn JC, Jelinek GA, Oxer HF, Thompson PL. Effect of adrenaline on survival in out-of-hospital cardiac arrest: A randomised double-blind placebo-controlled trial. Resuscitation 2011;82(9):1138-43.

\section{Li 1999 \{published data only\}}

Li PJ, Chen TT, Zhang JM. Clinical study on administration of vasopressin during closed-chest cardiopulmonary resuscitation. Chinese Critical Care Medicine 1999;11(1):28-31.
Lindner 1991a \{published data only\}

Lindner KH, Ahnefeld FW, Prengel AW. Comparison of standard and high-dose adrenaline in the resuscitation of asystole and electromechanical dissociation. Acta Anaesthesiologica Scandinavica 1991;35(3):253-6.

\section{Lindner 1997 \{published data only\}}

Lindner KH, Dirks B, Strohmenger HU, Prengel AW, Lindner IM, Lurie KG. Randomised comparison of epinephrine and vasopressin in patients with out-of-hospital ventricular fibrillation. Lancet 1997;349(9051):535-7.

\section{Lipman 1993 \{published data only\}}

Lipman J, Wilson W, Kobilski S, Scribante J, Lee C, Kraus P, et al. High-dose adrenaline in adult in-hospital asystolic cardiopulmonary resuscitation: a double-blind randomised trial. Anaesthesia and Intensive Care 1993;21(2):192-6.

\section{Mukoyama 2009 \{published data only\}}

Mukoyama T, Kinoshita K, Nagao K, Tanjoh K. Reduced effectiveness of vasopressin in repeated doses for patients undergoing prolonged cardiopulmonary resuscitation. Resuscitation 2009;80(7):755-61.

\section{Ong 2012 \{published data only\}}

Ong ME, Tiah L, Leong BS, Tan EC, Ong VY, Tan EA, et al. A randomised, double-blind multi-centre trial comparing vasopressin and adrenaline in patients with cardiac arrest at the emergency department. Proceedings of Singapore Healthcare 2010; Vol. 19:S96. [protect-au.mimecast.com/s/ Ld1wBRhnmzrC6W?domain=dx.doi.org]

Ong ME, Tiah L, Leong BS, Tan EC, Ong VY, Tan EA, et al. A randomised, double-blind multi-centre trial comparing vasopressin and adrenaline in patients with cardiac arrest at the emergency department (preadmission intravenous vasopressin, adrenaline outcome trial-PIVOT). Proceedings of Singapore Healthcare 2011; Vol. 20, issue 1 (Supplement):50. [protectau.mimecast.com/s/YZ5qBxUgLpkCxz?domain=dx.doi.org]

* Ong ME, Tiah L, Leong BS, Tan EC, Ong VY, Tan EA, et al. A randomised, double-blind, multi-centre trial comparing vasopressin and adrenaline in patients with cardiac arrest presenting to or in the emergency department. Resuscitation 2012;83:953-60.

Ong ME, Tiah L, Leong BS, Tan EC, Ong VY, Tan EA, et al. A randomized, double-blind multicenter trial comparing vasopressin and adrenaline in patients with cardiac arrest at the emergency department (preadmission intravenous vasopressin, adrenaline outcome trial [PIVOT]). Circulation 2011;124(Suppl 21):A176.

\section{Patterson 2005 \{published data only\}}

Patterson MD, Boenning DA, Klein BL, Fuchs S, Smith KM, Hegenbarth MA, et al. The use of high-dose epinephrine for patients with out-of-hospital cardiopulmonary arrest refractory to prehospital interventions. Pediatric Emergency care 2005;21:227-37. 
Perkins 2018 \{published data only\}

Perkins G, Quinn T, Deakin CD, Nolan JP, Lall R, Slowther A, et al. Pre-hospital Assessment of the Role of Adrenaline: Measuring the Effectiveness of Drug administration In Cardiac arrest (PARAMEDIC-2): trial protocol. Resuscitation 2016;108:75-81.

* Perkins GD, Ji C, Deakin CD, Quinn T, Nolan JP, Scomparin C, et al. A randomized trial of epinephrine in out-ofhospital cardiac arrest. New England Journal of Medicine 2018;379(8):711-21.

Perondi 2004 \{published data only\}

* Perondi MB, Reis AG, Paiva EF, Nadkarni VM, Berg RA. A comparison of high-dose and standard-dose epinephrine in children with cardiac arrest. New England Journal of Medicine 2004;350(17):1722-30.

Quintana EC. A comparison of high-dose and standarddose epinephrine in children with cardiac arrest. Annals of Emergency Medicine 2005; Vol. 45, issue 2:228-9. [0196-0644]

\section{Polglase 1994 \{published data only\}}

Polglase RF, Parish DC, Camp B. Prehospital administration of high-dose epinephrine. American Journal of Emergency Medicine 1994;12(6):688-9.

\section{Sanchez-Mendiola 1998 \{published data only\}}

Sanchez-Mendiola M, Vela-Trejo F, Herrera-Maldonado N, Hernandez-Valle A. High-dose epinephrine does not improve survival in hospitalized pediatric critically ill patients with cardiac arrest. Critical Care Medicine 1998;26(Suppl):57A.

\section{Schmidbauer 2000 \{published data only\}}

Schmidbauer S, Kneifel HA, Hallfeldt KK. Endobronchial application of high dose epinephrine in out of hospital cardiopulmonary resuscitation. Resuscitation 2000;47(1):89.

\section{Sherman 1997 \{published data only\}}

Sherman BW, Munger MA, Foulke GE, Rutherford WF, Panacek EA. High-dose versus standard-dose epinephrine treatment of cardiac arrest after failure of standard therapy. Pharmacotherapy 1997;17(2):242-7.

\section{Stiell 1992 \{published data only\}}

Stiell IG, Hebert PC, Weitzman BN, Wells GA, Raman S, Stark RM, et al. High-dose epinephrine in adult cardiac arrest. New England Journal of Medicine 1992;327(15):1045-50.

\section{Stiell 2001 \{published data only\}}

Stiell IG, Hebert PC, Wells GA, Vandemheen KL, Tang AS, Higginson LA, et al. Vasopressin versus epinephrine for inhospital cardiac arrest: a randomised controlled trial. Lancet 2001;358(9276):105-9.

\section{Wenzel 2004 \{published data only\}}

Di SG, Nine C, Catalano HN, Wenzel V, Krismer AC, Arntz HR, et al. A comparison of vasopressin and epinephrine for outof-hospital cardiopulmonary resuscitation. Prensa Medica Argentina 2005; Vol. 92, issue 10:641-3. [0032-745X]

* Wenzel V, Krismer AC, Arntz HR, Sitter H, Stadlbauer KH, Lindner $\mathrm{KH}$, et al. A comparison of vasopressin and epinephrine for out-of-hospital cardiopulmonary resuscitation. New England Journal of Medicine 2004;350(2):105-13.

Woodhouse 1995 \{published data only\}

Woodhouse SP, Cox S, Boyd P, Case C, Weber M. High dose and standard dose adrenaline do not alter survival, compared with placebo, in cardiac arrest. Resuscitation 1995;30(3):243-9.

\section{Zhu 2000 \{published data only\}}

Zhu HD, Zhou YS, Yu XZ, Shao X. Study of the optimal dosage of epinephrine during cardiopulmonary resuscitation. Chinese Journal of Coal Industry Medicine 2000;1:54-5.

\section{References to studies excluded from this review}

Aggarwal 1993 \{published data only\}

Aggarwal P, Gupta A. Standard-dose and high-dose epinephrine in cardiac arrest. National Medical Journal of India 1993;6(2):77-8

Berthier 1987 \{published data only\}

Berthier JC. Adrenaline: a new beginning. Pediatrie 1987;42:7-12

\section{Betleri 1966 \{published data only\}}

Betleri I, Kerenyi K, Lovasz L, Meszaros L. Successful resuscitation after postoperative cardiac arrest [Erfolgreiche Wiederbelebung nach postoperativem Herzstillstand]. Zentralblatt fur Chirurgie 1966;91(51):1931-3.

Callaham 1989 \{published data only\}

Callaham M. Epinephrine doses in cardiac arrest: is it time to outgrow the orthodoxy of ACLS?. Annals of Emergency Medicine 1989;18(9):1011-2.

Callaham 1991a \{published data only\}

Callaham M, Barton CW, Kayser S. Potential complications of high-dose epinephrine therapy in patients resuscitated from cardiac arrest. JAMA 1991;265(9):1117-22.

Callaham 1991b \{published data only\} Callaham M. High-dose epinephrine in cardiac arrest. Western Journal of Medicine 1991;155(3):289-90.

Carroll 2012 \{published data only\}

Carroll TG, Dimas VV, Raymond TT. Vasopressin rescue for inpediatric intensive care unit cardiopulmonary arrest refractory to initial epinephrine dosing: a prospective feasibility pilot trial. Pediatric Critical Care Medicine 2012;13(3):265-72.

Carvolth 1996 \{published data only\}

Carvolth RD, Hamilton AJ. Comparison of high-dose epinephrine versus standard-dose epinephrine in adult cardiac arrest in the prehospital setting. Prehospital and Disaster Medicine 1996; Vol. 11, issue 3:219-22.

Cohen 1975 \{published data only\}

Cohen MR, Turco SJ. Parenteral drugs used in cardiopulmonary resuscitation. Bulletin of the Parenteral Drug Association 1975;29(1):39-45. 
David 2007 \{published data only\}

David JS, Gueugniaud P, Riou B, Pham E, Dubien P, Goldstein P, et al. Does the prognosis of cardiac arrest differ in trauma patients?. Critical Care Medicine 2007;35(10):2251-5.

\section{Dieckmann 1995 \{published data only\}}

Dieckmann RA, Vardis R. High-dose epinephrine in pediatric out-of-hospital cardiopulmonary arrest. Pediatrics 1995; Vol. 95, issue 6:901-13.

\section{Di Stilio 2005 \{published data only\}}

Di Stilio G, Nine C, Catalano HN, Wenzel V, Krismer AC, Arntz HR, et al. A comparison of vasopressin and epinephrine for out-of-hospital cardiopulmonary resuscitation. [Analisis critico de un articulo: Vasopresina en la resucitacion... "no recomendar" el uso de vasopresina]. Prensa Medica Argentina 2005;92(10):641-3.

\section{Ghafourian 2015 \{published data only\}}

Ghafourian N, Maniae NH, Taherikalani M, Mehrazi M, Hossieni M, Valian F, et al. Combination of vasopressin epinephrine as a novel candidate in patients with cardiac arrest. Recent Advances in Cardiovascular Drug Discovery 2015;10(1):65-9.

\section{Grmec 2006 \{published data only\}}

Grmec S, Mally S. Vasopressin improves outcome in outof-hospital cardiopulmonary resuscitation of ventricular fibrillation and pulseless ventricular tachycardia: an observational cohort study. Critical Care 2006;10:R13.

\section{Hagihara 2012 \{published data only\}}

Hagihara A, Hasegawa M, Abe T, Nagata T, Wakata Y, Miyazaki S. Prehospital epinephrine use and survival among patients with out-of-hospital cardiac arrest. JAMA 2012;307(11):1161-8.

\section{Herlitz 1995 \{published data only\}}

Herlitz J, Ekstrom L, Wennerblom B, Axelsson A, Bang A, Holmberg S. Adrenaline in out-of-hospital ventricular fibrillation. Does it make any difference?. Resuscitation 1995;29(3):195-201.

Lee 2000 \{published data only (unpublished sought but not used)\} Lee CC, Jung YS, Yoon SK, Kim GW, Min YG, Crupi RS, et al. Vasopressin administration in out-of-hospital cardiac arrest (abstract ACEP Research Forum Philadelphia). Annals of Emergency Medicine 2000;36:S91.

\section{Lee 2001 \{published data only\}}

Lee CC, Kim GW, Kim SH, Crupi RS. Cases of aminophylline and vasopressin use after failed prehospital resuscitation of cardiac arrest. Prehospital Emergency Care 2001;5(3):304-7.

\section{Lindner 1991b \{published data only\}}

Lindner KH, Ahnefeld FW, Grunert A. Epinephrine versus norepinephrine in prehospital ventricular fibrillation. American Journal of Cardiology 1991, issue 5:427-8.

\section{McCrirrick 1992 \{published data only\}}

McCrirrick A, Kestin I. Haemodynamic effects of tracheal compared with intravenous adrenaline. Lancet 1992; Vol. 340, issue $8824: 868-70$

\section{McCrirrick 1994 \{published data only\}}

McCrirrick A, Monk CR. Comparison of i.v. and intra-tracheal administration of adrenaline. British Journal of Anaesthesia 1994; Vol. 72, issue 5:529-32.

\section{McIntyre 2004 \{published data only\}}

McIntyre KM. Vasopressin in asystolic cardiac arrest. New England Journal of Medicine 2004; Vol. 350, issue 2:179-81. [0028-4793]

\section{Mentzelopoulos 2007 \{published data only\}}

Mentzelopoulos S, Katsios N, Papastylianou A, Gisioti S, Stathopoulos A, Stamataki E, et al. Vasopressin, epinephrine, and methylprednisolone in inhospital cardiac arrest. Critical Care. London, 2007; Vol. 11, issue Suppl 2:324.

\section{Mentzelopoulos 2009 \{published data only\}}

Mentzelopoulos SD, Zakynthinos SG, Tzoufi M, Katsios N, Papastylianou A, Gkisioti S, et al. Vasopressin, epinephrine, and corticosteroids for in-hospital cardiac arrest. Archives of Internal Medicine 2009;169(1):15-24.

\section{Meyer 2011 \{published data only\}}

Meyer S, McGuire W, Gottschling S, Mohammed Shamdeen G, Gortner $\mathrm{L}$. The role of vasopressin and terlipressin in catecholamine-resistant shock and cardio-circulatory arrest in children: review of the literature. Wiener Medizinische Wochenschrift 2011;161:192-203.

\section{Morris 1997 \{published data only\}}

Morris DC, Dereczyk BE, Grzybowski M, Martin GB, Rivers EP, Wortsman J, et al. Vasopressin can increase coronary perfusion pressure during human cardiopulmonary resuscitation. Academic Emergency Medicine 1997; Vol. 4, issue 9:878-83.

\section{Niemann 2000 \{published data only\}}

Niemann JT, Stratton SJ. Endotracheal versus intravenous epinephrine and atropine in out-of-hospital "primary" and postcountershock asystole. Critical Care Medicine 2000; Vol. 28, issue 6:1815-9.

\section{Nishizawa 1993 \{published data only\}}

Nishizawa H, Miyazaki H, Ogawa K, Takita S, Hashimoto K, Sugiyama $\mathrm{M}$, et ak. Comparison of standard-dose epinephrine and high-dose epinephrine in cardiopulmonary arrest outside the hospital. Kokyu to Junkan - Respiration \& Circulation 1993;41(11):1083-7.

\section{Ohshige 2005 \{published data only\}}

Ohshige K, Shimazaki S, Hirasawa H, Nakamura M, Kin H, Fujii C, et al. Evaluation of out-of-hospital cardiopulmonary resuscitation with resuscitative drugs: A prospective comparative study in Japan. Resuscitation 2005, issue 1:53-61. 


\section{Olasveengen 2009 \{published data only\}}

Olasveengen TM, Sunde K, Brunborg C, Thowsen J, Steen PA, Wik L. Intravenous drug administration during out-of-hospital cardiac arrest: a randomized trial. JAMA 2010;302:2222-9.

\section{Olasveengen 2010 \{published data only\}}

Olasveengen TM, Wik L, Sunde K, Steen PA. Patient outcome when adrenaline is actually given vs. not given in a randomised study. Resuscitation 2010;81(2):S19.

\section{Olson 1989 \{published data only\}}

Olson DW, Thakur R, Stueven HA, Thompson B, Gruchow H, Hendley GE, et al. Randomized study of epinephrine versus methoxamine in prehospital ventricular fibrillation. Annals of Emergency Medicine 1989; Vol. 18, issue 3:250-3.

\section{Papastylianou 2010 \{published data only\}}

Papastylianou A, Malachias S, Zakynthinos S, Zakynthinos E, Makris D, Sourlas S, et al. Predictors of neurological recovery in refractory in hospital cardiac arrest. Intensive Care Medicine 2010;36:S122.

\section{Paradis 1991 \{published data only\}}

Paradis NA, Martin GB, Rosenberg J, Rivers EP, Goetting MG, Appleton TJ, et al. The effect of standard- and high-dose epinephrine on coronary perfusion pressure during prolonged cardiopulmonary resuscitation. JAMA 1991; Vol. 265, issue 9:1139-44.

\section{Patrick 1995 \{published data only\}}

Patrick WD, Freedman J, McEwen T, Light RB, Ludwig L, Roberts D. A randomized, double-blind comparison of methoxamine and epinephrine in human cardiopulmonary arrest. American Journal of Respiratory and Critical Care Medicine 1995; Vol. 152, issue 2:519-23.

\section{Pellegrino 2006 \{published data only\}}

Pellegrino AM. Does vasopressin improve survival?. Emergency Medical Services 2006;35(3):86-92.

\section{Quadrel 1995 \{published data only\}}

Quadrel M, Lavery RF, Jaker M, Atkin S, Tortella BJ, Cody RP. Prospective, randomized trial of epinephrine, metaproterenol, and both in the prehospital treatment of asthma in the adult patient. Annals of Emergency Medicine 1995; Vol. 26, issue 4:469-73.

\section{Quintana 2005 \{published data only\}}

Quintana EC. A comparison of high-dose and standard-dose epinephrine in children with cardiac arrest. Annals of Emergency Medicine 2005;45(2):228-9.

\section{Quinton 1987 \{published data only\}}

Quinton DN, O'Byrne G, Aitkenhead AR. Comparison of endotracheal and peripheral intravenous adrenaline in cardiac arrest. Is the endotracheal route reliable?. Lancet 1987; Vol. 1, issue 8537:828-9.
Salam 2005 \{published data only\}

Salam A. The therapeutic potential of vasopressin in cardiopulmonary resuscitation. Expert Opinion on Pharmacotherapy 2005;6(3):517-20.

\section{Silfvast 1985 \{published data only\}}

Silfvast T, Saarnivaara L, Kinnunen A, Erosuo J, Nick L, Pesonen P, et al. Comparison of adrenaline and phenylephrine in out-of-hospital cardiopulmonary resuscitation. A doubleblind study. Acta Anaesthesiologica Scandinavica 1985; Vol. 29, issue 6:610-3.

\section{Song 1997 \{published data only\}}

Song DF. Comparison between epinephrine and methoxamine for emergency treatment of the patients with sudden heart arrest. Chinese Journal of Anesthesiology 1997; Vol. 17, issue 2:108.

\section{Turner 1988 \{published data only\}}

Turner LM, Parsons M, Luetkemeyer RC, Ruthman JC, Anderson RJ, Aldag JC. A comparison of epinephrine and methoxamine for resuscitation from electromechanical dissociation in human beings. Annals of Emergency Medicine 1988; Vol. 17, issue 5:443-9.

\section{Weaver 1990 \{published data only\}}

Weaver WD, Fahrenbruch CE, Johnson DD, Hallstrom AP, Cobb LA, Copass MK. Effect of epinephrine and lidocaine therapy on outcome after cardiac arrest due to ventricular fibrillation. Circulation 1990; Vol. 82, issue 6:2027-34.

\section{Woodhouse 1992 \{published data only\}}

Woodhouse SP, Lewis-Driver D, Eller H. Catecholamines during cardiopulmonary resuscitation for cardiac arrest. Resuscitation 1992; Vol. 24, issue 3:263-72.

\section{Worster 2005 \{published data only\}}

Worster A, Upadhye S, Fernandes CM. Vasopressin versus epinephrine for out-of-hospital cardiopulmonary resuscitation. Canadian Journal of Emergency Medicine 2005;7(1):48-50. [1481-8035]

\section{Youngquist 2012 \{published data only\}}

Youngquist ST, Niemann JT. Regarding "Effect of adrenaline on survival in out-of-hospital cardiac arrest: A randomised doubleblind placebo-controlled trial". Resuscitation 2012;83(4):e105.

\section{Zwingmann 2012 \{published data only\}}

Zwingmann J, Mehlhorn AT, Hammer T, Bayer J, Sudkamp NP, Strohm PC. Survival and neurologic outcome after traumatic out-of-hospital cardiopulmonary arrest in a pediatric and adult population: a systematic review. Critical Care 2012;16(4):R117.

\section{References to ongoing studies}

Andersen 2018 \{unpublished data only\}

Andersen LW. Vasopressin and methylprednisolone for inhospital cardiac arrest (VAM-IHCA). clinicaltrials.gov/ct2/show/ NCT03640949 (first received 21 August 2018). 
Raymond 2008 \{unpublished data only\}

Raymond TT. A prospective, randomised, controlled trial of combination vasopressin and epinephrine to epinephrine only for in-intensive care unit paediatric cardiopulmonary resuscitation. clinicaltrials.gov/ct2/show/NCT00628550 (first received 5 March 2008)

\section{Additional references}

\section{Aung 2005}

Aung K, Htay T. Vasopressin for cardiac arrest: a systematic review and meta-analysis. Archives of Internal Medicine 2005;165(1):17-24.

\section{Beck 2018}

Beck B, Bray J, Cameron P, Smith K, Walker T, Grantham H, et al. Regional variation in the characteristics, incidence and outcomes of out-of-hospital cardiac arrest in Australia and New Zealand: results from the Aus-ROC Epistry. Resuscitation 2018;126:49-57.

\section{Belletti 2018}

Belletti A, Benedetto U, Putzu A, Martino EA, Biondi-Zoccai G, Angelini GD, et al. Vasopressors during cardiopulmonary resuscitation. A network meta-analysis of randomized trials. Critical Care Medicine 2018;46(5):e443-51.

\section{Berdowski 2010}

Berdowski J, Berg RA, Tijssen JG, Koster RW. Global incidences of out-of-hospital cardiac arrest and survival rates: Systematic review of 67 prospective studies. Resuscitation 2010;81(11):1479-87.

\section{Burnett 2012}

Burnett AM, Segal N, Salzman JG, McKnite MS, Frascone RJ. Potential negative effects of epinephrine on carotid blood flow and ETCO2 during active compression-decompression CPR utilizing an impedance threshold device. Resuscitation 2012;83(8):1021-4. [PUBMED: 22445865]

\section{Corrada 2013}

Corrada E, Mennuni MG, Grieco N, Sesana G, Beretta G, Presbitero P. Neurological recovery after out-of-hospital cardiac arrest: hospital admission predictors and one-year survival in an urban cardiac network experience. Minerva Cardioangiologica 2013;61(4):451-60. [PUBMED: 23846011]

\section{Daya 2015}

Daya MR, Schmicker RH, Zive DM, Rea TD, Nichol G, Buick JE, et al. Out-of-hospital cardiac arrest survival improving over time: results from the Resuscitation Outcomes Consortium (ROC). Resuscitation 2015; Vol. 91:108-15.

\section{Girotra 2014}

Girotra S, Cram P, Spertus JA, Nallamothu BK, Li Y, Jones PG, et al. Hospital variation in survival trends for in-hospital cardiac arrest. Journal of the American Heart Association 2014; Vol. 3, issue 3:e000871.

\section{Grasner 2016}

Gräsner JT, Lefering R, Koster RW, Masterson S, Böttiger BW, Herlitz J, et al. EuReCa ONE-27 Nations, ONE Europe, ONE Registry: a prospective one month analysis of out-of-hospital cardiac arrest outcomes in 27 countries in Europe. Resuscitation 2016; Vol. 105:188-95.

\section{Hasselqvist-Ax 2015}

Hasselqvist-Ax I, Riva G, Herlitz J, Rosenqvist M, Hollenberg J, Nordberg P, et al. Early cardiopulmonary resuscitation in out-ofhospital cardiac arrest. New England Journal of Medicine 2015; Vol. 372, issue 24:2307-15.

\section{Haywood 2018}

Haywood K, Whitehead L, Nadkarni VM, Achana F, Beesems S, Böttiger BW, et al. COSCA (Core Outcome Set for Cardiac Arrest) in adults: an advisory statement from the International Liaison Committee on Resuscitation. Resuscitation 2018;127:147-63.

\section{He 2010}

He C, Liao Y, Liu F, Xu D. Clinical experience from 102 cases of patients suffering from out of hospital cardiac arrest. China Modern Drugs 2010;48(7):151-2.

\section{Higgins 2017}

Higgins JP, Altman DG, Sterne JAC, editor(s). Chapter 8: Assessing risk of bias in included studies. In: Higgins JP, Churchill R, Chandler J, Cumpston MS, editor(s). Cochrane Handbook for Systematic Reviews of Interventions Version 5.2.0 (updated June 2017). Cochrane, 2017. Available from www.training.cochrane.org/handbook.

\section{Hu 2008}

$\mathrm{Hu}$ JH, Ma C. Combination of vasopressin. The Pre-hospital Emergency Cardiopulmonary Resuscitation (CPR). Chinese Community Physicians 2008.

\section{Jennett 1975}

Jennett B, Bond M. Assessment of outcome after severe brain damage. Lancet 1975;1(7905):480-4.

\section{Kim 2016}

Kim YJ, Ahn S, Sohn CH, Seo DW, Lee YS, Lee JH, et al. Long-term neurological outcomes in patients after out-of-hospital cardiac arrest. Resuscitation 2016;101:1-5. [PUBMED: 26826564]

\section{Kleinman 2018}

Kleinman ME, Perkins GD, Bhanji F, Billi JE, Bray JE, Callaway CW, et al. ILCOR scientific knowledge gaps and clinical research priorities for cardiopulmonary resuscitation and emergency cardiovascular care: a consensus statement. Resuscitation 2018;127:132-46.

\section{Larabee 2012}

Larabee TM, Liu KY, Campbell JA, Little CM. Vasopressors in cardiac arrest: a systematic review. Resuscitation 2012;83(8):932-9.

\section{Laver 2004}

Laver S, Farrow C, Turner D, Nolan J. Mode of death after admission to an intensive care unit following cardiac arrest. 
Intensive Care Medicine 2004;30(11):2126-8. [PUBMED: 15365608]

\section{Layek 2014}

Layek A, Maitra S, Pal S, Bhattacharjee S, Baidya DK. Efficacy of vasopressin during cardio-pulmonary resuscitation in adult patients: a meta-analysis. Resuscitation 2014; Vol. 85:853-63.

\section{Lefebvre 2011}

Lefebvre C, Manheimer E, Glanville J. Chapter 6: Searching for studies. In: Higgins JP, Green S, editor(s). Cochrane Handbook for Systematic Reviews of Interventions Version 5.1.0 (updated March 2011). The Cochrane Collaboration, 2011. Available from handbook.cochrane.org.

\section{Lin 2014}

Lin S, Callaway CW, Shah PS, Wagner J D, Beyene J, Ziegler CP, et al. Adrenaline for out-of-hospital cardiac arrest resuscitation: A systematic review and meta-analysis of randomized controlled trials. Resuscitation 2014;85(6):732-40.

\section{Lindner 1995}

Lindner KH, Prengel AW, Pfenninger EG, Lindner IM, Strohmenger HU, Georgieff M, et al. Vasopressin improves vital organ blood flow during closed-chest cardiopulmonary resuscitation in pigs. Circulation 1995;91(1):215-21.

\section{Link 2015}

Link MS, Berkow LC, Kudenchuk PJ, Halperin HR, Hess EP, Moitra VK, et al. Part 7: adult advanced cardiovascular life support: 2015 American Heart Association guidelines update for cardiopulmonary resuscitation and emergency cardiovascular care. Circulation 2015; Vol. 132:s444-64.

\section{Loomba 2015}

Loomba RS, Nijhawan K, Aggarwal S, Arora RR. Increased return of spontaneous circulation at the expense of neurologic outcomes: Is prehospital epinephrine for out-of-hospital cardiac arrest really worth it?. Journal of Critical Care 2015; Vol. 30, issue 6:1376-81.

\section{Lundin 2016}

Lundin A, Djärv T, Engdahl J, Hollenberg J, Nordberg P, RavnFischer A, et al. Drug therapy in cardiac arrest: a review of the literature. European Heart Journal: Cardiovascular Pharmacotherapy 2016; Vol. 2, issue 1:54-75.

\section{Mentzelopoulos 2012}

Mentzelopoulos SD, Zakynthinos SG, Siempos I, Malachias S, Ulmer H, Wenzel V. Vasopressin for cardiac arrest: Meta-analysis of randomized controlled trials. Resuscitation 2012;83(1):32-9.

\section{Myerburg 2013}

Myerburg RJ Halperin H, Egan DA, Boineau R, Chugh SS, Gillis AM, Goldhaber JI, Lathrop DA, Liu P, Niemann JT, Ornato JP, Sopko G, Van Eyk JE, Walcott GP, Weisfeldt ML, Wright JD, Zipes DP. Pulseless Electric Activity.. Circulation 2013;128(23):2532-41..

\section{Nakahara 2013}

Nakahara S, Tomio J, Takahashi H, Ichikawa M, Nishida M, Morimura N, et al. Evaluation of pre-hospital administration of adrenaline (epinephrine) by emergency medical services for patients with out of hospital cardiac arrest in Japan: controlled propensity matched retrospective cohort study. BMJ 2013; Vol. 347:f6829.

\section{Nolan 2002}

Nolan JP, De Latorre FJ, Steen PA, Chamberlain DA, Bossaert LL. Advanced life support drugs: do they really work?. Current Opinion in Critical Care 2002; Vol. 8, issue 3:212-8.

\section{Nolan 2013}

Nolan JP, Perkins GD. Is there a role for adrenaline during cardiopulmonary resuscitation?. Current Opinion in Critical Care 2013;19(3):169-74. [PUBMED: 23628783]

\section{Nolan 2014}

Nolan JP, Soar J, Smith GB, Gwinnutt C, Parrott F, Power S, et al. Incidence and outcome of in-hospital cardiac arrest in the United Kingdom National Cardiac Arrest Audit. Resuscitation 2014; Vol. 85, issue 8:987-82.

\section{Nolan 2015a}

Nolan JP, Soar J, Cariou A, Cronberg T, Moulaert VR, Deakin CD, et al. European Resuscitation Council and European Society of Intensive Care Medicine guidelines for post-resuscitation care 2015: section 5 of the European Resuscitation Council guidelines for resuscitation 2015. Resuscitation 2015;95:202-22. [PUBMED: 26477702]

\section{Nolan 2015b}

Nolan JP, Hazinski MF, Aickin R, Bhanji F, Billi JE, Callaway CW, et al. Part 1: executive summary: 2015 international consensus on cardiopulmonary resuscitation and emergency cardiovascular care science with treatment recommendations. Resuscitation 2015;95:e1-31. [PUBMED: 26477703]

\section{Paradis 1990}

Paradis NA, Martin GB, Rivers EP, Goetting MG, Appleton TJ, Feingold $\mathrm{M}$, et al. Coronary perfusion pressure and the return of spontaneous circulation in human cardiopulmonary resuscitation. JAMA 1990;263(8):1106-13.

\section{PAROS 2015}

Song KJ, Ko PC, Leong BS, Khunkhlai N, Naroo GY, Sarah A, et al. Outcomes for out-of-hospital cardiac arrests across 7 countries in Asia: the Pan Asian Resuscitation Outcomes Study (PAROS). Resuscitation 2015;96:100-8.

\section{Perkins 2014}

Perkins GD, Cottrell P, Gates S. Is adrenaline safe and effective as a treatment for out of hospital cardiac arrest?. BMJ 2014;348:g2435.

\section{Perkins 2015}

Perkins GD, Jacobs IG, Nadkarni VM, Berg RA, Bhanji F, Biarent $D$, et al. Cardiac arrest and cardiopulmonary resuscitation outcome reports: Update of the Utstein 
resuscitation registry templates for out-of-hospital cardiac arrest. Resuscitation 2015;96:328-40.

\section{Quinn 2009}

Quinn TJ, Dawson J, Walters MR, Lees KR. Exploring the reliability of the modified rankin scale. Stroke 2009;40(3):762-6.

\section{Reis 2002}

Reis AG, Nadkarni V, Perondi MB, Grisi S, Berg RA. A prospective investigation into the epidemiology of in-hospital pediatric cardiopulmonary resuscitation using the international Utstein reporting style. Pediatrics 2002;109(2):200-9.

\section{Ristagno 2009}

Ristagno G, Tang W, Huang L, Fymat A, Chang YT, Sun S, et al. Epinephrine reduces cerebral perfusion during cardiopulmonary resuscitation. Critical Care Medicine 2009;37(4):1408-15.

\section{Sandroni 2007}

Sandroni C, Nolan J, Cavallaro F, Antonelli M. In-hospital cardiac arrest: incidence, prognosis and possible measures to improve survival. Intensive Care Medicine 2007;33(2):237-45.

\section{Sasson 2010}

Sasson C, Rogers MA, Dahl J, Kellermann AL. Predictors of survival from out-of-hospital cardiac arrest: a systematic review and meta-analysis. Circulation. Cardiovascular Quality and Outcomes 2010;3(1):63-81.

\section{Scales 2016}

Scales DC, Golan E, Pinto R, Brooks SC, Chapman M, Dale CM, et al. Improving appropriate neurological prognostication after cardiac arrest: a stepped wedge cluster RCT. American Journal of Respiratory and Critical Care Medicine 2016;194(9):1083-91. [PUBMED: 27115286]

\section{Sillberg 2008}

Sillberg VA, Perry JJ, Stiell IG, Wells GA. Is the combination of vasopressin and epinephrine superior to repeated doses of epinephrine alone in the treatment of cardiac arrest: a systematic review. Resuscitation 2008;79(3):380-6.

\section{Soar 2011}

Soar J, Nolan JP. Adrenaline: proven benefit in cardiac arrest at last?. Resuscitation 2011;82(9):1115-6.

\section{Soar 2015}

Soar J, Callaway CW, Aibiki M, Bottiger BW, Brooks SC Deakin CD, et al. Part 4: advanced life support: 2015 international consensus on cardiopulmonary resuscitation and emergency cardiovascular care science with treatment recommendations. Resuscitation 2015;95:e71-120. [PUBMED: 26477429]

\section{Stiell 2004}

Stiell IG, Wells GA, Field B, Spaite DW, Nesbitt LP, De Maio VJ, et al. Advanced cardiac life support in out-of-hospital cardiac arrest. New England Journal of Medicine 2004; Vol. 351, issue 7:647-56.

\section{Teasdale 1998}

Teasdale GM, Pettigrew LE, Wilson JT, Murray G, Jennett B. Analyzing outcome of treatment of severe head injury: a review and update on advancing the use of the Glasgow Outcome Scale. Journal of Neurotrauma 1998;15(8):587-97.

\section{Teng 1987}

Teng EL, Chui HC. The Modified Mini-Mental State (3MS) examination. Journal of Clinical Psychiatry 1987;48(8):314-8.

\section{Utstein 2015}

Perkins GD, Jacobs IG, Nadkarni VM, Berg RA, Bhanji F, Biarent D, et al. Utstein Collaborators. Cardiac arrest and cardiopulmonary resuscitation outcome reports: update of the Utstein Resuscitation Registry Templates for Out-of-Hospital Cardiac Arrest: a statement for healthcare professionals from a Task Force of the International Liaison Committee on Resuscitation (American Heart Association, European Resuscitation Council, Australian and New Zealand Council on Resuscitation, Heart and Stroke Foundation of Canada, InterAmerican Heart Foundation, Resuscitation Council of Southern Africa, Resuscitation Council of Asia); and the American Heart Association Emergency Cardiovascular Care Committee and the Council on Cardiopulmonary, Critical Care, Perioperative and Resuscitation. Resuscitation 2015;96:328-40. [PUBMED: 25438254]

\section{Wenzel 2000}

Wenzel V, Lindner KH, Krismer AC, Voelckel WG, Schocke MF, Hund W, et al. Survival with full neurologic recovery and no cerebral pathology after prolonged cardiopulmonary resuscitation with vasopressin in pigs. Journal of the American College of Cardiology 2000;35(2):527-33.

\section{Wiedermann 2015}

Wiedermann FJ, Stichlberger M, Lederer W. Is epinephrine during cardiac arrest associated with worse outcomes in resuscitated patients? Effect of vasopressin and catecholamines on the migration of leukocytes. Critical Care 2015; Vol. 19:120. [PUBMED: 25881048]

\section{Wik 2016}

Wik L, Olsen JA, Persse D, Sterz F, Lozano M Jr, Brouwer MA, et al. Why do some studies find that CPR fraction is not a predictor of survival?. Resuscitation 2016;104:59-62.

\section{Wyer 2006}

Wyer PC, Perera P, Jin Z, Zhou Q, Cook DJ, Walter SD, et al. Vasopressin or epinephrine for out-of-hospital cardiac arrest. Annals of Emergency Medicine 2006;48:86-97.

\section{Xiao 2007}

Xiao Z, Huang J, Cai J, Fu D. Clinical research of vasopressin on patients suffering from out of hospital cardiac arrest. Lingnan Journal of Emergency Medicine 2007;12(6):412-3.

\section{Xiao-li 2010}

Xiao-li J, Dong-ping W, Xin I, Hui L, Xiao-xing L, Yan X, et al. Vasopressin and epinephrine versus epinephrine in management of patients with cardiac arrest: a meta-analysis. Signa Vitae 2010;5(1):20-16. 


\section{Xiaoli 2010}

Xiaoli J, Dongping W, Hui L, Yan X, Hong Z, Xin L. Vasopressin and epinephrine versus epinephrine alone in management of patients with out of hospital cardiac arrest: a metaanalysis. Heart 2010;96:A206-A7.

\section{Yang 2012}

Yang F. Clinical observation on 90 cases of patients suffering from out of hospital cardiac arrest. Chinese Foreign Medicine Research 2012;10(11):46-7.

\section{Zhang 2017}

Zhang Q, Liu B, Zhao L, Qi Z, Shao H, An L, et al. Efficacy of vasopressin-epinephrine compared to epinephrine alone for out of hospital cardiac arrest patients: a systematic review and meta-analysis. American Journal of Emergency Medicine 2017;35(10):1555-60.

\section{References to other published versions of this review Jacobs 2003}

Jacobs I, Finn J. Adrenaline and vasopressin for cardiac arrest. Cochrane Database of Systematic Reviews 2003, Issue 2. [DOI: 10.1002/14651858.CD003179]

* Indicates the major publication for the study

\section{CHARACTERISTICS OF STUDIES}

Characteristics of included studies [ordered by study ID]

Brown 1992

$\begin{array}{ll}\text { Methods } & \text { Prospective, multicentre, double-blind RCT } \\ & \text { Multiple EMS USA } \\ & 1 \text { October } 1989 \text { to } 1 \text { December } 1990\end{array}$

Participants Included: OHCA patients > 18 years; in VF after 3 DC shocks or rhythm changed to asystole/PEA, or patients in asystole or PEA after BLS, ETT and IV access, at time when first drug to be administered

Excluded: "Pregnancy, cardiac arrest associated with trauma, hypothermia, drowning, confirmed drug overdose or primary respiratory arrest, e.g. hanging, airway obstruction, patients with clear signs of irreversible cardiac arrest, e.g. rigor mortis, or patients where ETT and IV access could not be gained."

Participants: 1280 (632 standard-dose adrenaline group and 648 high-dose adrenaline group)

\begin{tabular}{|c|c|}
\hline \multirow[t]{3}{*}{ Interventions } & High-dose group: 0.2 mg per kilogram IV (1:1000) \\
\hline & $\begin{array}{l}\text { Standard-dose group: } 0.02 \mathrm{mg} \text { of adrenaline per kilogram of body weight IV }(1: 10,000) \text {, with } 20 \mathrm{ml} \text { nor- } \\
\text { mal saline flush }\end{array}$ \\
\hline & Single dose of study drug only, then "All other care as per American Heart Association guidelines." \\
\hline \multirow[t]{3}{*}{ Outcomes } & $\begin{array}{l}\text { Survival to hospital discharge, survival to hospital admission, neurological outcome, ROSC, successful } \\
\text { resuscitation }\end{array}$ \\
\hline & $\begin{array}{l}\text { Neuro outcomes measured using CPC at hospital discharge: 'conscious at discharge' was CPC1-3; 'un- } \\
\text { conscious at discharge' was CPC } 3 \text { or } 4 \text {. }\end{array}$ \\
\hline & No hospital length of stay reported \\
\hline \multirow[t]{3}{*}{ Notes } & Various USA Emergency Medical Services. Emergency Medical Service: EMT-D and paramedics \\
\hline & $\begin{array}{l}\text { Ethics not stated, not registered, no consort diagram, no sample size calculation, intention-to-treat } \\
\text { analysis }\end{array}$ \\
\hline & $\begin{array}{l}\text { Funding: Abbott Laboratories manufactured and supplied the syringes and epinephrine used in this } \\
\text { study }\end{array}$ \\
\hline
\end{tabular}

\section{Risk of bias}


Brown 1992 (Continued)

Random sequence genera- Unclear risk Quote: "Number and coded syringes placed in random order in packaged tion (selection bias) groups and randomly distributed to each centre by manufacturer"

Randomisation method not stated but done by manufacturer

Allocation concealment Low risk Numbered and coded syringes of equal volume and appearance
(selection bias)

Blinding of participants Low risk and personnel (perfor-

EMS staff and study investigators blinded to study treatment. Participant unmance bias)

All outcomes conscious at the time of event

\begin{tabular}{|c|c|c|}
\hline $\begin{array}{l}\text { Blinding of outcome as- } \\
\text { sessment (detection bias) } \\
\text { All outcomes }\end{array}$ & Low risk & $\begin{array}{l}\text { Participant unconscious at the time of event and blinding for hard outcome } \\
\text { (death/survival) unlikely to be associated with risk of bias. Uncertain as to } \\
\text { whether the assessor was aware of the allocation group for neurological out- } \\
\text { come }\end{array}$ \\
\hline
\end{tabular}

\begin{tabular}{lll}
\hline $\begin{array}{l}\text { Incomplete outcome data } \\
\text { (attrition bias) } \\
\text { All outcomes }\end{array}$ & Low risk & $\begin{array}{l}\text { All participants accounted for. Intention to treat analysis } \\
\text { Cases with missing data excluded for the variable of interest }\end{array}$ \\
\hline $\begin{array}{l}\text { Selective reporting (re- } \\
\text { porting bias) }\end{array}$ & Unclear risk & $\begin{array}{l}\text { Relevant outcomes reported, but not compared against a trial protocol/clini- } \\
\text { cal trial registry entry }\end{array}$ \\
\hline Other bias & Unclear risk & Role of industry funder in manuscript preparation unclear \\
& No postresuscitation care reported
\end{tabular}

Callaham 1992

$\begin{array}{ll}\text { Methods } & \text { Double-blind RCT } \\ \text { OHCA, San Francisco, California USA }\end{array}$

15 August 1990 to 15 January 1992

Participants Included: "All patients $\geq 18$ years, in nontraumatic, normothermic cardiac arrest, treated by paramedics, who would receive adrenaline according to American Heart Association advanced cardiac life support guidelines"

Excluded: hospital outcome unknown (1 patient), medication unknown (21 patients), did not receive study drug and were erroneous entries (5 patients)

Participants: 2694 patients with cardiac arrests during the study period, resuscitation attempted on 1062 patients, 843 met entry criteria, 27 excluded (1 hospital outcome unknown, 21 drug uncertain, 5 did not receive study drug) - 816 enrolled (not clear if after randomisation)

Excluding 270 patients in high-dose noradrenaline (NA) group, 546 patients: high-dose adrenaline = 286 , standard-dose adrenaline $=260$

Interventions

High-dose adrenaline (15 mg) versus standard-dose adrenaline (1 mg), diluted in $10 \mathrm{mls}$ of unknown substance, blindly substituted for advanced cardiac life support doses of adrenaline. Paramedics could give up to 3 doses (vials) of drug. Drug administered intravenously.

Outcomes

Survival to hospital discharge, survival to hospital admission (i.e. Critical Care Unit for at least one hour), neurological outcomes, pre-hospital ROSC ("presence of a measurable BP or palpable pulse that 
persisted for at least 5 minutes"), hospital LOS, critical care unit LOS, significant complications, neuro-

logical outcomes measured using CPC at hospital discharge, hospital length of stay

Notes - paramedics
Also compared noradrenaline versus adrenaline.
Ethics approval. not registered, sample size calculation performed, ITT not stated, 843 patients ran-
domised but 816 analysed ( 27 were lost to follow-up), plus unknown study group in 3 survivors and the
data not analysed.
The number of patients in 2 of the 3 study groups vary between Table 2 and Table 3 . This appears to be
a transposition typographical error i.e. Tabe 2 : $\mathrm{HDA}=286, \mathrm{SDA}=260, \mathrm{NA}=270$ versus Table $3: \mathrm{HDA}=286$,
SDA $=270, \mathrm{NA}=260$. By checking the calculations within the Tables, we concluded that the group num-
bers in Table 2 were correct, i.e. HDA $=286, \mathrm{SDA}=260, \mathrm{NA}=270$.
Funding: this study was funded by a grant from the State of California Emergency Medical Services Au-
thority, Sacramento.

\section{Risk of bias}

\begin{tabular}{|c|c|c|}
\hline Bias & Authors' judgement & Support for judgement \\
\hline $\begin{array}{l}\text { Random sequence genera- } \\
\text { tion (selection bias) }\end{array}$ & High risk & $\begin{array}{l}\text { Quasi randomisation using alternation, i.e. study drug and dose changed for } \\
\text { entire city on Wednesdays, i.e. non-concurrent controls. }\end{array}$ \\
\hline $\begin{array}{l}\text { Allocation concealment } \\
\text { (selection bias) }\end{array}$ & Low risk & $\begin{array}{l}\text { Colour coded identical vials of low dose adrenaline, high dose adrenaline or } \\
\text { noradrenaline }\end{array}$ \\
\hline $\begin{array}{l}\text { Blinding of participants } \\
\text { and personnel (perfor- } \\
\text { mance bias) } \\
\text { All outcomes }\end{array}$ & Low risk & $\begin{array}{l}\text { EMS staff and study investigators blinded to study treatment. Patient uncon- } \\
\text { scious at the time of event. }\end{array}$ \\
\hline $\begin{array}{l}\text { Blinding of outcome as- } \\
\text { sessment (detection bias) } \\
\text { All outcomes }\end{array}$ & Low risk & $\begin{array}{l}\text { Patient unconscious at the time of event and blinding for hard outcome } \\
\text { (death/survival) unlikely to be associated with risk of bias. Uncertain as to } \\
\text { whether the assessor was aware of the allocation group for neurological out- } \\
\text { come. }\end{array}$ \\
\hline $\begin{array}{l}\text { Incomplete outcome data } \\
\text { (attrition bias) } \\
\text { All outcomes }\end{array}$ & Unclear risk & $\begin{array}{l}\text { Data on witnessed and bystander CPR status missing in some } \\
\text { Study drug could not be identified with complete certainty in } 3 / 18 \text { survivors, } \\
\text { excluded }\end{array}$ \\
\hline $\begin{array}{l}\text { Selective reporting (re- } \\
\text { porting bias) }\end{array}$ & Unclear risk & $\begin{array}{l}\text { Relevant outcomes reported - but not compared against a trial protocol/clini- } \\
\text { cal trial registry entry }\end{array}$ \\
\hline Other bias & Unclear risk & $\begin{array}{l}\text { Not an intention to treat analysis, } 832 \text { enrolled, analysed } 816 \text { and unable to as- } \\
\text { sess impact } \\
\text { No postresuscitation care reported }\end{array}$ \\
\hline
\end{tabular}

\section{Callaway 2006}

$\begin{array}{ll}\text { Methods } & \text { Double blind RCT } \\ & \text { Pittsburgh, Pennsylvania }\end{array}$


Callaway 2006 (Continued)

May 2003 to April 2005

Participants Included: patients aged $\geq 18$ years who received $>$ or $=1$ dose of intravenous adrenaline during cardiopulmonary resuscitation for non-traumatic, out-of-hospital cardiac arrest

Excluded: if cardiac arrest resulted from trauma, if prisoner, if efforts were discontinued because of advanced directives or family wishes before study drug administration, if ROSC occurred before study drug administration, if no intravenous access was obtained, or open-label vasopressin used before study drug administration.

Participants: 701 patients, 376 not eligible $=325$ patients randomised ( 167 patients received vasopressin and 158 received placebo). One survivor in placebo group lost to follow-up after hospital discharge.

Interventions After first dose of adrenaline patient administered $40 \mathrm{IU}$ of vasopressin or placebo as soon as possible Endotracheal or intraosseous routes not allowed. "Physicians allowed to administer open-label vasopressin according to medical judgment".

Control: placebo

Outcomes Survival at 30 days, discharge disposition, ROSC at any time during resuscitation ("palpable pulses at any site for any duration, unambiguously indicated in the record when team decided that chest compressions no longer necessary for treatment"), presence of pulses at ED, adverse events

No neurological outcome reported. No hospital length of stay reported

Notes
Treated by paramedics from "City of Pittsburgh Bureau of Emergency Medical Services"
Ethics obtained, trial not registered, sample size calculation performed. Intention to treat analysis
used. Consort flow diagram used.
Funding: this study was supported by a grant from the Pittsburgh Emergency Medicine Foundation,
Pittsburgh, Pennsylvania.

\section{Risk of bias}

\begin{tabular}{|c|c|c|}
\hline Bias & Authors' judgement & Support for judgement \\
\hline $\begin{array}{l}\text { Random sequence genera- } \\
\text { tion (selection bias) }\end{array}$ & Low risk & Computer-generated list of random numbers in blocks of 50 \\
\hline $\begin{array}{l}\text { Allocation concealment } \\
\text { (selection bias) }\end{array}$ & Low risk & Identical vials \\
\hline $\begin{array}{l}\text { Blinding of participants } \\
\text { and personnel (perfor- } \\
\text { mance bias) } \\
\text { All outcomes }\end{array}$ & Low risk & $\begin{array}{l}\text { "Investigators, paramedics, and subjects were blinded as to whether drug or } \\
\text { placebo". }\end{array}$ \\
\hline $\begin{array}{l}\text { Blinding of outcome as- } \\
\text { sessment (detection bias) } \\
\text { All outcomes }\end{array}$ & Low risk & $\begin{array}{l}\text { Patient unconscious at the time of event and blinding for hard outcome } \\
\text { (death/survival) unlikely to be associated with risk of bias. }\end{array}$ \\
\hline $\begin{array}{l}\text { Incomplete outcome data } \\
\text { (attrition bias) } \\
\text { All outcomes }\end{array}$ & Low risk & $\begin{array}{l}\text { One patient lost to follow-up after hospital discharge. } 46 \text { patients received } \\
\text { open label vasopressin - accounted for in the results }\end{array}$ \\
\hline $\begin{array}{l}\text { Selective reporting (re- } \\
\text { porting bias) }\end{array}$ & Unclear risk & $\begin{array}{l}\text { Relevant outcomes reported - but not compared against a trial protocol/clini- } \\
\text { cal trial registry entry }\end{array}$ \\
\hline
\end{tabular}


Callaway 2006 (Continued)

Other bias Unclear risk Sensitivity analysis of including versus excluding patients who received openlabel vasopressin by physician after study drug administered

No postresuscitation care reported

\section{Choux 1995}

Double blind prospective randomised, single centre study
Lyon, France
January 1991 to July 1992 (18 months)

Participants Included: OHCA, over 18 years of age, initial ECG indicated asystole or PEA; initial ECG indicated VF, and either ECG rhythm remained in VF despite three successive counter-shocks or it changed to asystole or PEA.

Excluded: patients under 18 years of age, clear signs of irreversible cardiac arrest (such as rigor mortis, decomposition, or dependent lividity), and if received adrenaline before the mobile ICU care

Participants: 536 OHCA patients enrolled (265 standard-dose adrenaline group and 271 high-dose adrenaline group). All appear to have been analysed.

Repeated standard-dose adrenaline $(1 \mathrm{mg})$ vs repeated high-dose adrenaline $(5 \mathrm{mg})$ at $5 \mathrm{~min}$ intervals,
to a maximum of fifteen doses, according to standard protocols for ACLS. Except for the adrenaline
dosage, no other changes made to protocols. Drugs generally given intravenously through peripheral
antecubital short catheter or through CVC.

Outcomes Survival to hospital admission, survival day 21, neurological outcome, ROSC (return of a palpable pulse and blood pressure [palpable, auditory, or both]), 6-month survival, adverse effects

Neuro outcomes measured using GCS and EEG at 3 days and 21 days. No hospital length of stay reported

Notes

\begin{abstract}
SAMU (Fench Emergency Medical Service) "first-aid men initiated basic life support (BLS)". Mobile intensive care unit with doctor and nurse sent to scene immediately, advanced cardiac life support initiated
\end{abstract}

Ethics approval not stated, not registered. No sample size calculation, no consort diagram, intention to treat analysis not specified, missing data not reported. 65 not 63 patients admitted in HDA group as written in text

Funding:not stated. The drugs for the study were prepared by the Edouard Herriot Hospital's pharmacy (where the SAMU of Lyon is located).

\section{Risk of bias}

\begin{tabular}{lll}
\hline Bias & Authors' judgement & Support for judgement \\
\hline $\begin{array}{l}\text { Random sequence genera- } \\
\text { tion (selection bias) }\end{array}$ & Unclear risk & $\begin{array}{l}\text { Randomly assigned to receive either standard-dose (1 mg) epinephrine or } \\
\text { high-dose }(5 \mathrm{mg}) \text {. Randomisation process not described but used treatment } \\
\text { packs with } 15 \mathrm{ampoules} .\end{array}$ \\
\hline $\begin{array}{l}\text { Allocation concealment } \\
\text { (selection bias) }\end{array}$ & Low risk & $\begin{array}{l}\text { Study drugs prepared by hospital's pharmacy and delivered in packages of } 10 \\
\text { randomised treatments; each treatment contained } 15 \times 5 \mathrm{ml} \text { ampoules with } \\
\text { the same dosage }(1 \text { or } 5 \mathrm{mg}) \text { aimed at one cardiac arrest, } 5 \mathrm{ml} \text { ampoules iden- } \\
\text { tical in appearance. Investigators had no control; physicians used treatments } \\
\text { sequentially }\end{array}$ \\
\hline
\end{tabular}


Choux 1995 (Continued)

Blinding of participants Low risk EMS staff and study investigators blinded to study treatment. Patient unconand personnel (perforscious at the time of event.

mance bias)

All outcomes

\begin{tabular}{|c|c|c|}
\hline $\begin{array}{l}\text { Blinding of outcome as- } \\
\text { sessment (detection bias) } \\
\text { All outcomes }\end{array}$ & Low risk & $\begin{array}{l}\text { Patient unconscious at the time of event and blinding for hard outcome } \\
\text { (death/survival) unlikely to be associated with risk of bias. Neurological out- } \\
\text { come not reported. }\end{array}$ \\
\hline
\end{tabular}

No missing outcome data

Incomplete outcome data Low risk

(attrition bias)

All outcomes

\begin{tabular}{lll}
\hline $\begin{array}{l}\text { Selective reporting (re- } \\
\text { porting bias) }\end{array}$ & High risk & $\begin{array}{l}\text { Hospital Dischare Alive \% not reported - although it is reported as an outcome } \\
\text { measure on p4 of the manuscript }\end{array}$ \\
\hline Other bias & Unclear risk & $\begin{array}{l}\text { Intention to treat analysis not specified, number of exclusions described; fund- } \\
\text { ing source unclear }\end{array}$ \\
& No postresuscitation care reported
\end{tabular}

\section{Ducros 2011}

Methods $\quad$ Prospective, randomised, double-blinded controlled trial
Single, French pre-hospital setting in Paris

August 2001 to August 2004
Participants Included: adults with witnessed OHCA who presented with VF, PEA, or asystole and requiring ACLS, and for whom BLS with active compression-decompression CPR (already started by firefighters before ar- rival of medical team)
Excluded: unwitnessed cardiac arrest, spontaneous palpable carotid or femoral pulse restored before administration of vasopressor, lack of intravenous access, pregnancy, traumatic injuries and anatomic abnormalities that prevented safe femoral artery cannulation, presumed irreversible death or known terminal illness at beginning of ACLS

Participants: 48 patients screened, 4 patients excluded for ethical consideration, 44 patients witnessed cardiac arrest enrolled: standard-dose adrenaline group $\mathrm{N}=16$, adrenaline and vasopressin group $\mathrm{N}=$ 14 adrenaline,vasopressin and nitroglycerine group $\mathrm{N}=14$ plus $20 \mathrm{ml}$ normal saline flush. All 44 patients included in analysis.

Interventions

"Patients received either adrenaline alone ( $A$ alone) or adrenaline plus vasopressin $(A+V)$ or adrenaline plus vasopressin plus nitroglycerin $(A+V+N)$ ". Three successive administrations of study drugs every 5 minutes, all administered intravenously. "After 15 minutes study period, patients in cardiac arrest (regardless of group) received $1 \mathrm{mg}$ of adrenaline every 3 minutes until ROSC achieved or ACLS discontinued. Other interventions used at discretion of physician managing the CPR". Femoral arterial line inserted after first dose.

\begin{tabular}{ll}
\hline Outcomes & $\begin{array}{l}\text { Survival to hospital admission, Survival to hospital discharge, ROSC (not defined). No neurological out- } \\
\text { come reported. No hospital length of stay reported. }\end{array}$ \\
\hline Notes & $\begin{array}{l}\text { Prehospital emergency response two-tiered - "combines basic life support (BLS) with firefighters and } \\
\text { advanced cardiac life support (ACLS) with out-of-hospital emergency medical services" }\end{array}$ \\
& $\begin{array}{l}\text { Ethics approval, not registered. Sample size calculation performed, intention to treat analysis, missing } \\
\text { data not reported }\end{array}$
\end{tabular}


Ducros 2011 (Continued)

Funding: not stated

\section{Risk of bias}

Bias Authors' judgement Support for judgement

Random sequence genera- Low risk Randomly assigned to receive either standard-dose (1 mg) epinephrine or tion (selection bias) high-dose $(5 \mathrm{mg})$. Randomly generated by a computer

$\begin{array}{ll}\begin{array}{l}\text { Allocation concealment } \\ \text { (selection bias) }\end{array} & \begin{array}{l}\text { Study drugs prepared by hospital's pharmacy and delivered in packages of } 10 \\ \text { randomised treatments; each treatment contained } 15 \times 5 \mathrm{ml} \text { ampoules with } \\ \text { the same dosage ( } 1 \text { or } 5 \mathrm{mg}) \text { aimed at one cardiac arrest, } 5 \mathrm{ml} \text { ampoules iden- } \\ \text { tical in appearance, placed in sealed numbered envelopes }\end{array} \\ & \text { Investigators had no control; physicians used treatments sequentially }\end{array}$

$\begin{array}{ll}\begin{array}{l}\text { Blinding of participants } \\ \text { and personnel (perfor- }\end{array} & \text { Low risk } \\ \text { EMS staff and study investigators blinded to study treatment. Patient uncon- } \\ \text { scious at the time of event. }\end{array}$
mance bias)

All outcomes

\begin{tabular}{|c|c|c|}
\hline $\begin{array}{l}\text { Blinding of outcome as- } \\
\text { sessment (detection bias) }\end{array}$ & Low risk & $\begin{array}{l}\text { Patient unconscious at the time of event and blinding for hard outcome } \\
\text { (death/survival) unlikely to be associated with risk of bias. }\end{array}$ \\
\hline
\end{tabular}

Incomplete outcome data Low risk

(attrition bias)

No missing outcome data

All outcomes

\begin{tabular}{|c|c|c|}
\hline $\begin{array}{l}\text { Selective reporting (re- } \\
\text { porting bias) }\end{array}$ & Unclear risk & $\begin{array}{l}\text { Relevant outcomes reported - but not compared against a trial protocol/clini- } \\
\text { cal trial registry entry }\end{array}$ \\
\hline
\end{tabular}

Other bias Unclear risk $\quad$ Funding source not stated. No postresuscitation care reported

\section{Gueugniaud 1998}

\begin{tabular}{|c|c|}
\hline Methods & $\begin{array}{l}\text { Prospective, multicenter, randomised controlled trial } \\
12 \text { centres in France and Belgium } \\
1 \text { September } 1994 \text { to } 1 \text { September } 1996\end{array}$ \\
\hline \multirow[t]{4}{*}{ Participants } & $\begin{array}{l}\text { Included: Patients aged } 18+\text { who had out-of-hospital cardiac arrest if the cardiac rhythm continued to } \\
\text { be VF despite administration of external electrical shocks, asystole or PEA at the time epinephrine was } \\
\text { administered }\end{array}$ \\
\hline & $\begin{array}{l}\text { Excluded: traumatic cardiac arrest; obvious signs of irreversible cardiac arrest; or if epinephrine had } \\
\text { been injected before study resuscitation. }\end{array}$ \\
\hline & $\begin{array}{l}\text { Participants: 3,946 patients, "39 packages not used properly" = 3907; } 1938 \text { standard-dose adrenaline } \\
\text { group and } 1969 \text { high-dose adrenaline group (intention to treat analysis) }\end{array}$ \\
\hline & $\begin{array}{l}580(15 \%) \text { further exclusions ( } 45 \text { not eligible or received study drug inappropriately, } 190 \text { missing data or } \\
\text { lost to follow-up, } 345 \text { traumatic cardiac arrests) = 3,327 patients enrolled: 1,650 standard-dose adrena- } \\
\text { line group and 1,677 high-dose adrenaline group = final analysis }\end{array}$ \\
\hline
\end{tabular}


Gueugniaud 1998 (Continued)

Interventions
Patients received up to 15 high doses $(5 \mathrm{mg}$ ) or standard doses $(1 \mathrm{mg})$ of adrenaline "according to the current protocol for ACLS" (IV or occasionally endobronchial)

Outcomes

Survival to hospital discharge, survival to hospital admission, i.e. ICU admission (pulse and BP present), survival to 24 hours, neurologic outcome, ROSC (return of spontaneous palpable pulse and blood pressure for at least one minute)

Neuro outcomes were assessed at the time of admission and at one week according to the highest score on the Glasgow Coma Scale (from 3, worst, to 15, best) and at hospital discharge according to CPC: CPC 1-2 considered 'good'. No hospital length of stay reported.

Notes

EMS two-tiered (SAMU) - first tier has emergency medical ambulances staffed by technicians to provide basic life support. Second tier mobile intensive care unit, with doctor and nurse, sent to scene immediately, advanced cardiac life support initiated

Ethics approval, not registered, no consort diagram. No sample size calculation, intention to treat analysis initially, missing data not reported

Funding: supported in part in France by the Research Delegation of the Hospices Civils de Lyon and the Economic Services of the Edouard Herriot Hospital, and in Belgium by Les Amis du Service d'Aide Médicale Urgente.

\section{Risk of bias}

\begin{tabular}{lll}
\hline Bias & Authors' judgement & Support for judgement \\
\hline $\begin{array}{l}\text { Random sequence genera- } \\
\text { tion (selection bias) }\end{array}$ & Low risk & Central randomisation schedule \\
\hline $\begin{array}{l}\text { Allocation concealment } \\
\text { (selection bias) }\end{array}$ & Low risk & $\begin{array}{l}\text { "Two regimens of adrenaline provided in packages of } 15 \text { coded 5-ml ampoules } \\
\text { with the same dosage of adrenaline. Each package was used for one person } \\
\text { with cardiac arrest. Study packages were available in special sets of } 10 \text { ran- } \\
\text { domised packages in all the medical ambulances of the } 12 \text { centres." }\end{array}$
\end{tabular}

Blinding of participants Low risk
and personnel (perfor-
mance bias)
All outcomes

"All investigators and personnel providing care outside the hospital blinded as to which dose was administered and had no control over the order in which the sets used." Patient unconscious at the time of event.

\section{Blinding of outcome as- Low risk sessment (detection bias) All outcomes \\ Patient unconscious at the time of event and blinding for hard outcome (death/survival) unlikely to be associated with risk of bias. Uncertain as to whether the assessor was aware of the allocation group for neurological out- come.}

Incomplete outcome data High risk (attrition bias)

All outcomes
"39 packages not used properly for cardiac arrests, 580 patients (15\%) subsequently excluded from the final analysis (by two investigators unaware of treatment assignment): 45 patients who did not meet the eligibility criteria or who received the study medication inappropriately, 190 patients for whom essential data were not available or who were lost to follow-up, and 345 patients who had traumatic cardiac arrest."

\begin{tabular}{|c|c|c|}
\hline $\begin{array}{l}\text { Selective reporting (re- } \\
\text { porting bias) }\end{array}$ & Unclear risk & $\begin{array}{l}\text { Relevant outcomes reported - but not compared against a trial protocol/clini- } \\
\text { cal trial registry entry }\end{array}$ \\
\hline
\end{tabular}

\begin{abstract}
Table 1 shows results of intention to treat analysis but Table 3 showed results after $15 \%$ exclusions after randomisation. Baseline characteristics and some outcomes for treated group analysis only.
\end{abstract}

No difference shown in outcomes 


\begin{tabular}{|c|c|}
\hline Methods & $\begin{array}{l}\text { Multicenter study, randomly assigned adults with out-of-hospital cardiac arrest } \\
31 \text { SAMU and SMUR units, France } \\
1 \text { May } 2004 \text { to } 30 \text { April } 2006\end{array}$ \\
\hline \multirow[t]{3}{*}{ Participants } & $\begin{array}{l}\text { Included: adult patients ( } 18+\text { yrs) with OHCA presenting with VF, PEA, or asystole requiring vasopressor } \\
\text { therapy during CPR }\end{array}$ \\
\hline & $\begin{array}{l}\text { Excluded: successful defibrillation without administration of a vasopressor, traumatic cardiac arrest, } \\
\text { pregnancy, documented terminal illness, presence of a do-not resuscitate order, and obvious signs of } \\
\text { irreversible cardiac arrest. }\end{array}$ \\
\hline & $\begin{array}{l}\text { Participants: } 2956 \text { randomised and } 62(2 \%) \text { excluded from analysis, including } 26 \text { in the combination } \\
\text { therapy group and } 36 \text { in the epinephrine-only group }(P=0.22) \text {. Twenty-six of the excluded patients did } \\
\text { not consent to participation in the study, } 29 \text { had traumatic cardiac arrest, and } 7 \text { were treated but did } \\
\text { not meet the inclusion criteria. Data from the remaining } 2894 \text { patients - } 1442 \text { combination of adrena- } \\
\text { line and vasopressin and } 1452 \text { standard-dose adrenaline alone were analysed }\end{array}$ \\
\hline
\end{tabular}

\begin{tabular}{|c|c|}
\hline Interventions & $\begin{array}{l}\text { Successive injections of } 1 \mathrm{mg} \text { of adrenaline and saline placebo OR } 1 \mathrm{mg} \text { of adrenaline and } 40 \mathrm{IU} \text { of vaso- } \\
\text { pressin. Up to two study drug doses and then additional adrenaline if needed. All drugs administered } \\
\text { intravenously. }\end{array}$ \\
\hline \multirow[t]{2}{*}{ Outcomes } & $\begin{array}{l}\text { Survival to hospital discharge, survival to hospital admission, neurologic recovery, ROSC (spontaneous } \\
\text { return of a palpable pulse and measurable BP for at least } 1 \text { minute), one-year survival }\end{array}$ \\
\hline & $\begin{array}{l}\text { Neuro outcomes were assessed using CPC at hospital discharge: <3 (ie } 1 \text { or 2) considered 'good'. No } \\
\text { hospital length of stay reported. }\end{array}$ \\
\hline \multirow[t]{4}{*}{ Notes } & $\begin{array}{l}\text { EMS two-tiered service (Service d'Aide Médicale Urgente [SAMU]) - first tier emergency medical am- } \\
\text { bulances staffed by technicians to provide basic life support. Second tier mobile ICU, with doctor and } \\
\text { nurse, sent to scene immediately, advanced cardiac life support initiated }\end{array}$ \\
\hline & France - several units rural and metro \\
\hline & $\begin{array}{l}\text { Ethics approval, trial registered [NCT00127907], no consort diagram, sample size calculation. Inten- } \\
\text { tion-to-treat analysis. No interim analysis performed during the study period. }\end{array}$ \\
\hline & $\begin{array}{l}\text { Funding: supported by the Programme Hospitalier de Recherche Clinique } 2003 \text { of the French Ministry } \\
\text { of Health Research and the French Health Product Safety Agency and by the Research Delegation of the } \\
\text { Hospices Civils de Lyon. The Research Delegation of the Hospices Civils de Lyon has received grant sup- } \\
\text { port from Aguettant Laboratories. }\end{array}$ \\
\hline
\end{tabular}

\section{Risk of bias}

\begin{tabular}{lll}
\hline Bias & Authors' judgement & Support for judgement \\
\hline $\begin{array}{l}\text { Random sequence genera- } \\
\text { tion (selection bias) }\end{array}$ & Low risk & Central randomisation schedule \\
\hline $\begin{array}{l}\text { Allocation concealment } \\
\text { (selection bias) }\end{array}$ & Low risk & Sets of 40 drug boxes, with stratification according to centre \\
\hline
\end{tabular}


Gueugniaud 2008 (Continued)

Blinding of participants Low risk_ "All investigators and emergency medical service personnel unaware of which and personnel (perforstudy drugs used and had no control over the order in which the study-drug mance bias)

All outcomes sets used through out trial." "Possibility of making the physician aware of the identity of the study drugs was available in the case of adverse events, but never used." Patient unconscious at the time of event.

\begin{tabular}{|c|c|c|}
\hline $\begin{array}{l}\text { Blinding of outcome as- } \\
\text { sessment (detection bias) } \\
\text { All outcomes }\end{array}$ & Low risk & $\begin{array}{l}\text { Patient unconscious at the time of event and not blinding for hard outcome } \\
\text { (death/survival) unlikely to be associated with risk of bias. Not explicitly stated } \\
\text { if those assessing neurological status on discharge were blinded to the group } \\
\text { allocation }\end{array}$ \\
\hline $\begin{array}{l}\text { Incomplete outcome data } \\
\text { (attrition bias) } \\
\text { All outcomes }\end{array}$ & Low risk & $\begin{array}{l}2,956 \text { randomised: } 62 \text { patients }(2.1 \% \text { ) excluded from analysis ( } 26 \text { in combina- } \\
\text { tion therapy group and } 36 \text { in epinephrine-only group, } P=0.22 \text { ). } 26 \text { excluded } \\
\text { patients did not consent to participation, } 29 \text { traumatic cardiac arrest, and } 7 \\
\text { treated but did not meet inclusion criteria }=2894 \text { patient data analysed. }\end{array}$ \\
\hline $\begin{array}{l}\text { Selective reporting (re- } \\
\text { porting bias) }\end{array}$ & Unclear risk & $\begin{array}{l}\text { Relevant outcomes reported - but not compared against a trial protocol/clini- } \\
\text { cal trial registry entry }\end{array}$ \\
\hline Other bias & Unclear risk & $\begin{array}{l}\text { Survival data from } 7 \text { patients missing Table } 2 \text {, not reported in text or Table leg- } \\
\text { end. No postresuscitation care reported }\end{array}$ \\
\hline
\end{tabular}

Jacobs 2011

$\begin{array}{ll}\text { Methods } & \text { Double blind randomised placebo-controlled trial of adrenaline in out-of-hospital cardiac arrest } \\ \text { Perth, Western Australia } \\ 11 \text { August } 2006 \text { to } 30 \text { November } 2009\end{array}$

Participants Included: cardiac arrest from any cause, aged 18+ years, with resuscitation commenced by paramedics

Excluded: patients who responded early to defibrillation not randomised

Participants: 4103 OHCA patients screened, 3502 excluded - 2513 because resuscitation efforts were not commenced by paramedics as death had clearly been established. 601 randomised. Documentation available for 534 patients: 262 in placebo group and 272 in adrenaline group.

\begin{tabular}{ll}
\hline Interventions & $\begin{array}{l}1 \mathrm{mg} \text { adrenaline or } 1 \mathrm{ml} \text { normal saline (placebo) administered intravenously as clinically indicated with } \\
\text { maximum dose of } 10 \mathrm{ml} \text { (10 mg adrenaline or } 10 \mathrm{ml} \text { normal saline). No other resuscitation drugs admin- } \\
\text { istered pre-hospital during trial and endobronchial administration of drugs not permitted. }\end{array}$
\end{tabular}

Outcomes

Survival to hospital discharge, survival to hospital admission, neurologic outcome, pre-hospital ROSC (period of sustained ROSC in the field for greater 30 seconds). Neuro outcomes were assessed using CPC at hospital discharge: <3 (ie 1 or 2 ) considered 'good'. No hospital length of stay reported.

Notes $\quad$ EMS ALS paramedics

Ethics approval, registered with the Australian and New Zealand Clinical Trials Register (AC-

TRN12605000062628), sample size calculation, intention to treat analysis. No loss to follow-up.

Funding: this study was funded by the National Health and Medical Research Council (Grant No. 254537). The funding body had no involvement in any aspect of study design, conduct or analysis.

\section{Risk of bias}


Jacobs 2011 (Continued)

Random sequence genera- Low risk Computer generated randomisation schedule. tion (selection bias)

$\begin{array}{ll}\begin{array}{l}\text { Allocation concealment } \\ \text { (selection bias) }\end{array} & \text { "Study drugs commercially prepared, independent of investigators, in identi- } \\ & \text { cal } 10 \mathrm{ml} \text { vials containing either adrenaline } 1: 1000 \text { or placebo (sodium chloride } \\ 0.9 \%) \text { with tamperproof seals distinguishable only by a specific randomisation } & \text { number." Study drugs centrally issued to paramedic crews using the same dis- } \\ \text { tribution process as for other drugs used within the ambulance service. }\end{array}$

\begin{tabular}{|c|c|c|}
\hline $\begin{array}{l}\text { Blinding of participants } \\
\text { and personnel (perfor- }\end{array}$ & Low risk & $\begin{array}{l}\text { EMS staff and study investigators blinded to study treatment. Patient uncon- } \\
\text { scious at the time of event. }\end{array}$ \\
\hline
\end{tabular}

mance bias)

All outcomes

$\begin{array}{ll}\begin{array}{l}\text { Blinding of outcome as- } \\ \text { sessment (detection bias) }\end{array} & \text { Patient unconscious at the time of event and not blinding for hard outcome } \\ \text { All outcomes } & \text { (death/survival) unlikely to be associated with risk of bias. "CPC scores derived } \\ & \begin{array}{l}\text { from medical chart review for patients surviving to hospital discharge, with the } \\ \text { chart reviewer blinded to the study group allocation" }\end{array}\end{array}$

Incomplete outcome data High risk

(attrition bias)

All outcomes
$67(11 \%)$ unable to be analysed due to randomisation number not being recorded.

These are missing for all outcomes. Not sure how many lost form each group but numbers remaining look fairly balanced. Small number of survivors means that it is possible that bias has been introduced by losing a few survivors from one group.

\begin{tabular}{ll}
\hline $\begin{array}{l}\text { Selective reporting (re- } \\
\text { porting bias) }\end{array}$ & Low risk
\end{tabular}

\begin{tabular}{ll}
\hline Other bias & Intention to treat analysis; \\
& Planned sample size not achieved. \\
& $\begin{array}{l}\text { Some baseline imbalances but adjusted analysis performed (adjusting for age, } \\
\text { gender, bystander witnessed, initial rhythm shockable, and response interval. } \\
\text { This showed little difference but not certain how well this controlled for imbal- } \\
\text { ances. }\end{array}$
\end{tabular}

No postresuscitation care reported

\begin{tabular}{ll}
\hline Methods & "Randomised study" of in-hospital and ED cardiac arrest, cardiac arrest confirmed by ECG or monitor \\
\hline Participants & 83 patients with in-hospital (including ED) cardiac arrest "randomly divided" into 4 groups: (1) stan- \\
dard-dose adrenaline 22 patients, (2) high-dose adrenaline 21 patients, (3) low dose vasopressin 20 pa- \\
tients, (4) high dose vasopressin 20 patients
\end{tabular}

Interventions

(1) Standard dose $1 \mathrm{mg}$ adrenaline vs high dose adrenaline $5 \mathrm{mg}$

(2) Standard dose $1 \mathrm{mg}$ adrenaline vs $0.5 \mathrm{U} / \mathrm{kg}$ vasopressin

(3) Standard dose $1 \mathrm{mg}$ adrenaline vs $1.0 \mathrm{U} / \mathrm{kg}$ vasopressin.

Adrenaline was administered IV every 5 minutes and vasopressin every 10 minutes PRN. 
Li 1999 (Continued)

Outcomes Survival to hospital discharge, ROSC (longer 30 minutes), neurological outcome (described as discharged from hospital with pre-arrest conscious state, heart rate and respiratory rate status)

Notes

EMS not described.

Chinese paper, translated by independent researcher.

Ethics approval not stated. Trial not registered. Data collection started February 1996, conclusion date unknown. Did not compare VF with asystole/PEA. Discrepancy in survival data high dose vasopressin (33.5\% in the abstract vs $35 \%$ in the main text). No description of initial rhythm. ITT not stated. No missing data reported. No consort diagram.

Funding: not known

\section{Risk of bias}

\begin{tabular}{|c|c|c|}
\hline Bias & Authors' judgement & Support for judgement \\
\hline $\begin{array}{l}\text { Random sequence genera- } \\
\text { tion (selection bias) }\end{array}$ & Unclear risk & Randomisation method not reported - possible risk that it is not a RCT \\
\hline $\begin{array}{l}\text { Allocation concealment } \\
\text { (selection bias) }\end{array}$ & High risk & $\begin{array}{l}\text { Not reported - high risk of non-random allocation e.g. "84 patients with car- } \\
\text { diac arrest were divided into } 4 \text { groups" }\end{array}$ \\
\hline $\begin{array}{l}\text { Blinding of participants } \\
\text { and personnel (perfor- } \\
\text { mance bias) } \\
\text { All outcomes }\end{array}$ & Unclear risk & $\begin{array}{l}\text { Not reported. } \\
\text { Patient unconscious at the time of event. }\end{array}$ \\
\hline $\begin{array}{l}\text { Blinding of outcome as- } \\
\text { sessment (detection bias) } \\
\text { All outcomes }\end{array}$ & Unclear risk & $\begin{array}{l}\text { Patient unconscious at the time of event and blinding for hard outcome } \\
\text { (death/survival) unlikely to be associated with risk of bias. Uncertain as to } \\
\text { whether the assessor was aware of the allocation group for neurological out- } \\
\text { come. }\end{array}$ \\
\hline $\begin{array}{l}\text { Incomplete outcome data } \\
\text { (attrition bias) } \\
\text { All outcomes }\end{array}$ & Low risk & Analysis on all 83 patients \\
\hline $\begin{array}{l}\text { Selective reporting (re- } \\
\text { porting bias) }\end{array}$ & Unclear risk & $\begin{array}{l}\text { Relevant outcomes reported - but not compared against a trial protocol/clini- } \\
\text { cal trial registry entry }\end{array}$ \\
\hline Other bias & Unclear risk & $\begin{array}{l}\text { Intention to treat analysis not reported but all patients accounted for, but } \\
\text { funding source unclear. No postresuscitation care reported }\end{array}$ \\
\hline
\end{tabular}

Lindner 1991a

\begin{tabular}{|c|c|}
\hline Methods & $\begin{array}{l}\text { Prospective randomised double blind controlled trial } \\
\text { Ulm University Hospital, Germany }\end{array}$ \\
\hline Participants & $\begin{array}{l}\text { Included: in-hospital or out of hospital cardiac arrest, asystole or PEA } \\
\text { Excluded: < } 18 \text { years, obvious non-cardiac cause, e.g. trauma, patients given DC shock before adrena- } \\
\text { line administered }\end{array}$ \\
\hline & $\begin{array}{l}\text { Participants: } 68 \text { patients - } 40 \text { standard-dose adrenaline group, } 28 \text { high-dose adrenaline group - includ- } \\
\text { ed in analysis. }\end{array}$ \\
\hline
\end{tabular}


Lindner 1991a (Continued)

Interventions
Single dose of study drug, either standard-dose adrenaline $(1 \mathrm{mg}$ ) or high-dose adrenaline $(5 \mathrm{mg})$. If the first dose of adrenaline ( 1 or $5 \mathrm{mg}$ ) failed, standardized advanced life-support was applied in all cases (up to $10 \mathrm{mg}$ adrenaline). Study drugs administered intravenously, peripheral or external jugular vein.
Survival to hospital discharge, 12-hour survival (Initial resuscitation success - haemodynamic status stable, with or without dopamine, for at least 12 hours)

No neurological outcome reported. No hospital length of stay reported

Ethics approval, trial not registered, recruitment period not stated, ITT not stated, no missing data reported. No consort diagram - unclear if $\mathrm{N}=68$ was the number randomised i.e. whether or not there was any loss to follow-up.

Funding: not stated

\section{Risk of bias}

\begin{tabular}{|c|c|c|}
\hline Bias & Authors' judgement & Support for judgement \\
\hline $\begin{array}{l}\text { Random sequence genera- } \\
\text { tion (selection bias) }\end{array}$ & Unclear risk & Randomly allocated, method not described \\
\hline $\begin{array}{l}\text { Allocation concealment } \\
\text { (selection bias) }\end{array}$ & Low risk & Study drug prepared in identical ampoules \\
\hline $\begin{array}{l}\text { Blinding of participants } \\
\text { and personnel (perfor- } \\
\text { mance bias) } \\
\text { All outcomes }\end{array}$ & Low risk & $\begin{array}{l}\text { "Double blind". Investigators, paramedics, blinded to study treatment. Patient } \\
\text { unconscious at the time of event. }\end{array}$ \\
\hline $\begin{array}{l}\text { Blinding of outcome as- } \\
\text { sessment (detection bias) } \\
\text { All outcomes }\end{array}$ & Low risk & $\begin{array}{l}\text { Patient unconscious at the time of event and not blinding for hard outcome } \\
\text { (death/survival) unlikely to be associated with risk of bias. }\end{array}$ \\
\hline $\begin{array}{l}\text { Incomplete outcome data } \\
\text { (attrition bias) } \\
\text { All outcomes }\end{array}$ & Low risk & Analysis on all 68 patients \\
\hline $\begin{array}{l}\text { Selective reporting (re- } \\
\text { porting bias) }\end{array}$ & Unclear risk & $\begin{array}{l}\text { Relevant outcomes reported - but not compared against a trial protocol/clini- } \\
\text { cal trial registry entry }\end{array}$ \\
\hline Other bias & Unclear risk & $\begin{array}{l}\text { Intention to treat analysis not stated; unequal numbers in each group (40:28); } \\
\text { but funding source not stated. No postresuscitation care reported }\end{array}$ \\
\hline
\end{tabular}

\section{Lindner 1997}

Methods

Prospective, randomised controlled trial comparing vasopressin with adrenaline in patients with VF in out-of-hospital cardiac arrest

Greater metropolitan area of Ulm, Germany

July 1994 to December 1995 
Excluded: age $<18$ years, OHCA due to trauma or terminal illness, pregnancy or bronchial epinephrine administration.

Participants: 40 patients randomised - 20 standard-dose adrenaline group, 20 vasopressin group - 40 included in analysis.

$\begin{array}{ll}\text { Interventions } & \text { Adrenaline (1 mg intravenously; } \mathrm{N}=20 \text { ) or vasopressin ( } 40 \mathrm{U} \text { intravenously; } \mathrm{N}=20) \text { in } 10 \mathrm{ml} \text { syringes via } \\ \text { peripheral or external jugular vein then flushed with Ringers Lactate. One dose of study drug and then } \\ \text { usual care. }\end{array}$
usual care.

\begin{tabular}{|c|c|}
\hline Outcomes & $\begin{array}{l}\text { Survival to hospital discharge, survival to hospital admission (successful resuscitation to ICU admis- } \\
\text { sion), survival for } 24 \text { hours, neurological outcome, ROSC (return of spontaneous, palpable carotid pulse } \\
\text { for undefined period at any time after drug administration). Neuro outcomes were assessed using GCS } \\
\text { with mean (sd) GCS compared between treatment groups. No hospital length of stay reported }\end{array}$ \\
\hline \multirow[t]{3}{*}{ Notes } & $\begin{array}{l}\text { First response team mobile intensive care unit staffed "by paramedics and a physician specialising in } \\
\text { emergency care" }\end{array}$ \\
\hline & $\begin{array}{l}\text { Ethics approval, trial not registered, sample size calculation reported, ITT performed. No missing data } \\
\text { reported. Consort diagram. }\end{array}$ \\
\hline & Funding: supported by a grant from the Laerdal Foundation, Norway. \\
\hline
\end{tabular}

\section{Risk of bias}

\begin{tabular}{|c|c|c|}
\hline Bias & Authors' judgement & Support for judgement \\
\hline $\begin{array}{l}\text { Random sequence genera- } \\
\text { tion (selection bias) }\end{array}$ & Low risk & Computer generated randomisation \\
\hline $\begin{array}{l}\text { Allocation concealment } \\
\text { (selection bias) }\end{array}$ & Low risk & Numbered and pre-coded, pre-filled syringes identical in appearance. \\
\hline $\begin{array}{l}\text { Blinding of participants } \\
\text { and personnel (perfor- } \\
\text { mance bias) } \\
\text { All outcomes }\end{array}$ & Low risk & $\begin{array}{l}\text { Double blind study. Investigators, paramedics, blinded to study treatment. Pa- } \\
\text { tient unconscious at the time of event. }\end{array}$ \\
\hline $\begin{array}{l}\text { Blinding of outcome as- } \\
\text { sessment (detection bias) } \\
\text { All outcomes }\end{array}$ & Low risk & $\begin{array}{l}\text { Patient unconscious at the time of event and not blinding for hard outcome } \\
\text { (death/survival) unlikely to be associated with risk of bias. Uncertain as to } \\
\text { whether the assessor was aware of the allocation group for neurological out- } \\
\text { come. }\end{array}$ \\
\hline $\begin{array}{l}\text { Incomplete outcome data } \\
\text { (attrition bias) } \\
\text { All outcomes }\end{array}$ & Low risk & All patients accounted for. No missing data reported \\
\hline $\begin{array}{l}\text { Selective reporting (re- } \\
\text { porting bias) }\end{array}$ & Unclear risk & $\begin{array}{l}\text { Relevant outcomes reported - but not compared against a trial protocol/clini- } \\
\text { cal trial registry entry }\end{array}$ \\
\hline Other bias & Unclear risk & $\begin{array}{l}\text { Intention to treat analysis stated in abstract. No post resuscitation care report- } \\
\text { ed. }\end{array}$ \\
\hline
\end{tabular}




\begin{tabular}{ll}
\hline Participants & $\begin{array}{l}\text { Included: adult patients requiring CPR, witnessed asystolic cardiac arrest in ICU. 80\% '"overwhelming } \\
\text { sepsis" }\end{array}$ \\
& $\begin{array}{l}\text { Participants: } 40 \text { patients randomised, } 5 \text { excluded (3 missing data, } 2 \text { did not meet inclusion criteria). } 16 \\
\text { standard-dose adrenaline group, } 19 \text { high-dose adrenaline group }\end{array}$ \\
\hline Interventions & $\begin{array}{l}\text { Patients received standard dose of adrenaline (1 mg every five minutes) or high-dose adrenaline (10 mg } \\
\text { every five minutes), up to } 3 \text { doses then standard adrenaline }\end{array}$ \\
\hline Outcomes & $\begin{array}{l}\text { Survival to } 12 \text { hours, survival to } 24 \text { hours, ICU survivors, days in ICU, "successfully resuscitated" (not de- } \\
\text { fined). No neurological outcome reported. No hospital length of stay reported. }\end{array}$ \\
\hline Notes & $\begin{array}{l}\text { Ethics approval, no sample size calculation, ITT not reported. No missing data reported. No consort di- } \\
\text { agram }\end{array}$ \\
Funding: not stated
\end{tabular}

\section{Risk of bias}

\begin{tabular}{|c|c|c|}
\hline Bias & Authors' judgement & Support for judgement \\
\hline $\begin{array}{l}\text { Random sequence genera- } \\
\text { tion (selection bias) }\end{array}$ & Low risk & Computer generated randomisation code \\
\hline $\begin{array}{l}\text { Allocation concealment } \\
\text { (selection bias) }\end{array}$ & Low risk & $\begin{array}{l}\text { Ampoules sealed by smelting and labelled drug A or drug B. Ampoules identi- } \\
\text { cal and code broken after trial }\end{array}$ \\
\hline $\begin{array}{l}\text { Blinding of participants } \\
\text { and personnel (perfor- } \\
\text { mance bias) } \\
\text { All outcomes }\end{array}$ & Unclear risk & Not stated but ampoules identical. Patient unconscious at the time of event \\
\hline $\begin{array}{l}\text { Blinding of outcome as- } \\
\text { sessment (detection bias) } \\
\text { All outcomes }\end{array}$ & Unclear risk & $\begin{array}{l}\text { Patient unconscious at the time of event and not blinding for hard outcome } \\
\text { (death/survival) unlikely to be associated with risk of bias. }\end{array}$ \\
\hline $\begin{array}{l}\text { Incomplete outcome data } \\
\text { (attrition bias) } \\
\text { All outcomes }\end{array}$ & Low risk & 5 patients excluded after being entered into the study, 3 with missing data \\
\hline $\begin{array}{l}\text { Selective reporting (re- } \\
\text { porting bias) }\end{array}$ & Unclear risk & $\begin{array}{l}\text { Relevant outcomes reported - but not compared against a trial protocol/clini- } \\
\text { cal trial registry entry }\end{array}$ \\
\hline Other bias & Unclear risk & $\begin{array}{l}80 \% \text { of patients had "overwhelming sepsis"; funding source unclear. No post } \\
\text { resuscitation care reported. }\end{array}$ \\
\hline
\end{tabular}

Mukoyama 2009

Methods Prospective, single centre, randomised controlled clinical trial

June 2001 to May 2006 
Mukoyama 2009 (Continued)

Participants
Included: out-of-hospital cardiac arrest (presumed cardiac etiology) after the arrival of the EMTs, or if they were transported to ED under CPR on arrival at ED

Excluded: age $<18$ years $(N=6)$, lack of intravenous access, injection of vasopressors in the pre-hospital setting, indications of emergency cardiopulmonary bypass $(\mathrm{N}=61)$, documented terminal illness ( $N$ $=18$ ), do-not-resuscitate order, non-cardiac etiology according to the Utstein criteria, e.g. asphyxia, pneumonia $(\mathrm{N}=17)$ excluded after randomisation

Patients $(\mathrm{N}=17)$ found to have cardiac arrest from non-cardiac cause also excluded after randomisation.

Participants: 534 patients randomised, 198 (37\%) excluded - 96 had traumatic cardiac arrest and 102 treated but did not meet inclusion criteria. 336 patients analysed: vasopressin group $\mathrm{N}=178$; adrenaline group $\mathrm{N}=158$

Receive maximum of four injections of either $1 \mathrm{mg}$ of adrenaline (control group) or $40 \mathrm{IU}$ of vasopressin
(study group) immediately after ED admission, repeated every 5 to $10 \mathrm{~min}$ until the cumulative dose
reached. No combined injections of vasopressors administered in either group. All drugs injected intra-
venously with $20 \mathrm{ml}$ normal saline flush after each dose

Outcomes Survival to hospital discharge, neurological outcome, ROSC (defined as "return of spontaneous circulation by the time patient moved from ED to ICU and intensive care commenced"), 24-hour survival. Neuro outcomes were assessed using CPC at hospital discharge: < 3 (i.e. 1 or 2) considered 'good'. No hospital length of stay reported.

Notes

Nearest available ambulance dispatched to scene, manned by three emergency medical technicians (EMTs) providing basic life support and airway maintenance. "EMTs strictly prohibited from intravenously injecting vasopressors or any other drugs in the pre-hospital setting"

Ethics approval, no trial registration, no sample size calculation, no missing data reported. Consort diagram.

Abstract states that there were $\mathrm{N}=137$ in Vaspressin group and 118 in the Adreanaline group - but from Table 1 it can be seen that these numbers only relate to the non-VF sub-group. Analysis included both the VF and non-VF patients.

Funding: not stated.

All of the authors declared that they had no conflicts of interest to disclose.

\section{Risk of bias}

Bias Authors' judgement Support for judgement

Random sequence genera- Unclear risk Randomisation not described

tion (selection bias)

Allocation concealment $\quad$ Unclear risk $\quad$ Not described
(selection bias)

\begin{tabular}{|c|c|c|}
\hline $\begin{array}{l}\text { Blinding of participants } \\
\text { and personnel (perfor- }\end{array}$ & Unclear risk & $\begin{array}{l}\text { Blinding of EMS staff not reported. It is likely that there was no blinding of the } \\
\text { drugs administered. Patient unconscious at the time of event }\end{array}$ \\
\hline
\end{tabular}
mance bias)

All outcomes

\begin{tabular}{lll}
\hline $\begin{array}{l}\text { Blinding of outcome as- } \\
\text { sessment (detection bias) }\end{array}$ & Unclear risk & $\begin{array}{l}\text { Not reported. Patient unconscious at the time of event and not blinding for } \\
\text { All outcomes }\end{array}$
\end{tabular}


Mukoyama 2009 (Continued)

Incomplete outcome data (attrition bias)

High risk Patients (37\%) excluded after randomisation

All outcomes

CPC scores clarified with authors

\begin{tabular}{|c|c|c|}
\hline $\begin{array}{l}\text { Selective reporting (re- } \\
\text { porting bias) }\end{array}$ & Unclear risk & $\begin{array}{l}\text { Relevant outcomes reported - but not compared against a trial protocol/clini- } \\
\text { cal trial registry entry. ROSC definition not "Utstein" }\end{array}$ \\
\hline
\end{tabular}

Other bias Unclear risk $\quad$ Funding source unclear. No post resuscitation care reported.

Ong 2012

Methods Randomised, double-blind, multi-centre, parallel design trial, four adult public hospital ED's

Singapore

9 March 2006 to 19 January 2009

Participants

Included: All cardiac arrest patients in ED, including pre-hospital and ED arrests aged > 16 (age >=21 for one hospital).

Excluded: traumatic cardiac arrest or when CPR contraindicated (e.g., for those 'obviously dead' as defined by the presence of decomposition, rigor mortis, or dependent lividity).

Participants: 790 patients screened: 63 excluded, 727 randomised: low dose adrenaline $=353$; vasopressin= 374 - and analysed. 3 patients lost to follow-up (1 standard-dose adrenaline group, 2 vasopressin group) after discharge.

Interventions Eligible patients randomly assigned to receive intravenous adrenaline (1 $\mathrm{mg}$ ) or vasopressin (40 IU) in ED. One dose only then open-label adrenaline

Outcomes

Survival to hospital discharge or 30 days post arrest, survival to hospital admission (patients successfully resuscitated admitted to ICU), neurological outcome, ROSC ("presence of any palpable pulse detected by manual palpation of a major artery"). Neurological outcomes were assessed using CPC at hospital discharge: < 3 (i.e. 1 or 2) considered 'good'.

Notes Paramedics with basic life support skills who can defibrillate with automated external defibrillators
and insert laryngeal mask airways

Ethics approval, not registered. Sample size calculation. ITT not stated but evident from consort diagram. Planned, blinded, safety monitoring interim conducted when 300 participants enrolled. Safety monitoring committee (SMC) - two independent clinicians and one statistician.

Funding: the study was funded by National Medical Research Council, Ministry of Health, Singapore (NMRC/0673/2002); Singapore Health Services Pivotal Trials Grant, Singapore (PTC01/2006/006); and Singapore General Hospital Research Fund, Singapore (SRF\#145/08). The funding sources had no involvement in the study design, collection, analysis, and interpretation of data, writing of manuscript, and in the decision to submit the manuscript for publication.

\section{Risk of bias}

\begin{tabular}{lll}
\hline Bias & Authors' judgement & Support for judgement \\
\hline $\begin{array}{ll}\text { Random sequence genera- } \\
\text { tion (selection bias) }\end{array}$ & Low risk & $\begin{array}{l}\text { Randomisation stratified by site, with varying block sizes of four and six, via } \\
\text { the use of a randomisation envelope. Randomisation list generated by trial } \\
\text { statistician. Trial drug administered in sequential order according to the ran- } \\
\text { domisation list }\end{array}$ \\
& &
\end{tabular}


Ong 2012 (Continued)

$\begin{array}{ll}\begin{array}{l}\text { Allocation concealment } \\ \text { (selection bias) }\end{array} & \text { Low risk } \\ & \begin{array}{l}\text { Study drugs pre-prepared, in coded } 10 \mathrm{ml} \text { syringes with identical appearance, } \\ \text { by trial pharmacist, according to randomised list. Study drugs placed in the } \\ \text { randomisation envelopes and kept in ED. }\end{array}\end{array}$

\begin{tabular}{|c|c|c|}
\hline $\begin{array}{l}\text { Blinding of participants } \\
\text { and personnel (perfor- }\end{array}$ & Low risk & $\begin{array}{l}\text { All participants, assessors, and other personnel blinded except the pharmacist } \\
\text { and trial statistician. Patient unconscious at the time of event }\end{array}$ \\
\hline
\end{tabular}

mance bias)

All outcomes

\begin{tabular}{lll}
\hline $\begin{array}{l}\text { Blinding of outcome as- } \\
\text { sessment (detection bias) } \\
\text { All outcomes }\end{array}$ & Low risk & $\begin{array}{l}\text { "Unblinding was performed at the end of the trial when all participants com- } \\
\text { pleted follow-up." Patient unconscious at the time of event and not blinding } \\
\text { for hard outcome (death/survival) unlikely to be associated with risk of bias. }\end{array}$ \\
\hline $\begin{array}{l}\text { Incomplete outcome data } \\
\begin{array}{l}\text { (attrition bias) } \\
\text { All outcomes }\end{array}\end{array}$ & Low risk & $\begin{array}{l}\text { Three patients lost to follow-up after discharge -> 1 year follow-up data miss- } \\
\text { ing }\end{array}$ \\
\hline $\begin{array}{l}\text { Selective reporting (re- } \\
\text { porting bias) }\end{array}$ & Unclear risk & $\begin{array}{l}\text { Relevant outcomes reported - but not compared against a trial protocol/clini- } \\
\text { cal trial registry entry }\end{array}$ \\
\hline $\begin{array}{l}\text { Other bias } \\
\text { Unclear risk }\end{array}$ & $\begin{array}{l}\text { Cohort chart shows intention to treat analysis not stated, all patients account- } \\
\text { ed for. No post resuscitation care reported. }\end{array}$
\end{tabular}

\section{Patterson 2005}

Methods Multicentre, randomised study of out-of-hospital cardiopulmonary arrest

7 tertiary paediatric centre ED's, USA

May 1991 to October 1996

Participants Included: OHCA refractory to pre-hospital resuscitation efforts. Cardiopulmonary arrest classified as "medical" or "traumatic." Ages ranged from newborn to 22 years.

Excluded: - respiratory arrest alone (0 patients), responding to pre-hospital interventions before ED arrival ( 2 patients), "do not resuscitate" orders (0 patients), evidence of prolonged cessation of circulation, i.e. rigor mortis, dependent lividity, and core temperature less than $33 \mathrm{C}$ (not suffering from exposure or near drowning, 8 patients), arrested ED (7 patients).

Participants: 230 patients randomised, excluded 17 from analysis ( 8 patients were found to have rigor/dependent lividity, 2 patients presented to the emergency department with a perfusing rhythm, and 7 patients arrested in the emergency department) $=213$ patients included in analysis: (171 medical and 59 trauma)

86 patients received standard dose (59 medical and 27 trauma patients) and 127 patients received high dose (95 medical and 32 trauma patients)

Interventions

"Standard-dose $(0.01 \mathrm{mg} / \mathrm{kg})$ adrenaline vs high-dose $(0.1 \mathrm{mg} / \mathrm{kg}$ for the initial dose and $0.2 \mathrm{mg} / \mathrm{kg}$ for subsequent doses) adrenaline administered every 5 minutes until ROSC". Standard dose group eligible to have doses doubled for second and subsequent doses at physician's discretion. Adrenaline administered via an intravenous (IV) line, intraosseous (IO) line, or endotracheal (ET) tube (ET doses doubled).

Outcomes

Survived to hospital discharge, survived at least 24 hours, neurological outcome (Glasgow Outcome Scale), ROSC - ("return of a cardiac rhythm with a palpable pulse for greater than 20 minutes and admission" to ICU). Neurological outcomes were assessed using the Glasgow Outcome Scale at hospital discharge; scores not dichotomised into good/poor. No hospital length of stay reported. 
Patterson 2005 (Continued)

Notes
"All the hospitals participating in this study were served by emergency medical systems with advanced life support capabilities"

Ethics approval, not registered. Intention to treat analysis, sample size calculation. No missing data reported. Consort chart. Study stopped early because of changes in ethics requirement.

Funding: this study was supported in part by a grant from the Nation's Capital Affiliate of the American Heart Association.

\title{
Risk of bias
}

\begin{tabular}{lll}
\hline Bias & Authors' judgement & Support for judgement \\
\hline $\begin{array}{ll}\text { Random sequence genera- } \\
\text { tion (selection bias) }\end{array}$ & High risk & $\begin{array}{l}\text { "Randomization method varied by institution and by whether enrolment oc- } \\
\text { curred at the time of pre-hospital contact (2 centres) or arrival to ED (5 cen- } \\
\text { tres). Six centres randomised patients by using individual envelopes designat- } \\
\text { ing high or standard dosage that had been generated using a table of random } \\
\text { digits. One centre used an "acute medical record system" - patients whose } \\
\text { medical record number ended in an odd digit were assigned to the study } \\
\text { group, whereas patients with even medical record numbers were assigned to } \\
\text { the standard-dose group." }\end{array}$
\end{tabular}

\begin{tabular}{|c|c|c|}
\hline $\begin{array}{l}\text { Allocation concealment } \\
\text { (selection bias) }\end{array}$ & Unclear risk & opaque tamper proof envelopes \\
\hline $\begin{array}{l}\text { Blinding of participants } \\
\text { and personnel (perfor- } \\
\text { mance bias) } \\
\text { All outcomes }\end{array}$ & High risk & $\begin{array}{l}\text { Only blinded in } 2 / 7 \text { centres secondary to the technical difficulty in doing so. } \\
\text { Patients unconscious at the time of event. }\end{array}$ \\
\hline $\begin{array}{l}\text { Blinding of outcome as- } \\
\text { sessment (detection bias) } \\
\text { All outcomes }\end{array}$ & Unclear risk & Unknown \\
\hline $\begin{array}{l}\text { Incomplete outcome data } \\
\text { (attrition bias) } \\
\text { All outcomes }\end{array}$ & Low risk & All patients accounted for, excluded 17 from analysis. \\
\hline $\begin{array}{l}\text { Selective reporting (re- } \\
\text { porting bias) }\end{array}$ & Unclear risk & $\begin{array}{l}\text { Relevant outcomes reported - but not compared against a trial protocol/clini- } \\
\text { cal trial registry entry }\end{array}$ \\
\hline Other bias & Unclear risk & $\begin{array}{l}\text { Study stopped early secondary to implementation of new regulations on waiv- } \\
\text { er of informed consent. No post resuscitation care reported. }\end{array}$ \\
\hline
\end{tabular}

\section{Perkins 2018}

Multicenter, randomised, double-blind, placebo-controlled PARAMEDIC2 trial conducted by five Na-
tional Health Service ambulance services in the United Kingdom

Participants

\begin{abstract}
Included: 8,014 adult patients with out-of-hospital cardiac arrest in the United Kingdom for which advanced life support was provided by trial-trained paramedics.

Excluded: known or apparent pregnancy, age of less than 16 years, cardiac arrest from anaphylaxis or asthma, or the administration of epinephrine before the arrival of the trial-trained paramedic. Traumatic cardiac arrests were excluded in accordance with local protocols In one ambulance service.
\end{abstract}

Participants: parenteral epinephrine 4015, saline placebo 3999 
Perkins 2018 (Continued)

Interventions

Paramedics at five National Health Service ambulance services administered either parenteral epinephrine or saline placebo, along with standard care. Single doses of epinephrine or saline administered by an intravenous or intraosseous route every 3 to 5 minutes.

Outcomes day survival to hospital discharge, rate of survival until hospital discharge with a favourable neuro-
logic outcome, lengths of stay in the hospital (LOS) and in the intensive care unit (ICU), the rates of sur-
vival at hospital discharge and at 3 months, and the neurologic outcomes at hospital discharge and at 3
months, serious adverse events (death, hospitalisation, and disability), other adverse events.

Notes

Funding: funded by the U.K. National Institute for Health Research and others; Current Controlled Trials number, ISRCTN73485024.

\section{Risk of bias}

\begin{tabular}{lll}
\hline Bias & Authors' judgement & Support for judgement \\
\hline $\begin{array}{l}\text { Random sequence genera- } \\
\text { tion (selection bias) }\end{array}$ & Low risk & $\begin{array}{l}\text { The programming team at the Warwick Clinical Trials Unit provided randomi- } \\
\text { sation with concealed assignment. }\end{array}$ \\
\hline $\begin{array}{l}\text { Allocation concealment } \\
\text { (selection bias) }\end{array}$ & Low risk & $\begin{array}{l}\text { A randomisation sequence was computer-generated by the minimization } \\
\text { method with an overall assignment ratio of } 1: 1 .\end{array}$ \\
\hline $\begin{array}{l}\text { Blinding of participants } \\
\text { and personnel (perfor- } \\
\text { mance bias) }\end{array}$ & Low risk & $\begin{array}{l}\text { Concealed assignment: uniquely numbered but otherwise identical-appearing } \\
\text { trial packs contained } 10 \text { prefilled syringes, with each syringe containing either } \\
1 \text { mg of epinephrine or } 0.9 \% \text { saline. Concealed assignment of study drug and } \\
\text { placebo. }\end{array}$ \\
\hline
\end{tabular}

\begin{tabular}{|c|c|c|}
\hline $\begin{array}{l}\text { Blinding of outcome as- } \\
\text { sessment (detection bias) } \\
\text { All outcomes }\end{array}$ & Low risk & $\begin{array}{l}\text { Outcomes assessed by research paramedics, who were unaware of treatment } \\
\text { assignments. }\end{array}$ \\
\hline
\end{tabular}

\begin{tabular}{ll}
\hline Incomplete outcome data Low risk & Between the opening of the trial packs and administration of epinephrine or \\
(attrition bias) & placebo, 87 patients (1.1\%) were ineligible to participate in the trial. Anoth- \\
All outcomes & er 2 patients had unknown trial-group assignments because of missing tri- \\
al-pack numbers. Data for the primary outcome were available for 4012 pa- \\
tients $(99.9 \%)$ in the epinephrine group \\
and 3995 patients $(99.9 \%)$ in the placebo group.
\end{tabular}

\begin{tabular}{|c|c|c|}
\hline $\begin{array}{l}\text { Selective reporting (re- } \\
\text { porting bias) }\end{array}$ & Low risk & $\begin{array}{l}\text { Characteristics of patients well balanced at baseline, concurrent treatments } \\
\text { were similar.as were key intervals in providing service (e.g., between the emer- } \\
\text { gency call and ambulance arrival) between the two groups. The proportion of } \\
\text { patients who had a return of spontaneous circulation during the prehospital } \\
\text { resuscitation phase was higher in the epinephrine group than in the placebo } \\
\text { group }(36.3 \% \text { vs. } 11.7 \%) \text {, as was the proportion who were transported to the } \\
\text { hospital }(50.8 \% \text { vs. } 30.7 \%) \text {. }\end{array}$ \\
\hline
\end{tabular}

\begin{tabular}{ll}
\hline Other bias & $\begin{array}{l}\text { Prespecified subgroup analyses included the patient's age, cause of cardiac ar- } \\
\text { rest, initial cardiac rhythm, whether the cardiac arrest was witnessed, whether } \\
\text { CPR was performed by a bystander, interval between the emergency call } \\
\text { and ambulance arrival at the scene, interval between ambulance arrival and } \\
\text { the trial-agent administration, and the interval between the emergency call } \\
\text { and trial-agent administration. A P value for interaction was reported in each } \\
\text { analysis. }\end{array}$ \\
& $\begin{array}{l}\text { Post hoc sensitivity analyses (which incorporated best-case and worst-case } \\
\text { scenarios and multiple imputation) were conducted for survival at } 30 \text { days, } \\
\text { survival at hospital discharge, and survival with a good neurologic outcome at } \\
\text { discharge. No post resuscitation care reported. }\end{array}$
\end{tabular}


Perondi 2004

Methods
Childrens Institute Sao Paulo Brazil
31 October 1999 to 30 September 2001

Included: children who remained in cardiac arrest despite CPR and an initial, standard dose of adrena-
line (0.01 mg per kilogram)
Excluded: neonates, children with sustained trauma, those whose cardiac arrest had commenced out-
side the hospital, and those with do-not-resuscitate orders. Only initial cardiac arrest evaluated
Participants: of 185 cardiac arrests that occurred during the study period, 117 children met the exclu-
sion criteria (excluded 67 cases because of orders not to attempt resuscitation). Remaining 68 children
were included in the study - 34 children high dose and 34 children low dose adrenaline.

Interventions "High-dose adrenaline ( $0.1 \mathrm{mg}$ per kilogram of body weight) compared with standard-dose adrenaline (0.01 mg per kilogram) as rescue therapy for in-hospital cardiac arrest in children after failure of initial, standard dose of adrenaline". Administered intravenously.

\begin{tabular}{ll}
\hline Outcomes & Survived to hospital discharge, survived at least 24 hours, neurological outcome, ROSC (Any and sus- \\
tained $>20$ min). Neurological outcomes were assessed a 6 months after the discharge using the "pae- \\
diatric cerebral performance category'. No hospital length of stay reported.
\end{tabular}

Notes

Ethics approval, trial not registered, Utstein-style reporting guidelines used, sample size calculation, intention to treat analysis, no missing data supported, a priori sensitivity analyses. Consort chart. Protocol violations occurred in 18 cases. Not clear if the $\mathrm{N}=117$ cases were excluded before or after randomisation.

Apriori defined sub-group analysis of asphyxia-precipitated cardiac arrests

Low number of survivors. No post-arrest hypothermia or extracorporeal membrane oxygenation to any patients

Funding: not stated

\begin{tabular}{lll}
\hline Risk of bias & Authors' judgement & Support for judgement \\
\hline Bias & Low risk & $\begin{array}{l}\text { Randomization performed by single pharmacist using random-number gener- } \\
\text { ator. Treatment packages labelled with consecutive numbers provided by ran- } \\
\text { dom-number generator }\end{array}$ \\
\hline $\begin{array}{l}\text { Random sequence genera- } \\
\text { tion (selection bias) }\end{array}$ & $\begin{array}{l}\text { Pharmacist prepared treatment packages, each containing 10 1-ml vials of ep- } \\
\text { inephrine in a solution of } 1: 1000 \text { or } 1: 10,000, \text { labelled with consecutive num- } \\
\text { bers provided by random-number generator }\end{array}$ \\
$\begin{array}{l}\text { Allocation concealment } \\
\text { (selection bias) }\end{array}$ & Low risk & $\begin{array}{l}\text { Double blind, only pharmacist aware of concentrations. Patient unconscious } \\
\text { at the time of event. }\end{array}$ \\
\hline $\begin{array}{l}\text { Blinding of participants } \\
\text { and personnel (perfor- } \\
\text { mance bias) } \\
\text { All outcomes }\end{array}$ & Low risk & $\begin{array}{l}\text { Patient unconscious at the time of event and not blinding for hard outcome } \\
\text { (death/survival) unlikely to be associated with risk of bias. Uncertain as to } \\
\text { whether the assessor was aware of the allocation group for neurological out- } \\
\text { come. }\end{array}$ \\
\hline $\begin{array}{l}\text { Blinding of outcome as- } \\
\text { sessment (detection bias) } \\
\text { All outcomes }\end{array}$ & Low risk &
\end{tabular}


Perondi 2004 (Continued)

Incomplete outcome data Unclear risk Protocol violations occurred in 18 cases. Sensitivity analysis showed no differ(attrition bias) ence.

All outcomes

\begin{tabular}{lll}
$\begin{array}{l}\text { Selective reporting (re- } \\
\text { porting bias) }\end{array}$ & Unclear risk & $\begin{array}{l}\text { Relevant outcomes reported - but not compared against a trial protocol/clini- } \\
\text { cal trial registry entry }\end{array}$ \\
\hline Other bias & Unclear risk & $\begin{array}{l}\text { Intention-to-treat analysis; but funding source unclear. No post resuscitation } \\
\text { care reported. }\end{array}$
\end{tabular}

\section{Polglase 1994}

Methods Randomised, unblinded study OHCA

Georgia, USA

October 1990 to January 1992

\begin{tabular}{ll}
\hline Participants & Included: adult OHCA patients \\
& $\begin{array}{l}\text { Excluded: } 161 \text { OHCA patients 'reviewed' (randomised) - } 56 \text { patients with "irregularities in dosing or in- } \\
\text { complete documentation". Most exclusions given } 1 \mathrm{mg} \text { adrenaline. }\end{array}$ \\
& Participants: 105 (41 on $1 \mathrm{mg}$ dose, 30 on $5 \mathrm{mg}$ dose, 34 on $10 \mathrm{mg}$ dose) \\
\hline Interventions & $\begin{array}{l}1 \mathrm{mg} \text { adrenaline compared to } 5 \mathrm{mg} \text { and } 10 \mathrm{mg} \text { doses. } 1 \mathrm{mg} \text { prefilled syringe; "5 and } 10 \mathrm{mg} \text { doses drawn } \\
\text { from } 30 \mathrm{ml} \text { syringe". First and successive doses dictated by dose on card otherwise ACLS algorithm fol- } \\
\text { lowed }\end{array}$ \\
\hline Sutcomes & BP). No neurological outcome reported. No hospital length of stay reported. \\
\hline Notes & $\begin{array}{l}\text { Suburban and rural Emergency Medical Service. Study stopped for futility (no survivors to hospital dis- } \\
\text { charge) }\end{array}$ \\
Research 'Letter to Editor'. Ethics approval, trial not registered, no sample size calculation, intention to \\
treat analysis not reported. No missing data reported. No consort diagram. No survivors among exclud- \\
ed cases \\
Funding: not stated
\end{tabular}

\section{Risk of bias}

\begin{tabular}{lll}
\hline Bias & Authors' judgement & Support for judgement \\
\hline $\begin{array}{l}\text { Random sequence genera- } \\
\text { tion (selection bias) }\end{array}$ & Unclear risk & $\begin{array}{l}\text { "Index cards containing assigned doses of 1mg, 5mg and 10mg doses adrena- } \\
\text { line randomised (method not stated) and placed in paramedic drug boxes" }\end{array}$ \\
\hline $\begin{array}{l}\text { Allocation concealment } \\
\text { (selection bias) }\end{array}$ & High risk & Probably not - since paramedics could have altered the dose given \\
\hline $\begin{array}{l}\text { Blinding of participants } \\
\begin{array}{l}\text { and personnel (perfor- } \\
\text { mance bias) }\end{array}\end{array}$ & High risk & \\
\begin{tabular}{l} 
All outcomes \\
\hline
\end{tabular} & $\begin{array}{l}\text { Unblinded study - EMS staff knew which study drug they were using. Patient } \\
\text { unconscious at the time of event. }\end{array}$ \\
\hline
\end{tabular}


Polglase 1994 (Continued)

Blinding of outcome as- Unclear risk Unblinded study - but patient unconscious at the time of event and not blindsessment (detection bias)

All outcomes ing for hard outcome (death/survival) unlikely to be associated with risk of bias.

\begin{tabular}{lll}
$\begin{array}{l}\text { Incomplete outcome data } \\
\text { (attrition bias) } \\
\text { All outcomes }\end{array}$ & High risk & $\begin{array}{l}56 \text { patients (35\%) with "irregularities in dosing or incomplete documentation". } \\
\text { Most exclusions given 1mg adrenaline, no survivors }\end{array}$ \\
\hline $\begin{array}{l}\text { Selective reporting (re- } \\
\text { porting bias) }\end{array}$ & Unclear risk & $\begin{array}{l}\text { Relevant outcomes reported - but not compared against a trial protocol/clini- } \\
\text { cal trial registry entry }\end{array}$ \\
\hline $\begin{array}{l}\text { Other bias } \\
\text { Unclear risk }\end{array}$ & $\begin{array}{l}\text { Intention to treat analysis not reported. Exclusions based on "irregularities in } \\
\text { dosing" suggests a 'per-protocol' analysis; funding source unclear. No post re- } \\
\text { suscitation care reported. }\end{array}$
\end{tabular}

Sanchez-Mendiola 1998

\begin{tabular}{|c|c|}
\hline Methods & $\begin{array}{l}\text { Randomized, unblinded, controlled trial } \\
\text { Mexico }\end{array}$ \\
\hline Participants & $\begin{array}{l}\text { Included: paediatric patients hospitalised in the Paediatric Intensive Care Unit that developed asystole } \\
\text { during their hospital stay } \\
\text { Participants: } 36 \text { patients randomised and included in the analysis ( } 16 \text { received standard-dose adrena- } \\
\text { line and } 20 \text { high-dose adrenaline) }\end{array}$ \\
\hline Interventions & $\begin{array}{l}\text { Randomized to receive first adrenaline high-dose }(0.1 \mathrm{mg} / \mathrm{kg}) \text { or standard-dose adrenaline }(0.01 \mathrm{mg} / \\
\mathrm{kg}) \text {, with subsequent doses using the high dose, "as per the American Heart Association (AHA) and } \\
\text { American Academy of Pediatrics (AAP) guidelines" (at the time). }\end{array}$ \\
\hline Outcomes & $\begin{array}{l}\text { ROSC, survival to hospital discharge, neurologic outcome (method for assessing not stated- just 'neuro- } \\
\text { logic damage'). No hospital length of stay reported. }\end{array}$ \\
\hline Notes & $\begin{array}{l}\text { Conference abstract. Ethics not reported, not registered, no dates when study conducted, no duration } \\
\text { of study, no sample size calculation, ITT not stated. No consort chart. No missing data reported. Used } \\
\text { high dose adrenaline for subsequent doses for both groups } \\
\text { Funding: not stated }\end{array}$ \\
\hline
\end{tabular}

\section{Risk of bias}

\begin{tabular}{lll}
\hline Bias & Authors' judgement & Support for judgement \\
\hline $\begin{array}{l}\text { Random sequence genera- } \\
\text { tion (selection bias) }\end{array}$ & Unclear risk & Randomisation process not described but "randomised" stated \\
\hline $\begin{array}{l}\text { Allocation concealment } \\
\text { (selection bias) }\end{array}$ & High risk & Not reported - likely to be high risk \\
\hline $\begin{array}{l}\text { Blinding of participants } \\
\text { and personnel (perfor- } \\
\text { mance bias) } \\
\begin{array}{l}\text { All outcomes } \\
\hline\end{array}\end{array}$ & High risk & Caregivers not blinded to drug dose administered. \\
\hline
\end{tabular}


Sanchez-Mendiola 1998 (Continued)
Blinding of outcome as- Unclear risk
Not reported - unclear risk but patient unconscious at the time of event and sessment (detection bias) not blinding for hard outcome (death/survival) unlikely to be associated with All outcomes risk of bias.

\begin{tabular}{lll}
\hline $\begin{array}{l}\text { Incomplete outcome data } \\
\text { (attrition bias) } \\
\text { All outcomes }\end{array}$ & Low risk & Intention to treat analysis not stated but all cases accounted for \\
\hline $\begin{array}{l}\text { Selective reporting (re- } \\
\text { porting bias) }\end{array}$ & Unclear risk & $\begin{array}{l}\text { Relevant outcomes reported - but not compared against a trial protocol/clini- } \\
\text { cal trial registry entry }\end{array}$ \\
\hline Other bias & High risk & $\begin{array}{l}\text { Funding source unclear; Insufficient details (conference abstract) to assess } \\
\text { other potential sources of bias. } \\
\text { Overall high risk of bias. No post resuscitation care reported. }\end{array}$ \\
\hline
\end{tabular}

\section{Schmidbauer 2000}

\begin{tabular}{ll}
\hline Methods & RCT OHCA \\
& Three years \\
& Munich, Germany \\
\hline Participants & Selection criteria not reported but "out of hospital cardiac arrest" stated in title \\
& Participants: 57 patients analysed (32 standard dose adrenaline and 25 high-dose adrenaline) \\
\hline Interventions & $\begin{array}{l}\text { Initial dose of } 2.5 \text { mg adrenaline vs initial } 5 \text { mg high-dose adrenaline both via endobronchial route (un- } \\
\text { clear if other doses administered) }\end{array}$ \\
\hline Outcomes & ROSC. No neurological outcome reported. No hospital length of stay reported. \\
\hline Notes & $\begin{array}{l}\text { Research letter. Ethics not reported, trial not registered, no dates when study conducted, no sample } \\
\text { size calculation, intention to treat analysis not stated, no consort diagram, no missing data reported - } \\
\text { no details re the number randomised } \\
\text { Funding: not stated }\end{array}$
\end{tabular}

\section{Risk of bias}

\begin{tabular}{lll}
\hline Bias & Authors' judgement & Support for judgement \\
\hline $\begin{array}{l}\text { Random sequence genera- } \\
\text { tion (selection bias) }\end{array}$ & Unclear risk & $\begin{array}{l}\text { No details of randomisation process - simply states "controlled prospective } \\
\text { randomised study" }\end{array}$ \\
\hline $\begin{array}{l}\text { Allocation concealment } \\
\text { (selection bias) }\end{array}$ & Unclear risk & No description \\
\hline $\begin{array}{l}\text { Blinding of participants } \\
\text { and personnel (perfor- } \\
\text { mance bias) } \\
\text { All outcomes }\end{array}$ & Unclear risk & No mention of blinding. Patient unconscious at the time of event. \\
\hline
\end{tabular}


Schmidbauer 2000 (Continued)

Blinding of outcome as- Unclear risk No mention of blinding. Patient unconscious at the time of event and not sessment (detection bias) blinding for hard outcome (death/survival) unlikely to be associated with risk All outcomes of bias.

\begin{tabular}{lll}
$\begin{array}{l}\text { Incomplete outcome data } \\
\text { (attrition bias) } \\
\text { All outcomes }\end{array}$ & Unclear risk & Only results for 57 patients reported - over three yea \\
\hline $\begin{array}{l}\text { Selective reporting (re- } \\
\text { porting bias) }\end{array}$ & High risk & Only ROSC reported for VF and Asystole patients
\end{tabular}

Other bias Unclear risk Funding source unclear; Insufficient details to assess other potential sources of bias. No post resuscitation care reported.

Overall high risk of bias

\section{Sherman 1997}

Methods $\quad$ Prospective, multicenter, blinded, controlled trial
8 USA academic centre emergency departments

1 year

\section{Participants}

Included: atraumatic, non-hypothermic out of hospital cardiac arrest, who experienced VF or asystole. and received at least one standard dose of adrenaline 0.5 to $1.0 \mathrm{mg}$.

Excluded: less than 18 years of age, solid organ transplant recipients, not considered candidates for full cardiopulmonary resuscitation, suspected of being pregnant, did not have venous access, or had already received high-dose adrenaline or intravenous a-agonist therapy during resuscitation.

Particpants: patients who received study drug but who did not meet entrance criteria, as determined by the blinded investigator, were excluded from data analysis. Two patients were excluded due to inadequate data collection. 140 patients in analysis: 78 received high-dose adrenaline and 62 received standard-dose adrenaline dard-dose adrenaline failed to resuscitate patients in with asystole or VF. "Study drug administered through peripheral, antecubital, or central venous route by high flow-rate infusion every 5 minutes but not endotracheal administration". "Up to 4 doses of the drug allowed". "If the resuscitation attempt continued, further adrenaline administered at discretion of primary physician". Potency of drugs tested every 6 months.

\section{Outcomes}

Discharged from hospital, neurologic outcome, ROSC ("presence of organised cardiac rhythm and palpable pulse at any time during resuscitation"), improvement in cardiac rhythm. It was planned to evaluate neurologic outcomes using the Glasgow Coma Scale however, there were no survivors to hospital discharge. Hospital length of sty was reported - but there were no patients who survived to hospital discharge.

\section{Notes}

$$
\begin{aligned}
& \text { "Cardiopulmonary resuscitation provided by paramedics and emergency medical technicians, guided } \\
& \text { by standard ACLS protocol". } \\
& \text { Ethics approval, not registered, sample size calculation performed. ITT not stated - patients who re- } \\
& \text { ceived study drug but did not meet entrance requirement excluded from data analysis. } \\
& \text { Enrollment discontinued before reaching target goal of } 354 \text { patients - geographic relocation of investi- } \\
& \text { gators, concerns re deferred consent, intercurrent results of recent trials, similar trials. No consort dia- } \\
& \text { gram. No missing data reported }
\end{aligned}
$$




\section{Risk of bias}

\begin{tabular}{|c|c|c|}
\hline Bias & Authors' judgement & Support for judgement \\
\hline $\begin{array}{l}\text { Random sequence genera- } \\
\text { tion (selection bias) }\end{array}$ & Low risk & Computer generated randomisation \\
\hline $\begin{array}{l}\text { Allocation concealment } \\
\text { (selection bias) }\end{array}$ & Low risk & $\begin{array}{l}\text { Adrenaline "prepackaged in dilutions of either } 0.1 \mathrm{mg} / \mathrm{ml}(1: 10,000) \text { or } 1 \mathrm{mg} / \\
\mathrm{ml}(1: 1000) \text { in } 12-\mathrm{ml} \text {, otherwise identical, blinded vials". Numbered sequentially }\end{array}$ \\
\hline $\begin{array}{l}\text { Blinding of participants } \\
\text { and personnel (perfor- } \\
\text { mance bias) } \\
\text { All outcomes }\end{array}$ & Low risk & "Blinded" but who not stated.Patient unconscious at the time of event. \\
\hline $\begin{array}{l}\text { Blinding of outcome as- } \\
\text { sessment (detection bias) } \\
\text { All outcomes }\end{array}$ & Low risk & $\begin{array}{l}\text { Patient unconscious at the time of event and not blinding for hard outcome } \\
\text { (death/survival) unlikely to be associated with risk of bias. }\end{array}$ \\
\hline $\begin{array}{l}\text { Incomplete outcome data } \\
\text { (attrition bias) } \\
\text { All outcomes }\end{array}$ & Low risk & Two patients (1.4\%) were excluded due to inadequate data collection. \\
\hline $\begin{array}{l}\text { Selective reporting (re- } \\
\text { porting bias) }\end{array}$ & Unclear risk & $\begin{array}{l}\text { Relevant outcomes reported - but not compared against a trial protocol/clini- } \\
\text { cal trial registry entry }\end{array}$ \\
\hline Other bias & High risk & $\begin{array}{l}\text { Intention to treat analysis not stated. "Enrollment discontinued before reach- } \\
\text { ing target goal secondary to geographic movement of investigators, concerns } \\
\text { regarding use of deferred consent, and intercurrent results of other recent, } \\
\text { similar trials"; Role of industry funder unclear. No post resuscitation care re- } \\
\text { ported. }\end{array}$ \\
\hline
\end{tabular}

\section{Stiell 1992}

\begin{tabular}{ll}
\hline Methods & Triple blinded RCT in or out of hospital cardiac arrest \\
& 2 tertiary hospitals Ottawa Canada \\
& 18 December 1989 to 8 January 1992
\end{tabular}

\section{Participants}

Included: "Patients treated for cardiac arrest (in or out of hospital), required epinephrine, if collapsed outside the hospital and no advanced-life-support measures other than defibrillation before reaching the hospital"

Excluded: "<16 years of age, had a terminal illness, had not been given CPR for more than 15 minutes, trauma, second cardiac arrest during same hospital admission or were in operating theatre or recovery room"

Participants: 788 patients of whom 138 excluded (72 ineligible and not randomised, 66 patients after randomisation $=650$ patients: 317 patients high-dose group and 333 patients standard-dose group analysed - no further loss to follow-up 
Stiell 1992 (Continued)

33 patients (14 standard-dose adrenaline and 19 high-dose adrenaline) given medication but ineligible for study (16 trauma patients, 9 terminal illness, 3 second arrest during hospitalisation, 2 more than 15 minutes without CPR, 2 respiratory arrest, $1<16$ years

Interventions

Administered up to five doses of high-dose $(7 \mathrm{mg})$ or standard-dose $(1 \mathrm{mg})$ adrenaline at five-minute intervals according to standard protocols for advanced cardiac life support. If physicians wanted to administer more than 5 doses adrenaline $1 \mathrm{mg}$ given. Drugs administered IV (peripheral or central venous catheter) or occasionally endobronchial but not in the pre-hospital setting.

Outcomes

Survived until hospital discharge, neurological outcome, successful resuscitation (return of pulse and blood pressure for at least 1 hour), any ROSC. Neurological outcomes were assessed using CPC at hospital discharge: ('1' considered 'good'); and mini-mental examination scores. No hospital length of stay reported.

Notes Emergency medical service used EMT who provided BLS but did not intubate patients or administer IV drugs.

Ethics approval, trial not registered, independent data-monitoring committee. Interim analysis performed, 125 patients in each arm. Sample size calculation not done, ITT analysis not stated. No consort diagram. Missing data reported.

Funding: supported by a grant (03089R) from the Emergency Health Services Branch of the Ontario Ministry of Health. Dr. Stiell is a Career Scientist of the Health Research Personnel Development Program of the Ontario Ministry of Health.

\section{Risk of bias}

\begin{tabular}{lll}
\hline Bias & Authors' judgement & Support for judgement \\
\hline $\begin{array}{l}\text { Random sequence genera- } \\
\text { tion (selection bias) }\end{array}$ & Low risk & $\begin{array}{l}\text { Each hospital provided central randomisation schedule but order of use of the } \\
\text { packages which depended by chance on the location of each cardiac arrest }\end{array}$ \\
\hline $\begin{array}{l}\text { Allocation concealment } \\
\text { (selection bias) }\end{array}$ & Low risk & $\begin{array}{l}\text { Study drugs prepared by pharmacy, packages of } 5 \text { coded and pre-loaded sy- } \\
\text { ringes, located at } 61 \text { sites in the two hospitals. "The order of use of packages } \\
\text { depended on location of each cardiac arrest" }\end{array}$ \\
\hline
\end{tabular}

\begin{tabular}{|c|c|c|}
\hline $\begin{array}{l}\text { Blinding of participants } \\
\text { and personnel (perfor- }\end{array}$ & Low risk & $\begin{array}{l}\text { Pre-loaded syringes - assume EMS staff blinded to treatment allocation. Pa- } \\
\text { tient unconscious at the time of event. }\end{array}$ \\
\hline
\end{tabular}

mance bias)

All outcomes

\begin{tabular}{lll}
\hline $\begin{array}{l}\text { Blinding of outcome as- } \\
\begin{array}{l}\text { sessment (detection bias) } \\
\text { All outcomes }\end{array}\end{array}$ & Low risk & $\begin{array}{l}\text { "All assessments were made in a double blind manner". Patient unconscious } \\
\text { at the time of event and not blinding for hard outcome (death/survival) unlike- } \\
\text { ly to be associated with risk of bias. }\end{array}$ \\
\hline $\begin{array}{l}\text { Incomplete outcome data } \\
\begin{array}{l}\text { (attrition bias) } \\
\text { All outcomes }\end{array}\end{array}$ & Low risk & $\begin{array}{l}66 \text { patients (9\%) excluded post randomisation (21 eligible but did not receive } \\
\text { study drug, 33 received study drug but not eligible,12 patients received study } \\
\text { drug inappropriately). No patients lost to follow-up }\end{array}$
\end{tabular}

\begin{tabular}{lll}
\hline $\begin{array}{l}\text { Selective reporting (re- } \\
\text { porting bias) }\end{array}$ & Unclear risk & $\begin{array}{l}\text { Relevant outcomes reported - but not compared against a trial protocol/clini- } \\
\text { cal trial registry entry }\end{array}$ \\
\hline Other bias & Unclear risk & $\begin{array}{l}\text { Sensitivity analysis undertaken including the 33 patients (14 standard dose } \\
\text { group and } 19 \text { high dose group) who received the study drug but were declared } \\
\text { ineligible, no difference in results. No post resuscitation care reported. }\end{array}$ \\
\hline
\end{tabular}


Stiell 2001

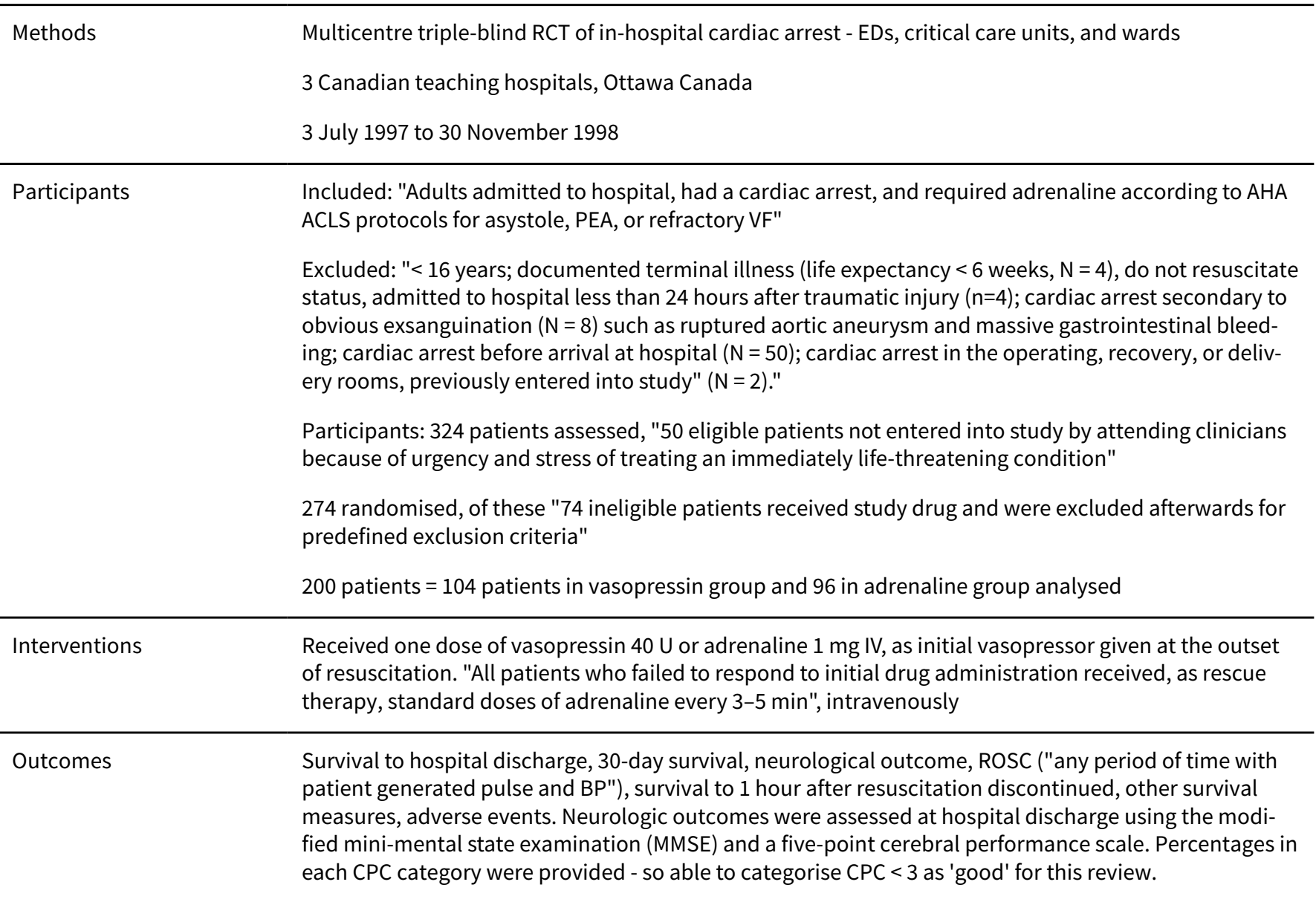

Notes

Ethics approval, not registered, sample size calculation but not powered to detect clinically meaningful differences, adjudication committee, Intention to treat analysis. No loss to follow-up. Potency of study drugs tested at two months storage

Funding: the work was funded by a peer-reviewed grant from the Heart and Stroke Foundation of Canada. Ferring, Canada, provided the vasopressin.

\section{Risk of bias}

Bias Authors' judgement Support for judgement

Random sequence genera- Low risk tion (selection bias)

Computer-generated randomisation. "Study drugs randomly distributed to all cardiac arrest carts in all designated study areas. Distribution of study drugs on the cardiac arrest carts done by consecutive allocation from a computer-generated random listing stratified by centre and prepared by the data coordinating centre. Once opened, entire cardiac arrest box returned to hospital pharmacy and another study box released in appropriate sequence according to randomisation schedule"

$\begin{array}{ll}\begin{array}{l}\text { Allocation concealment } \\ \text { (selection bias) }\end{array} & \text { Low risk } \\ & \begin{array}{l}\text { "All drugs prepared by Ottawa Hospital pharmacy in identical preloaded } 10 \mathrm{~mL} \\ \text { syringes. Study syringes packaged in special cardiac-arrest trays and boxes at } \\ \text { multiple sites throughout study hospitals" }\end{array}\end{array}$

Blinding of participants Low risk Paper states "Triple blind". Patient unconscious at the time of event.
and personnel (perfor-
mance bias)
All outcomes


Stiell 2001 (Continued)

Blinding of outcome as- Low risk Assessors blinded for primary outcome (ROSC at 1 hour). Unclear for discharge sessment (detection bias) from hospital and other secondary outcomes. Patient unconscious at the time All outcomes of event and not blinding for hard outcome (death/survival) unlikely to be associated with risk of bias. Uncertain as to whether the assessor was aware of the allocation group for neurological outcome.

Incomplete outcome data Low risk All excluded cases accounted for, no loss to follow-up
(attrition bias)
All outcomes

\begin{tabular}{lll}
\hline $\begin{array}{l}\text { Selective reporting (re- } \\
\text { porting bias) }\end{array}$ & Unclear risk & $\begin{array}{l}\text { Primary and secondary outcomes defined a priori reported. Relevant out- } \\
\text { comes reported - but not compared against a trial protocol/clinical trial reg- } \\
\text { istry entry }\end{array}$ \\
\hline Other bias & Unclear risk & $\begin{array}{l}\text { Intention to treat analysis not stated. "74 ineligible patients received study } \\
\text { drug and were excluded afterwards for predefined exclusion criteria". No post } \\
\text { resuscitation care reported. }\end{array}$ \\
\hline
\end{tabular}

Wenzel 2004

Dethods
$\begin{aligned} & 33 \text { communities and involved } 44 \text { physician-staffed emergency medical service units in Austria, Ger- } \\ & \text { many, and Switzerland }\end{aligned}$

June 1999 to March 2002

Participants

Included: Adult patients who had an out-of-hospital cardiac arrest and presented with ventricular fibrillation, PEA or asystole requiring CPR with vasopressor therapy. Patients who presented with pulseless electrical activity or asystole underwent randomisation immediately; patients with VF underwent randomisation after first three attempts at defibrillation had failed

Excluded: successful defibrillation without administration of a vasopressor, documented terminal illness, lack of IV access, hemorrhagic shock, pregnancy, cardiac arrest after trauma, age less than 18 years, and presence of a do-not-resuscitate order

Participants: 5967 screened, 4748 ineligible, 1219 patients underwent randomisation; 33 were excluded because of missing study-drug codes. Among remaining 1186 patients, 589 vasopressin and 597 adrenaline were analysed

Interventions

Box containing the study drugs - either two ampoules of $1 \mathrm{mg}$ of adrenaline or two ampoules of $40 \mathrm{IU}$ of vasopressin opened and either $1 \mathrm{mg}$ of adrenaline or $40 \mathrm{IU}$ of vasopressin injected intravenously. If spontaneous circulation not restored within three minutes after first injection of study drug, same drug at same dose injected again. If spontaneous circulation not restored, patient given additional injection of adrenaline at discretion of treating emergency physician. All drugs followed by $20 \mathrm{mls}$ normal saline

Outcomes Survival to hospital discharge, survival to hospital admission, neurological outcome, ROSC (not defined). Neurological outcomes were assessed using CPC at hospital discharge. Percentages in each CPC category were provided - so able to categorise CPC $<3$ as 'good' for this review. No hospital length of stay reported.

Notes

Emergency Medical Service - "44 physician-staffed emergency medical service units"

Ethics approval, trial not registered, data and safety monitoring committee, sample size calculation, intention-to-treat analysis. Consort flow diagram provided. Missing data reported. Internal, blinded administrative interim analysis performed. Funding ended December 2001, therefore enrolment stopped in March 2002 
Wenzel 2004 (Continued)

Funding: supported in part by a Founders Grant for Training in Clinical Critical Care Research, Society of Critical Care Medicine, Des Plaines, Ill.; by Science Funds No. 7280 of the Austrian National Bank, Vienna, Austria; by the Dean's Office of the Leopold-Franzens University College of Medicine, Innsbruck, Austria; by the Laerdal Foundation for Acute Medicine, Stavanger, Norway; by an Austrian Science Foundation grant (P-14169-MED), Vienna, Austria; by Pfizer, Karlsruhe, Germany; by the Science Foundation of the Tyrolean State Hospitals, Innsbruck, Austria; and by the Department of Anesthesiology and Critical Care Medicine, Leopold-Franzens University, Innsbruck, Austria.

\section{Risk of bias}

\begin{tabular}{|c|c|c|}
\hline Bias & Authors' judgement & Support for judgement \\
\hline $\begin{array}{l}\text { Random sequence genera- } \\
\text { tion (selection bias) }\end{array}$ & Low risk & Randomly generated (? how) blocks of 10 stratified by Centre \\
\hline $\begin{array}{l}\text { Allocation concealment } \\
\text { (selection bias) }\end{array}$ & Low risk & $\begin{array}{l}\text { Not explicitly stated whether each ambulance has more than one box of study } \\
\text { drugs to select from - albeit study ampoules identical in appearance }\end{array}$ \\
\hline $\begin{array}{l}\text { Blinding of participants } \\
\text { and personnel (perfor- } \\
\text { mance bias) } \\
\text { All outcomes }\end{array}$ & Low risk & $\begin{array}{l}\text { EMS staff and study investigators blinded to study treatment. Patient uncon- } \\
\text { scious at the time of event. }\end{array}$ \\
\hline $\begin{array}{l}\text { Blinding of outcome as- } \\
\text { sessment (detection bias) } \\
\text { All outcomes }\end{array}$ & Low risk & $\begin{array}{l}\text { Patient unconscious at the time of event and not blinding for hard outcome } \\
\text { (death/survival) unlikely to be associated with risk of bias. Uncertain as to } \\
\text { whether the assessor was aware of the allocation group for neurological out- } \\
\text { come. }\end{array}$ \\
\hline $\begin{array}{l}\text { Incomplete outcome data } \\
\text { (attrition bias) } \\
\text { All outcomes }\end{array}$ & Low risk & $\begin{array}{l}11 \text { patients in the vasopressin group (1.9\%) and } 9 \text { in the epinephrine group } \\
(1.5 \%) \text { lost to follow-up before hospital discharge. } \\
11 \text { patients (19.3\%) in the vasopressin group and } 12 \text { patients ( } 20.7 \%) \text { in adren- } \\
\text { aline group who survived to hospital discharge lost to follow-up for neurologi- } \\
\text { cal outcome. }\end{array}$ \\
\hline $\begin{array}{l}\text { Selective reporting (re- } \\
\text { porting bias) }\end{array}$ & Unclear risk & $\begin{array}{l}\text { Relevant outcomes reported - but not compared against a trial protocol/clini- } \\
\text { cal trial registry entry }\end{array}$ \\
\hline Other bias & Unclear risk & $\begin{array}{l}\text { Intention-to-treat analysis; but role of industry funder unclear. No post resus- } \\
\text { citation care reported. }\end{array}$ \\
\hline
\end{tabular}

Woodhouse 1995

Methods Placebo controlled, randomised trial

Brisbane Australia

July 1989 to December 1992

Participants Included: In-hospital and out-of-hospital arrests (45\%), primary cardiac arrest only

Excluded: "Secondary causes were suspected as per the Utstein style"

Participants: 406 patients treated - 53 excluded; "10 for protocol violations, 7 had inadequate records and 36 terminated prematurely (cancers, severe multiple organ disease, extreme old age)"

353 eligible patients, 14 patients (16 episodes) did not receive study drug and were excluded 
Woodhouse 1995 (Continued)

339 patients but 145 received open-label $1 \mathrm{mg}$ adrenaline instead of placebo (analysed separately)

194 patients recruited to study, 94 high-dose adrenaline and 100 placebo (saline) analysed

$\begin{array}{ll}\text { Interventions } & \text { High dose }(10 \mathrm{mg} \text { ) adrenaline vs. placebo (saline), two doses only. Two defibrillations (not three) before } \\ & \text { randomisation for VF patients. "Once patient given both ampoules, open label 1mg adrenaline could be } \\ \text { administered" }\end{array}$
administered"

Outcomes Survival at hospital discharge, immediate survival (stable cardiac rhythm with palpable pulse at time
cardiac arrest team left). No neurological outcome reported. No hospital length of stay reported.

Notes $\quad$ Ethics approval, trial not registered, sample size calculation, ITT analysis not described, no Consort chart. "Study undertaken in a general hospital with cardiac arrests supervised by numerous middle-level medical staff unhappy to use the placebo". Missing data not reported.

Funding: Astra Pharmaceuticals (Sydney) was responsible for the manufacture and packaging of the trial material.

\section{Risk of bias}

\begin{tabular}{|c|c|c|}
\hline Bias & Authors' judgement & Support for judgement \\
\hline $\begin{array}{l}\text { Random sequence genera- } \\
\text { tion (selection bias) }\end{array}$ & Unclear risk & $\begin{array}{l}\text { Randomisation method not described but it is stated "randomised into the tri- } \\
\text { al" }\end{array}$ \\
\hline $\begin{array}{l}\text { Allocation concealment } \\
\text { (selection bias) }\end{array}$ & Low risk & $\begin{array}{l}\text { Blinded, randomised box containing two } 10 \mathrm{ml} \text { ampoules, either } 10 \mathrm{mg} \text { adrena- } \\
\text { line or saline }\end{array}$ \\
\hline $\begin{array}{l}\text { Blinding of participants } \\
\text { and personnel (perfor- } \\
\text { mance bias) } \\
\text { All outcomes }\end{array}$ & Low risk & $\begin{array}{l}\text { Clinical staff blinded to study treatment. Patient unconscious at the time of } \\
\text { event. }\end{array}$ \\
\hline $\begin{array}{l}\text { Blinding of outcome as- } \\
\text { sessment (detection bias) } \\
\text { All outcomes }\end{array}$ & Low risk & $\begin{array}{l}\text { Yes - data sheet sent to central area where" where the data was validated, in a } \\
\text { blinded fashion". Patient unconscious at the time of event and not blinding for } \\
\text { hard outcome (death/survival) unlikely to be associated with risk of bias. }\end{array}$ \\
\hline $\begin{array}{l}\text { Incomplete outcome data } \\
\text { (attrition bias) } \\
\text { All outcomes }\end{array}$ & High risk & $\begin{array}{l}\text { Excluded } 10 \text { patients for protocol violations, } 7 \text { for inadequate records } \\
145 \text { patients received open-label } 1 \mathrm{mg} \text { adrenaline instead of study drug }\end{array}$ \\
\hline $\begin{array}{l}\text { Selective reporting (re- } \\
\text { porting bias) }\end{array}$ & Unclear risk & $\begin{array}{l}\text { Relevant outcomes reported - but not compared against a trial protocol/clini- } \\
\text { cal trial registry entry }\end{array}$ \\
\hline Other bias & High risk & $\begin{array}{l}\text { "Supervising physicians gave significant preference for males, patients with } \\
\text { no previous cardiac history and without multiple organ disease to be given } \\
\text { open } 1 \mathrm{mg} \text { adrenaline." Patients in asystole "preferentially placed in the trial } \\
\text { group" (114 (69\%) vs. } 170(88 \%)) \text { and patients in ventricular fibrillation "pref- } \\
\text { erentially given open } 1 \mathrm{mg} \text { adrenaline" ( } 31(21 \%) \text { vs. } 24(12 \%) \text { P < } 0.03) \text {; Role of } \\
\text { industry funder unclear }\end{array}$ \\
\hline
\end{tabular}

$\begin{array}{ll}\text { Methods } & \text { Randomised trial, single centre } \\ \text { Chinese university hospital }\end{array}$


Zhu 2000 (Continued)

\begin{tabular}{ll} 
Participants & 66 patients with cardiac arrest recruited in ED \\
\hline Interventions & $\begin{array}{l}\text { Control (group A) } 1 \mathrm{mg} \text { adrenaline } 5 \text { minutely; experimental (group B) } 2 \text { mg adrenaline } 3 \text { minutely; } \\
\text { graded dosage (group C) initial dose } 1 \mathrm{mg} \text { adrenaline, progressively increased dosage } 2 \mathrm{mg} \text { adrenaline } \\
3 \text { minutely }\end{array}$ \\
\hline Outcomes & $\begin{array}{l}\text { ROSC ("spontaneous circulation restoration"), survival to hospital discharge, neurological outcome } \\
\text { (method of assessment unclear). No hospital length of stay reported. }\end{array}$ \\
\hline Notes & $\begin{array}{l}\text { Chinese paper translated into English by independent researcher. No description of EMS or when study } \\
\text { conducted }\end{array}$ \\
& $\begin{array}{l}\text { No ethics approval stated, registration of study not stated, no consort diagram, intention to treat analy- } \\
\text { sis not stated }\end{array}$ \\
& Funding: not known
\end{tabular}

\section{Risk of bias}

\begin{tabular}{|c|c|c|}
\hline Bias & Authors' judgement & Support for judgement \\
\hline $\begin{array}{l}\text { Random sequence genera- } \\
\text { tion (selection bias) }\end{array}$ & Unclear risk & Randomisation not described but it is stated "randomised into the trial" \\
\hline $\begin{array}{l}\text { Allocation concealment } \\
\text { (selection bias) }\end{array}$ & Unclear risk & Not reported \\
\hline $\begin{array}{l}\text { Blinding of participants } \\
\text { and personnel (perfor- } \\
\text { mance bias) } \\
\text { All outcomes }\end{array}$ & Unclear risk & Not reported. Patient unconscious at the time of event. \\
\hline $\begin{array}{l}\text { Blinding of outcome as- } \\
\text { sessment (detection bias) } \\
\text { All outcomes }\end{array}$ & Unclear risk & $\begin{array}{l}\text { Not reported. Patient unconscious at the time of event and not blinding for } \\
\text { hard outcome (death/survival) unlikely to be associated with risk of bias. Un- } \\
\text { certain as to whether the assessor was aware of the allocation group for neu- } \\
\text { rological outcome. }\end{array}$ \\
\hline $\begin{array}{l}\text { Incomplete outcome data } \\
\text { (attrition bias) } \\
\text { All outcomes }\end{array}$ & Low risk & Complete, 66 patients \\
\hline $\begin{array}{l}\text { Selective reporting (re- } \\
\text { porting bias) }\end{array}$ & Unclear risk & $\begin{array}{l}\text { Relevant outcomes reported - but not compared against a trial protocol/clini- } \\
\text { cal trial registry entry }\end{array}$ \\
\hline Other bias & Unclear risk & $\begin{array}{l}\text { Reported that there were no difference in baseline characteristics of groups } \\
\text { (age, gender, aetiology cardiac arrest time), data not shown. No description } \\
\text { of rhythm of cardiac arrest. No intention to treat analysis stated but all } 66 \text { pa- } \\
\text { tients included in the analysis. Funding source not stated. No post resuscita- } \\
\text { tion care reported. }\end{array}$ \\
\hline
\end{tabular}

ACLS - advanced cardiac life support

AHA - American Heart Association

BLS - basic life support

BP - blood pressure

CPC - Cerebral Performance Category

CVC - central venous catheter

DC - direct current

ECG - electorcardiogram 
ED - emergency department

EMS - emergency medical service

EMT-D - emergency medical technician-defibrillator (a member of an emergency medical services crew withspecial training in the use of cardiac defibrillating equipment)

ETT - endotrachel tube

GCS - Glasgow Coma Score

HDA high dose adrenaline

ITT - intention-to-treat

IU - international unit

IV - intravenous

LOS - length of stay (usually means in hospital)

mg - milligram

$\mathrm{ml}$ - millilitre

OHCA - out-of-hospital cardiac arrest

PEA - pulseless electrical activity

RCT - randomised controlled trial

ROSC - return of spontaneous circulation

SAMU - Service d'Aide Médicale Urgente (Emergency Medical Service in France)

SDA - standard dose adrenaline

VF - ventricular fibrillation

Characteristics of excluded studies [ordered by study ID]

\begin{tabular}{|c|c|}
\hline Study & Reason for exclusion \\
\hline Aggarwal 1993 & Not RCT - critique \\
\hline Berthier 1987 & Not RCT - review paper \\
\hline Betleri 1966 & Not RCT - case study \\
\hline Callaham 1989 & Not RCT - editorial \\
\hline Callaham 1991a & Not RCT - cohort study \\
\hline Callaham 1991b & Not RCT - letter \\
\hline Carroll 2012 & Not RCT - feasibility study \\
\hline Carvolth 1996 & Not RCT - before-and-after study \\
\hline Cohen 1975 & Not RCT - review paper \\
\hline David 2007 & Not RCT - cohort study \\
\hline Di Stilio 2005 & Not RCT - critique \\
\hline Dieckmann 1995 & Not RCT - cohort study \\
\hline Ghafourian 2015 & Not RCT - 'controls' not randomised \\
\hline Grmec 2006 & Not RCT - cohort study \\
\hline Hagihara 2012 & Not RCT - cohort study \\
\hline Herlitz 1995 & Not RCT - cohort study \\
\hline
\end{tabular}




\begin{tabular}{|c|c|}
\hline Study & Reason for exclusion \\
\hline Lee 2000 & $\begin{array}{l}\text { Conference abstract, preliminary report of } 10 \text { cases, no information of trial could be found, data } \\
\text { sought but no response from author }\end{array}$ \\
\hline Lee 2001 & Not RCT - case series \\
\hline Lindner 1991b & Not study drugs - comparison of noradrenaline \\
\hline McCrirrick 1992 & Not cardiac arrest - anaesthetised patients \\
\hline McCrirrick 1994 & Not cardiac arrest - bypass surgery patients \\
\hline Mclntyre 2004 & Not RCT - editorial \\
\hline Mentzelopoulos 2007 & $\begin{array}{l}\text { Not study drugs - comparison of vasopressin+epinephrine+methylprednisolone versus place- } \\
\text { bo+epinephrine+placebo. }\end{array}$ \\
\hline Mentzelopoulos 2009 & $\begin{array}{l}\text { Not study drugs - comparison of vasopressin+epinephrine+methylprednisolone versus place- } \\
\text { bo+epinephrine+placebo. }\end{array}$ \\
\hline Meyer 2011 & Not RCT - review \\
\hline Morris 1997 & Not RCT - convenience sample pilot study \\
\hline Niemann 2000 & Not RCT - retrospective cohort study \\
\hline Nishizawa 1993 & Not RCT - cohort study \\
\hline Ohshige 2005 & Not RCT - cohort study \\
\hline Olasveengen 2009 & Not study drugs - RCT of intravenous drugs, not specifically adrenaline or vasopressin \\
\hline Olasveengen 2010 & Not RCT - post-hoc analysis \\
\hline Olson 1989 & Not study drugs - comparison of methoxamine versus epinephrine \\
\hline Papastylianou 2010 & Not RCT - cohort \\
\hline Paradis 1991 & Surrogate outcomes - coronary perfusion pressures and plasma catecholamines \\
\hline Patrick 1995 & Not study drugs - comparison of methoxamine versus epinephrine \\
\hline Pellegrino 2006 & Not RCT - review paper \\
\hline Quadrel 1995 & Not cardiac arrest - asthma patients \\
\hline Quintana 2005 & Not RCT - critique \\
\hline Quinton 1987 & $\begin{array}{l}\text { Surrogate outcomes - comparison of endotracheal versus intravenous adrenaline; surrogate out- } \\
\text { comes of plasma concentration of adrenaline and noradrenaline }\end{array}$ \\
\hline Salam 2005 & Not RCT - critique \\
\hline Silfvast 1985 & Not study drugs - comparison of adrenaline and phenylephrine \\
\hline Song 1997 & Not study drugs - comparison of methoxamine versus epinephrine \\
\hline
\end{tabular}




\begin{tabular}{ll}
\hline Study & Reason for exclusion \\
\hline Turner 1988 & Not study drugs - comparison of methoxamine versus epinephrine \\
\hline Weaver 1990 & Not study drugs - comparison of epinephrine and lidocaine \\
\hline Woodhouse 1992 & Surrogate outcomes - plasma catecholamines \\
\hline Worster 2005 & Not RCT - review of Wenzel 2004 paper \\
\hline Youngquist 2012 & Not RCT - letter \\
\hline Zwingmann 2012 & Not RCT - systematic review of mortality after out-of-hospital resuscitation of patients suffering a \\
trauma
\end{tabular}

\section{Characteristics of ongoing studies [ordered by study ID]}

\section{Andersen 2018}

\begin{tabular}{ll} 
Trial name or title & Vasopressin and methylprednisolone for in-hospital cardiac arrest (VAM-IHCA) \\
\hline Methods & $\begin{array}{l}\text { Investigator-initiated, multicentre, randomised, placebo-controlled, parallel group, double-blind, } \\
\text { superiority trial of vasopressin and methylprednisolone during adult in-hospital cardiac arrest. } \\
5 \text { enrolling sites in Denmark }\end{array}$ \\
Adult in-hospital cardiac arrest: $(\mathrm{n}=492)$ receiving at least 1 dose of adrenaline will be enrolled \\
Inclusion criteria: \\
$\begin{array}{l}\text { 1. In-hospital cardiac arrest } \\
\text { 2. Age } \geq 18 \text { years } \\
\text { 3. Received at least } 1 \text { dose of adrenaline during cardiopulmonary resuscitation } \\
\text { Exclusion criteria: } \\
\text { 1. Clearly-documented "do-not-resuscitate" order prior to the cardiac arrest } \\
\text { 2. Prior enrolment in the trial } \\
\text { 3. Mechanical circulatory support at the time of the cardiac arrest } \\
\text { 4. Known or suspected pregnancy at the time of the cardiac arrest }\end{array}$
\end{tabular}

Interventions

"The study drugs will consist of $40 \mathrm{mg}$ methylprednisolone (Solu-medrol ${ }^{\circledR}$, Pfizer) and $20 \mathrm{IU}$ of vasopressin (Empressin ${ }^{\circledR}$, Amomed Pharma $\mathrm{GmbH}$ ) given as soon as possible after the first dose of adrenaline. Additional doses of vasopressin (20 IU) will be administered after each adrenaline dose for a maximum of four doses ( $80 \mathrm{IU})$. The placebo for vasopressin will consist of $1 \mathrm{~mL}$ of $9 \mathrm{mg} / \mathrm{mL}$ $\mathrm{NaCl}$ ("normal saline") from $2 \mathrm{~mL}$ ampoules identical to the vasopressin ampoules. The placebo for methylprednisolone will also consist of $1 \mathrm{~mL}$ of $9 \mathrm{mg} / \mathrm{mL} \mathrm{NaCl}$ "

$\begin{array}{ll}\text { Outcomes } & \text { "The primary outcome is return of spontaneous circulation and key secondary outcomes include } \\ \text { survival at } 30 \text { days and survival at } 30 \text { days with a favourable neurological outcome" }\end{array}$

\begin{tabular}{ll}
\hline Starting date & September 2018 \\
\hline Contact information & $\begin{array}{l}\text { Contact: Lars W Andersen, MD, MPH, PhD Associate Professor, Aarhus University Hospital lwander- } \\
\text { sen@clin.au.dk }\end{array}$ \\
\hline Notes & clinicaltrials.gov/ct2/show/NCT03640949 \\
\hline \hline
\end{tabular}

Adrenaline and vasopressin for cardiac arrest (Review) 
Raymond 2008

Trial name or title

A prospective, randomised, controlled trial of combination vasopressin and epinephrine to epinephrine only for in-intensive care unit paediatric cardiopulmonary resuscitation

\begin{tabular}{ll}
\hline Methods & Prospective, randomized, controlled trial \\
\hline Participants & up to 18 years (child, adult) \\
\hline Interventions & Experimental: 1
\end{tabular}

Paediatric patients that experience in-hospital CPA who remain in cardiac arrest despite CPR and an initial, standard dose of epinephrine $(0.01 \mathrm{mg} / \mathrm{kg})$, will be randomly assigned to receive vasopressin $(0.8$ units $/ \mathrm{kg}$ ) rescue as the second vasopressor medication

Active Comparator: 2

Paediatric patients that experience in-hospital CPA who remain in cardiac arrest despite CPR and an initial, standard dose of epinephrine $(0.01 \mathrm{mg} / \mathrm{kg})$, will be randomly assigned to receive standard-dose epinephrine $(0.01 \mathrm{mg} / \mathrm{kg})$ rescue as the second vasopressor medication

\section{Outcomes}

Primary outcome measures:

Combination vasopressin and epinephrine (CPA refractory to cardiopulmonary resuscitation and initial epinephrine dosing) will increase the proportion of patients surviving to hospital discharge by $25 \%$ compared to epinephrine alone. Time frame: Immediate

Secondary Outcome Measures:

Combination vasopressin and epinephrine will decrease the time to ROSC. Time frame: Immediate Vasopressin and epinephrine will improve the proportion of CPA survivors with favourable neurologic outcome (short-term Pediatric Overall Performance Category) (POPC) score discharge of 1 3 or unchanged from hospital admission at the time of hospital. Time frame: Period of hospitalisation

Vasopressin and epinephrine will improve the proportion of CPA survivors with favourable neurologic outcome (short-term Paediatric Cerebral Performance Category) (PCPC) score of 1 - 3 or unchanged from hospital admission at time of hospital discharge. Time frame: Period of hospitalisation

Combination vasopressin and epinephrine will improve 24-hour survival. Time frame: 24 hours Combination vasopressin and epinephrine will decrease the proportion of patients who require prolonged CPR (CPR > 20 minutes) to achieve sustained ROSC. Time frame: Immediate Combination vasopressin and epinephrine will increase organ recovery in those people who meet brain death criteria following the CPA event. Time frame: Period of hospitalisation Combination epinephrine and vasopressin will improve rates of return of spontaneous circulation (ROSC). Time frame: Immediate

\begin{tabular}{ll}
\hline Starting date & April 2008 \\
\hline Contact information & clinicaltrials.gov/ct2/show/NCT00628550; Tia.Tortoriello@Childrens.com \\
\hline Notes & $\begin{array}{l}\text { Study completion date was listed as December 2011. Researchers attempted to be contacted in } \\
\text { February 2018 for an update, but no response }\end{array}$ \\
\hline
\end{tabular}

\section{DATA AND ANALYSES}


Comparison 1. Standard dose adrenaline (SDA) versus placebo

\begin{tabular}{lllll}
\hline Outcome or subgroup title & No. of studies & $\begin{array}{l}\text { No. of partici- } \\
\text { pants }\end{array}$ & Statistical method & Effect size \\
\hline $\begin{array}{l}\text { 1 Survival to hospital dis- } \\
\text { charge }\end{array}$ & 2 & 8538 & Risk Ratio (M-H, Random, 95\% Cl) & $1.44[1.11,1.86]$ \\
\hline $\begin{array}{l}2 \text { Survival to hospital admis- } \\
\text { sion }\end{array}$ & 2 & 8489 & Risk Ratio (M-H, Random, 95\% Cl) & $2.51[1.67,3.76]$ \\
\hline 3 Neurological outcome & 2 & & Risk Ratio (M-H, Random, 95\% Cl) & $1.21[0.90,1.62]$ \\
\hline 4 ROSC & 3 & 8535 & Risk Ratio (M-H, Random, 95\% Cl) & $2.86[2.21,3.71]$ \\
\hline
\end{tabular}

\section{Analysis 1.1. Comparison 1 Standard dose adrenaline (SDA)} versus placebo, Outcome 1 Survival to hospital discharge.

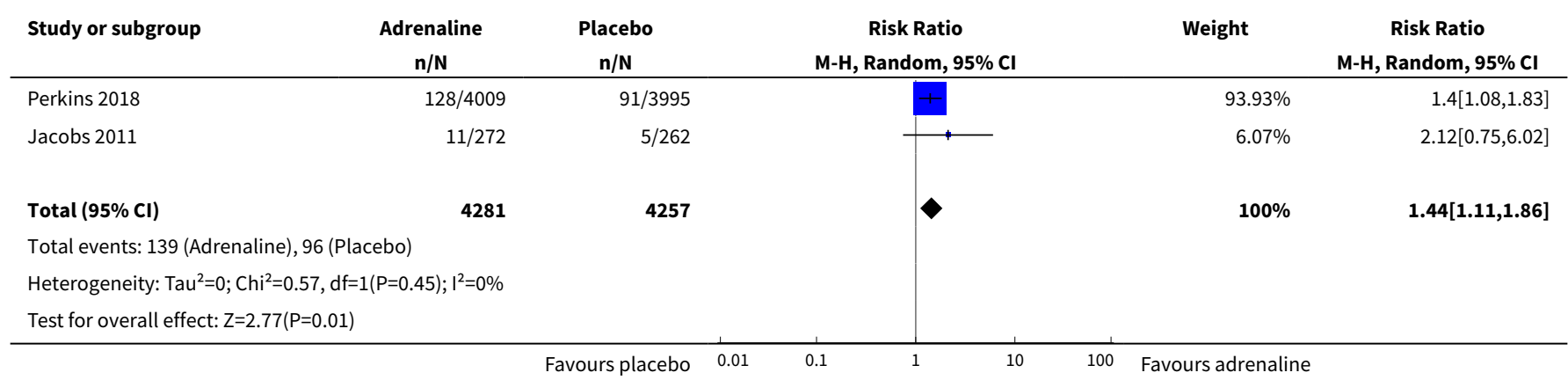

Analysis 1.2. Comparison 1 Standard dose adrenaline (SDA) versus placebo, Outcome 2 Survival to hospital admission.

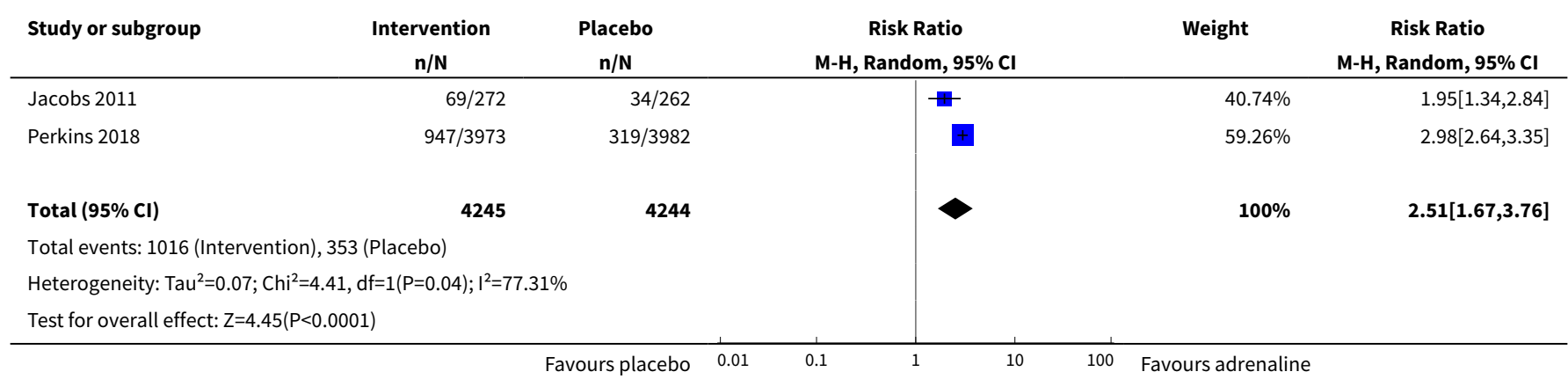


Analysis 1.3. Comparison 1 Standard dose adrenaline (SDA) versus placebo, Outcome 3 Neurological outcome.

\begin{tabular}{|c|c|c|c|c|c|}
\hline Study or subgroup & $\begin{array}{c}\text { Intervention } \\
\mathbf{n} / \mathbf{N} \\
\end{array}$ & $\begin{array}{c}\text { Placebo } \\
\mathbf{n} / \mathbf{N}\end{array}$ & $\begin{array}{c}\text { Risk Ratio } \\
\text { M-H, Random, 95\% Cl }\end{array}$ & Weight & $\begin{array}{c}\text { Risk Ratio } \\
\text { M-H, Random, } 95 \% \mathrm{Cl}\end{array}$ \\
\hline Jacobs 2011 & $9 / 272$ & $5 / 262$ & $\longrightarrow$ & $7.47 \%$ & $1.73[0.59,5.11]$ \\
\hline Perkins 2018 & $87 / 4007$ & $74 / 3994$ & & $92.53 \%$ & $1.17[0.86,1.59]$ \\
\hline Total $(95 \% \mathrm{Cl})$ & 4279 & 4256 & $\gamma$ & $100 \%$ & $1.21[0.9,1.62]$ \\
\hline \multicolumn{6}{|c|}{ Total events: 96 (Intervention), 79 (Placebo) } \\
\hline \multicolumn{6}{|c|}{ Heterogeneity: $\mathrm{Tau}^{2}=0 ; \mathrm{Chi}^{2}=0.47, \mathrm{df}=1(\mathrm{P}=0.49) ; \mathrm{I}^{2}=0 \%$} \\
\hline Test for overall effect & & & & & \\
\hline
\end{tabular}

Analysis 1.4. Comparison 1 Standard dose adrenaline (SDA) versus placebo, Outcome 4 ROSC.

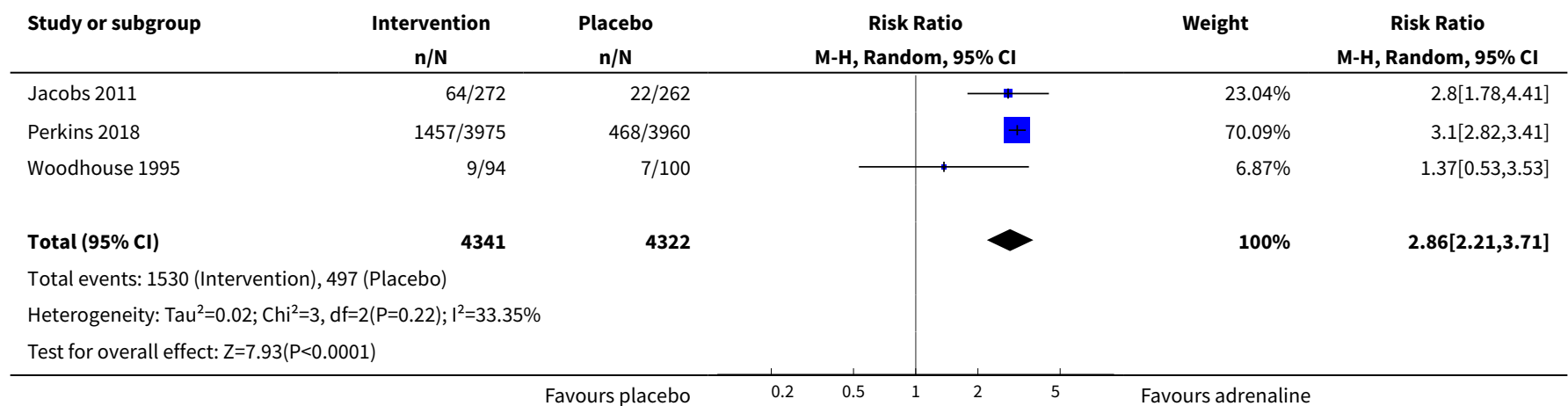

Comparison 2. Standard dose adrenaline (SDA) versus high dose adrenaline (HDA)

\begin{tabular}{lllll}
\hline $\begin{array}{l}\text { Outcome or subgroup ti- } \\
\text { tle }\end{array}$ & No. of studies & $\begin{array}{l}\text { No. of partici- } \\
\text { pants }\end{array}$ & Statistical method & Effect size \\
\hline $\begin{array}{l}\text { 1 Survival to hospital dis- } \\
\text { charge }\end{array}$ & 10 & 6274 & Risk Ratio (M-H, Random, 95\% Cl) & $1.10[0.75,1.62]$ \\
\hline $\begin{array}{l}\text { 2 Survival to hospital dis- } \\
\text { charge (adult vs child) }\end{array}$ & 10 & 6274 & Risk Ratio (M-H, Random, 95\% Cl) & $1.10[0.75,1.62]$ \\
\hline $\begin{array}{l}2.1 \text { Adults } \\
\text { 2.2 Children }\end{array}$ & 7 & 5957 & Risk Ratio (M-H, Random, 95\% Cl) & $0.97[0.73,1.29]$ \\
\hline $\begin{array}{l}3 \text { Survival to hospital dis- } \\
\text { charge (OHCA vs IHCA) }\end{array}$ & 9 & 317 & Risk Ratio (M-H, Random, 95\% Cl) & $1.54[0.17,13.66]$ \\
\hline $\begin{array}{l}3.1 \text { OHCA } \\
\text { 3.2 IHCA }\end{array}$ & 5 & 6206 & Risk Ratio (M-H, Random, 95\% Cl) & $1.00[0.74,1.34]$ \\
\hline $\begin{array}{l}\text { 4 Survival to hospital ad- } \\
\text { mission }\end{array}$ & 5 & 5701 & Risk Ratio (M-H, Random, 95\% Cl) & $0.97[0.72,1.32]$ \\
\hline
\end{tabular}




\begin{tabular}{lllll}
\hline $\begin{array}{l}\text { Outcome or subgroup ti- } \\
\text { tle }\end{array}$ & No. of studies & $\begin{array}{l}\text { No. of partici- } \\
\text { pants }\end{array}$ & Statistical method & Effect size \\
\hline 5 24-hour survival & 5 & 4179 & Risk Ratio (M-H, Random, 95\% Cl) & $1.04[0.76,1.43]$ \\
\hline 6 Neurological outcome & 4 & 5803 & Risk Ratio (M-H, Random, 95\% Cl) & $0.91[0.65,1.26]$ \\
\hline 7 ROSC (OHCA vs IHCA) & 12 & 6364 & Risk Ratio (M-H, Random, 95\% Cl) & $1.16[1.06,1.28]$ \\
\hline 7.1 OHCA & 8 & 6174 & Risk Ratio (M-H, Random, 95\% Cl) & $1.13[1.06,1.22]$ \\
\hline 7.2 IHCA & 4 & 190 & Risk Ratio (M-H, Random, 95\% Cl) & $1.78[0.82,3.88]$ \\
\hline 8 ROSC (adults vs children) & 13 & 7014 & Risk Ratio (M-H, Random, 95\% Cl) & $1.15[1.02,1.29]$ \\
\hline 8.1 ROSC-adults & 10 & 6697 & Risk Ratio (M-H, Random, 95\% Cl) & $1.14[1.01,1.29]$ \\
\hline 8.2 ROSC-children & 3 & 317 & Risk Ratio (M-H, Random, 95\% Cl) & $1.31[0.67,2.56]$ \\
\hline
\end{tabular}

Analysis 2.1. Comparison 2 Standard dose adrenaline (SDA) versus high dose adrenaline (HDA), Outcome 1 Survival to hospital discharge.

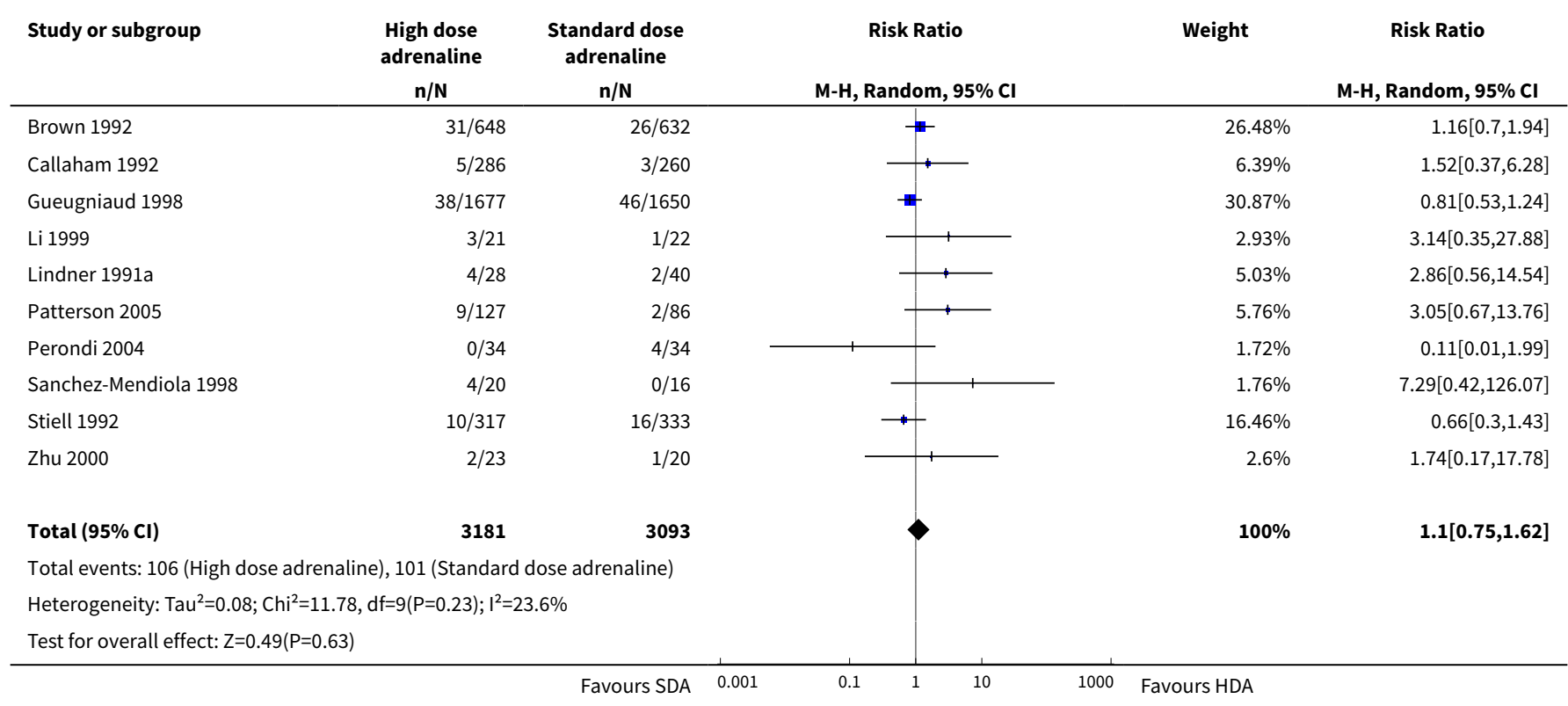

Analysis 2.2. Comparison 2 Standard dose adrenaline (SDA) versus high dose adrenaline (HDA), Outcome 2 Survival to hospital discharge (adult vs child).

\begin{tabular}{|c|c|c|c|c|c|c|}
\hline Study or subgroup & $\begin{array}{c}\text { High dose } \\
\text { adrenaline } \\
\mathbf{n} / \mathbf{N} \\
\end{array}$ & $\begin{array}{c}\text { Standard dose } \\
\text { adrenaline } \\
\mathrm{n} / \mathrm{N} \\
\end{array}$ & & $\begin{array}{c}\text { Risk Ratio } \\
\text { M-H, Random, } 95 \% \mathrm{Cl} \\
\end{array}$ & Weight & $\begin{array}{c}\text { Risk Ratio } \\
\text { M-H, Random, 95\% Cl }\end{array}$ \\
\hline \multicolumn{7}{|l|}{ 2.2.1 Adults } \\
\hline Brown 1992 & $31 / 648$ & $26 / 632$ & & $\rightarrow$ & $26.48 \%$ & $1.16[0.7,1.94]$ \\
\hline
\end{tabular}




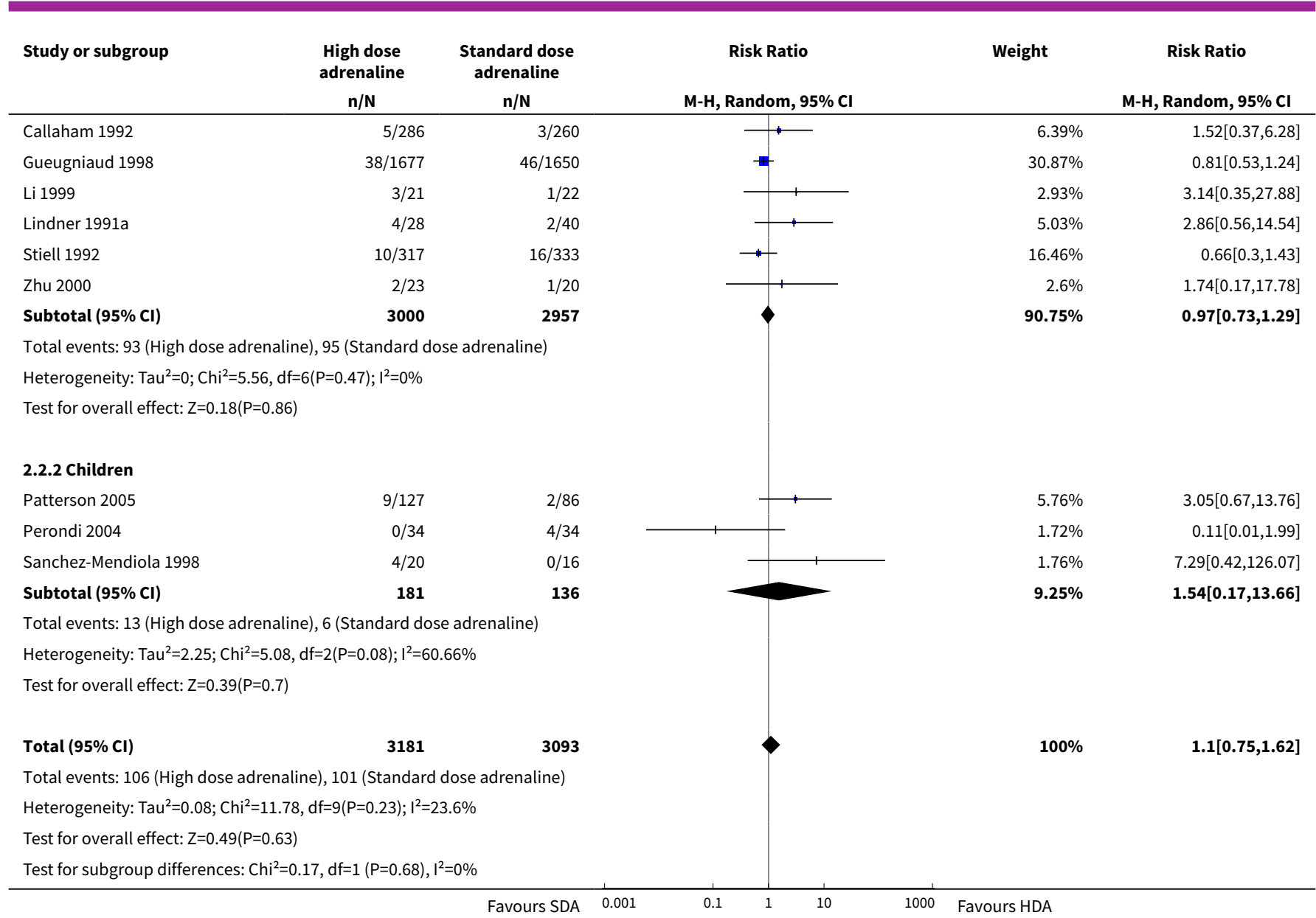

Analysis 2.3. Comparison 2 Standard dose adrenaline (SDA) versus high dose adrenaline (HDA), Outcome 3 Survival to hospital discharge (OHCA vs IHCA).

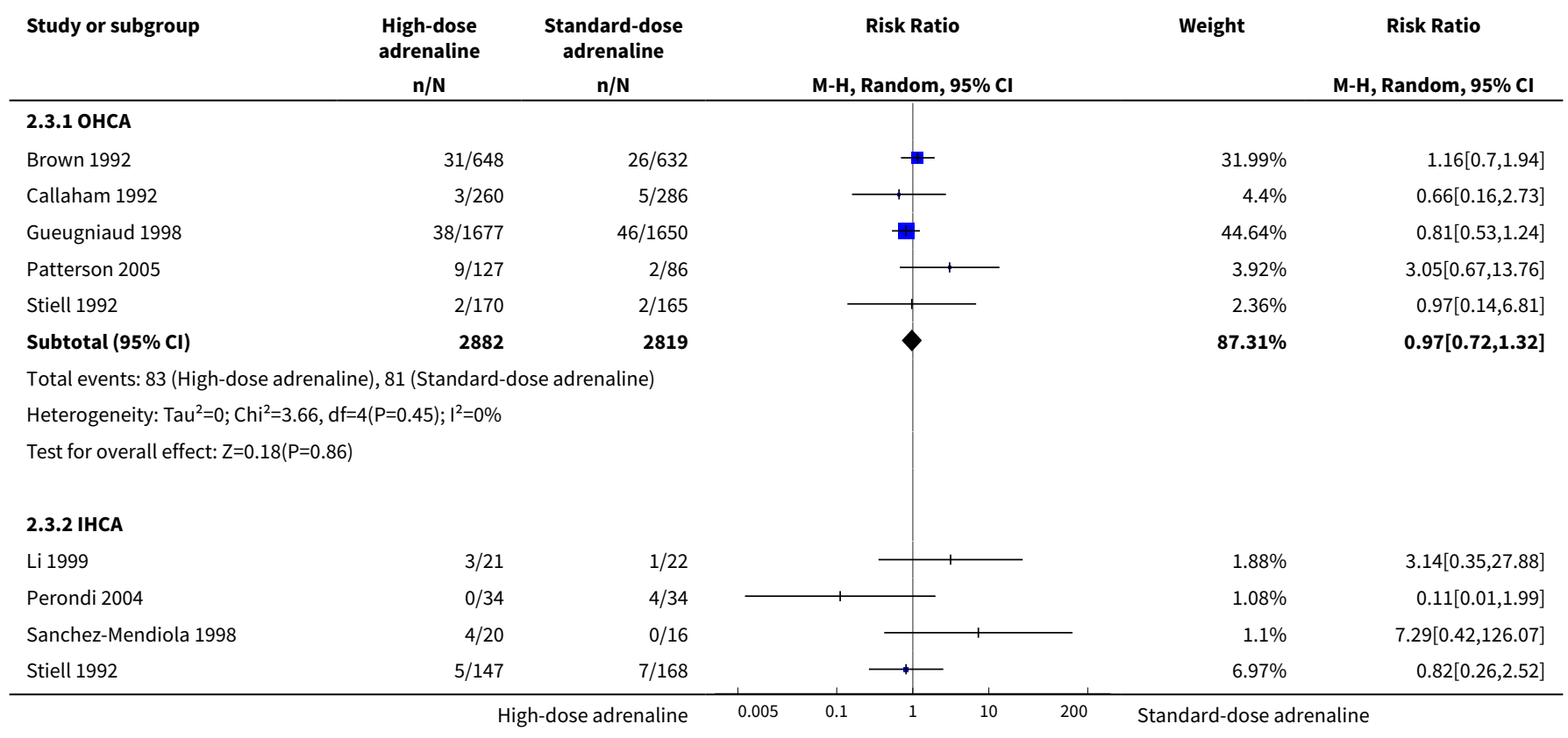




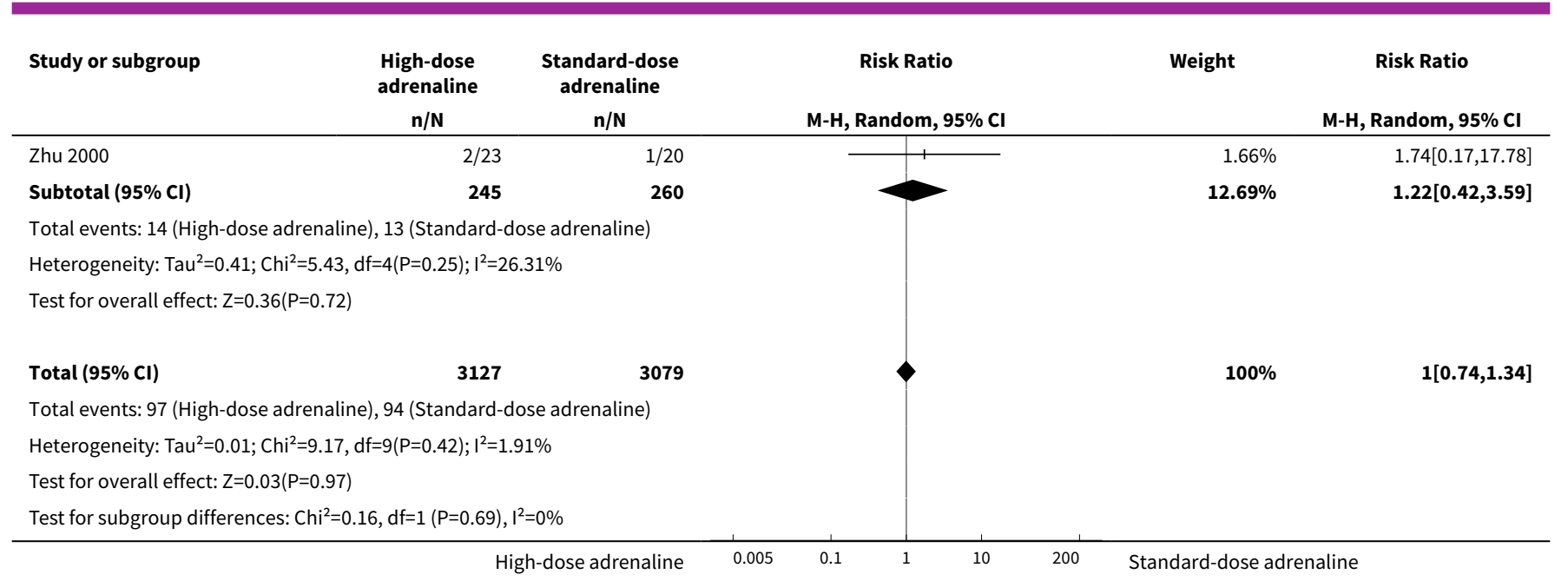

Analysis 2.4. Comparison 2 Standard dose adrenaline (SDA) versus high dose adrenaline (HDA), Outcome 4 Survival to hospital admission.

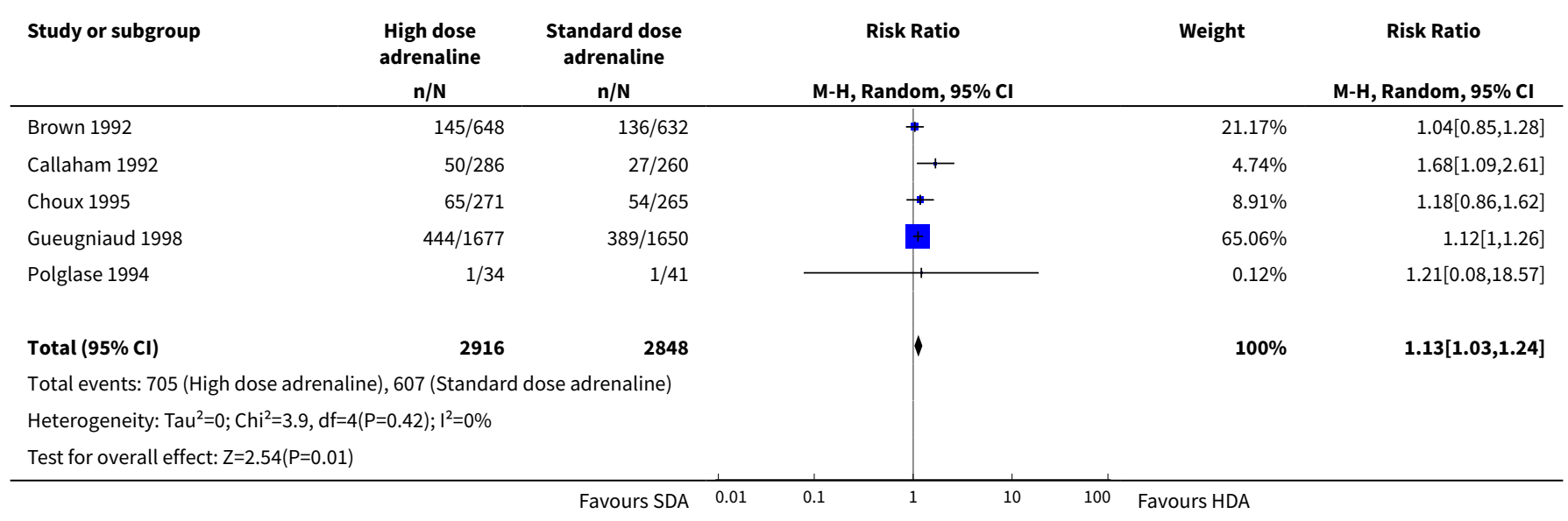

Analysis 2.5. Comparison 2 Standard dose adrenaline (SDA) versus high dose adrenaline (HDA), Outcome 5 24-hour survival.

\begin{tabular}{|c|c|c|c|c|c|}
\hline Study or subgroup & $\begin{array}{l}\text { HDA } \\
\mathrm{n} / \mathrm{N}\end{array}$ & $\begin{array}{l}\text { SDA } \\
\mathrm{n} / \mathrm{N}\end{array}$ & $\begin{array}{c}\text { Risk Ratio } \\
\text { M-H, Random, 95\% Cl }\end{array}$ & Weight & $\begin{array}{c}\text { Risk Ratio } \\
\text { M-H, Random, } 95 \% \mathrm{Cl}\end{array}$ \\
\hline Choux 1995 & $40 / 271$ & $36 / 265$ & + & $28.67 \%$ & $1.09[0.72,1.65]$ \\
\hline Gueugniaud 1998 & $272 / 1677$ & $263 / 1650$ & & $50.29 \%$ & $1.02[0.87,1.19]$ \\
\hline Lipman 1993 & $4 / 19$ & $5 / 16$ & $\longrightarrow$ & $6.84 \%$ & $0.67[0.22,2.09]$ \\
\hline Patterson 2005 & $20 / 127$ & $7 / 86$ & $\longrightarrow$ & $11.89 \%$ & $1.93[0.86,4.38]$ \\
\hline Perondi 2004 & $1 / 34$ & $7 / 34$ & 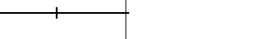 & $2.3 \%$ & $0.14[0.02,1.1]$ \\
\hline Total $(95 \% \mathrm{Cl})$ & 2128 & 2051 & & $100 \%$ & $1.04[0.76,1.43]$ \\
\hline \multicolumn{6}{|c|}{ Total events: 337 (HDA), 318 (SDA) } \\
\hline \multicolumn{6}{|c|}{ Heterogeneity: $\mathrm{Tau}^{2}=0.05 ; \mathrm{Chi}^{2}=6.52, \mathrm{df}=4(\mathrm{P}=0.16) ; \mathrm{I}^{2}=38.66 \%$} \\
\hline \multicolumn{6}{|c|}{ Test for overall effect: $Z=0.24(P=0.81)$} \\
\hline
\end{tabular}


Analysis 2.6. Comparison 2 Standard dose adrenaline (SDA) versus high dose adrenaline (HDA), Outcome 6 Neurological outcome.

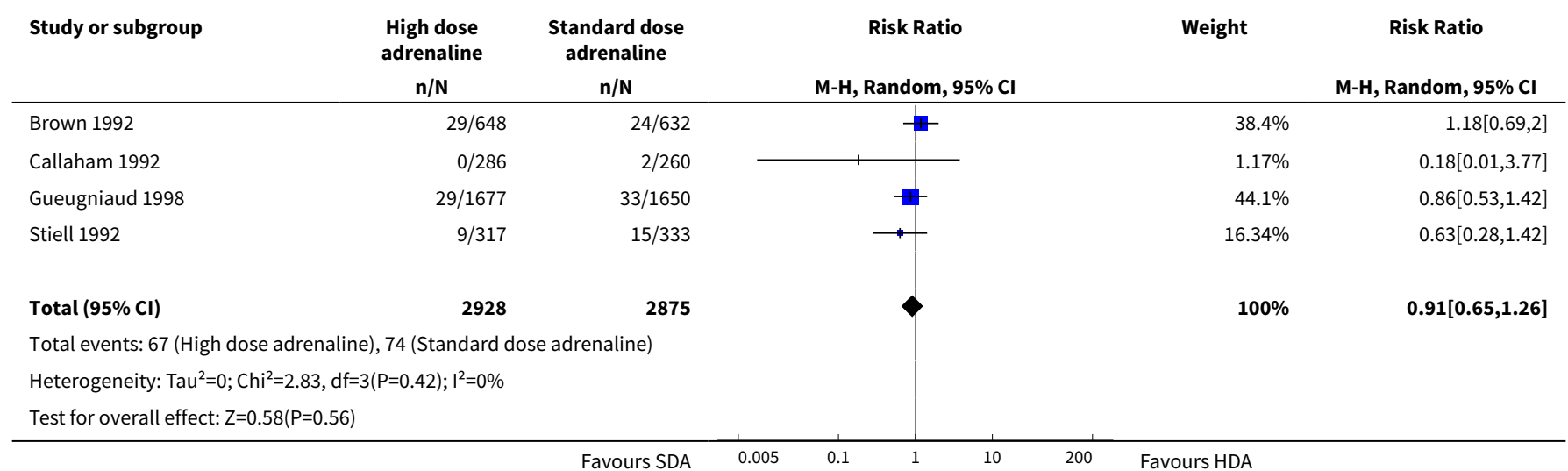

\section{Analysis 2.7. Comparison 2 Standard dose adrenaline (SDA) versus high dose adrenaline (HDA), Outcome 7 ROSC (OHCA vs IHCA).}

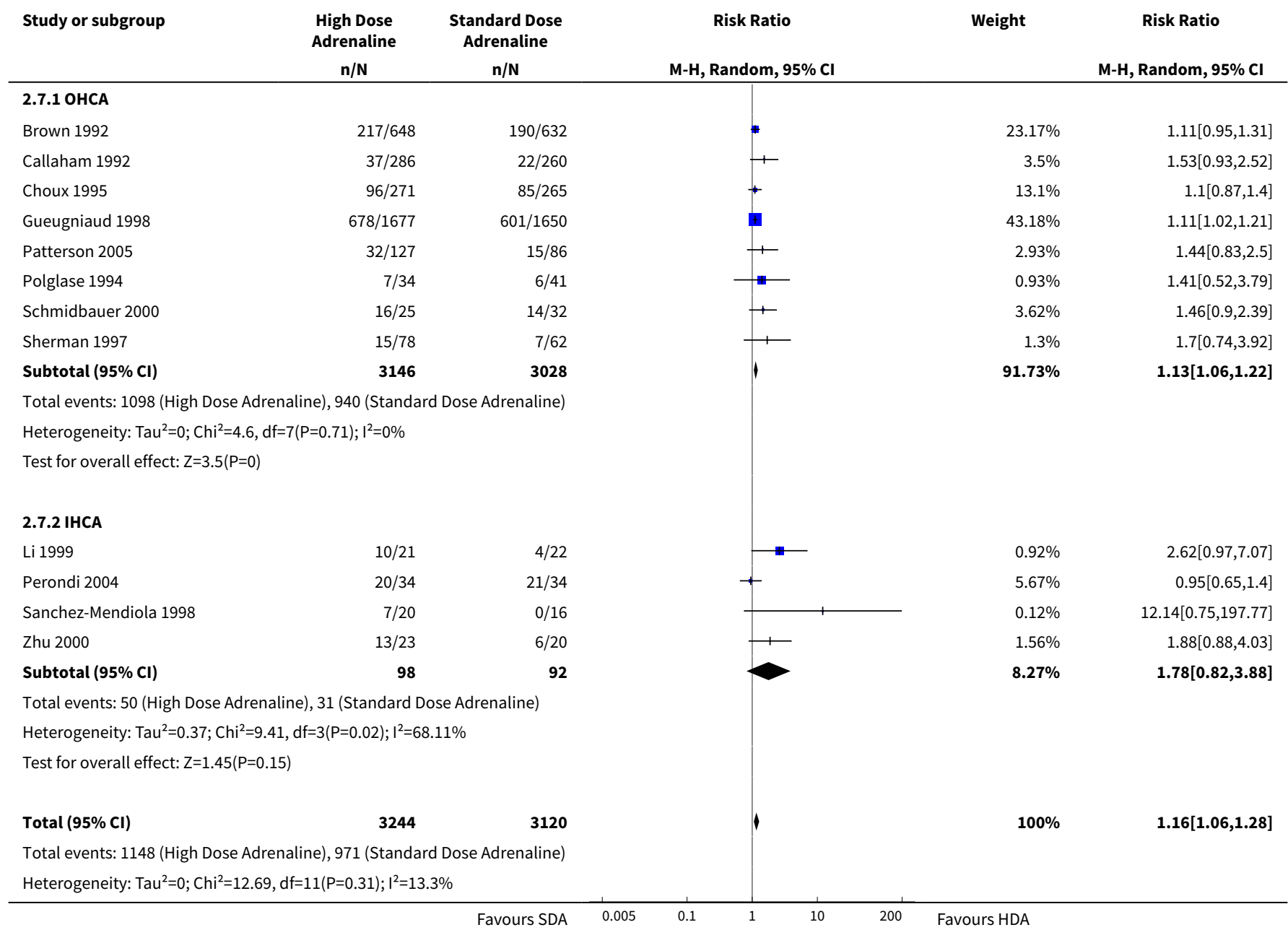




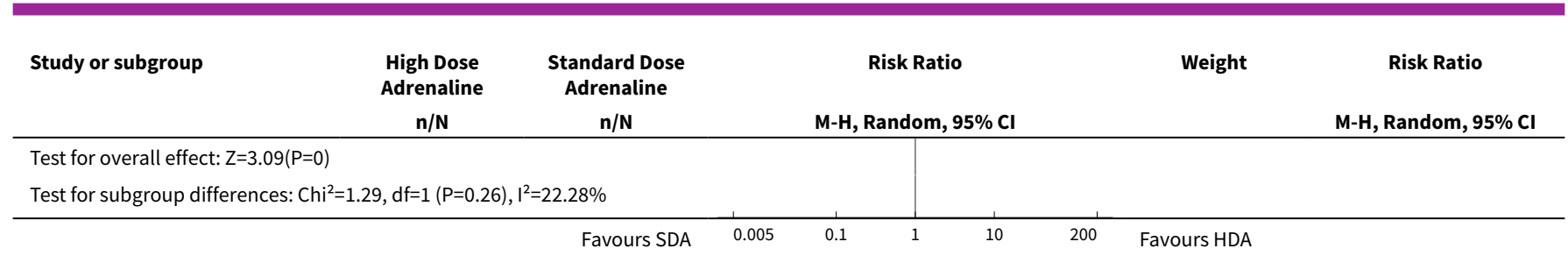

Analysis 2.8. Comparison 2 Standard dose adrenaline (SDA) versus

\begin{tabular}{|c|c|c|c|c|c|}
\hline \multirow[t]{2}{*}{ Study or subgroup } & $\begin{array}{l}\text { High dose } \\
\text { adrenaline }\end{array}$ & $\begin{array}{l}\text { Standard dose } \\
\text { adrenaline }\end{array}$ & Risk Ratio & \multirow[t]{2}{*}{ Weight } & \multirow{2}{*}{$\begin{array}{c}\text { Risk Ratio } \\
\text { M-H, Random, } 95 \% \mathrm{Cl}\end{array}$} \\
\hline & $n / N$ & $\mathrm{n} / \mathrm{N}$ & M-H, Random, $95 \% \mathrm{Cl}$ & & \\
\hline \multicolumn{6}{|l|}{ 2.8.1 ROSC-adults } \\
\hline Brown 1992 & $217 / 648$ & $190 / 632$ & * & $20.02 \%$ & $1.11[0.95,1.31]$ \\
\hline Callaham 1992 & $37 / 286$ & $22 / 260$ & + & $4.89 \%$ & $1.53[0.93,2.52]$ \\
\hline Choux 1995 & $96 / 271$ & $85 / 265$ & + & $14.07 \%$ & $1.1[0.87,1.4]$ \\
\hline Li 1999 & $10 / 21$ & $4 / 22$ & 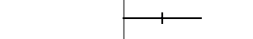 & $1.4 \%$ & $2.62[0.97,7.07]$ \\
\hline Polglase 1994 & $7 / 34$ & $6 / 41$ & \begin{tabular}{l|l}
-1 \\
\end{tabular} & $1.41 \%$ & $1.41[0.52,3.79]$ \\
\hline Schmidbauer 2000 & $16 / 25$ & $14 / 32$ & + & $5.05 \%$ & $1.46[0.9,2.39]$ \\
\hline Sherman 1997 & $15 / 78$ & $7 / 62$ & + & $1.96 \%$ & $1.7[0.74,3.92]$ \\
\hline Stiell 1992 & $56 / 317$ & $76 / 333$ & $\rightarrow$ & $10.21 \%$ & $0.77[0.57,1.05]$ \\
\hline Zhu 2000 & $13 / 23$ & $6 / 20$ & 1 & $2.33 \%$ & $1.88[0.88,4.03]$ \\
\hline \multicolumn{6}{|c|}{$\begin{array}{l}\text { Total events: } 1145 \text { (High dose adrenaline), } 1011 \text { (Standard dose adrena- } \\
\text { line) }\end{array}$} \\
\hline \multicolumn{6}{|c|}{ Heterogeneity: $\mathrm{Tau}^{2}=0.01 ; \mathrm{Chi}^{2}=13.96, \mathrm{df}=9(\mathrm{P}=0.12) ; \mathrm{I}^{2}=35.52 \%$} \\
\hline \multicolumn{6}{|c|}{ Test for overall effect: $Z=2.12(P=0.03)$} \\
\hline \multicolumn{6}{|l|}{ 2.8.2 ROSC-children } \\
\hline Patterson 2005 & $32 / 127$ & $15 / 86$ & + & $4.17 \%$ & $1.44[0.83,2.5]$ \\
\hline Perondi 2004 & $20 / 34$ & $21 / 34$ & + & $7.42 \%$ & $0.95[0.65,1.4]$ \\
\hline Sanchez-Mendiola 1998 & $7 / 20$ & $0 / 16$ & & $0.19 \%$ & $12.14[0.75,197.77]$ \\
\hline Subtotal $(95 \% \mathrm{Cl})$ & 181 & 136 & & $11.77 \%$ & $1.31[0.67,2.56]$ \\
\hline \multicolumn{6}{|c|}{ Total events: 59 (High dose adrenaline), 36 (Standard dose adrenaline) } \\
\hline \multicolumn{6}{|c|}{ Heterogeneity: $\mathrm{Tau}^{2}=0.19 ; \mathrm{Chi}^{2}=5.4, \mathrm{df}=2(\mathrm{P}=0.07) ; \mathrm{I}^{2}=62.96 \%$} \\
\hline \multicolumn{6}{|c|}{ Test for overall effect: $Z=0.78(P=0.43)$} \\
\hline \multicolumn{6}{|c|}{$\begin{array}{l}\text { Total events: } 1204 \text { (High dose adrenaline), } 1047 \text { (Standard dose adrena- } \\
\text { line) }\end{array}$} \\
\hline \multicolumn{6}{|c|}{ Heterogeneity: $\operatorname{Tau}^{2}=0.01 ; \mathrm{Chi}^{2}=18.3, \mathrm{df}=12(\mathrm{P}=0.11) ; \mathrm{I}^{2}=34.42 \%$} \\
\hline \multicolumn{6}{|c|}{ Test for overall effect: $Z=2.23(P=0.03)$} \\
\hline Test for subgroup differer & $5, \mathrm{df}=1(\mathrm{P}=0.7), \mathrm{I}^{2}$ & & & & \\
\hline
\end{tabular}


Comparison 3. Standard dose adrenaline (SDA) versus vasopressin

\begin{tabular}{|c|c|c|c|c|}
\hline $\begin{array}{l}\text { Outcome or subgroup } \\
\text { title }\end{array}$ & No. of studies & $\begin{array}{l}\text { No. of partici- } \\
\text { pants }\end{array}$ & Statistical method & Effect size \\
\hline $\begin{array}{l}1 \text { Survival to hospital dis- } \\
\text { charge }\end{array}$ & 6 & 2511 & Risk Ratio (M-H, Random, 95\% Cl) & $1.25[0.84,1.85]$ \\
\hline $\begin{array}{l}2 \text { Survival to hospital dis- } \\
\text { charge (OHCA vs IHCA) }\end{array}$ & 5 & 1784 & Risk Ratio (M-H, Random, 95\% Cl) & $1.19[0.84,1.68]$ \\
\hline $2.1 \mathrm{OHCA}$ & 3 & 1542 & Risk Ratio (M-H, Random, 95\% Cl) & $1.26[0.76,2.07]$ \\
\hline $2.2 \mathrm{IHCA}$ & 2 & 242 & Risk Ratio (M-H, Random, 95\% Cl) & $2.21[0.29,17.06]$ \\
\hline $\begin{array}{l}3 \text { Survival to hospital ad- } \\
\text { mission }\end{array}$ & 3 & 1953 & Risk Ratio (M-H, Random, 95\% Cl) & $1.27[1.04,1.54]$ \\
\hline 4 Neurological Outcome & 4 & 2406 & Risk Ratio (M-H, Random, 95\% Cl) & $0.82[0.54,1.25]$ \\
\hline 5 ROSC & 6 & 2531 & Risk Ratio $(\mathrm{M}-\mathrm{H}$, Random, 95\% Cl) & $1.10[0.90,1.33]$ \\
\hline 6 ROSC (OHCA vs IHCA) & 5 & 1804 & Risk Ratio (M-H, Random, 95\% Cl) & $1.19[0.84,1.68]$ \\
\hline $6.1 \mathrm{OHCA}$ & 3 & 1562 & Risk Ratio $(\mathrm{M}-\mathrm{H}$, Random, 95\% Cl) & $1.05[0.80,1.39]$ \\
\hline $6.2 \mathrm{IHCA}$ & 2 & 242 & Risk Ratio (M-H, Random, 95\% Cl) & $1.76[0.40,7.71]$ \\
\hline
\end{tabular}

Analysis 3.1. Comparison 3 Standard dose adrenaline (SDA) versus vasopressin, Outcome 1 Survival to hospital discharge.

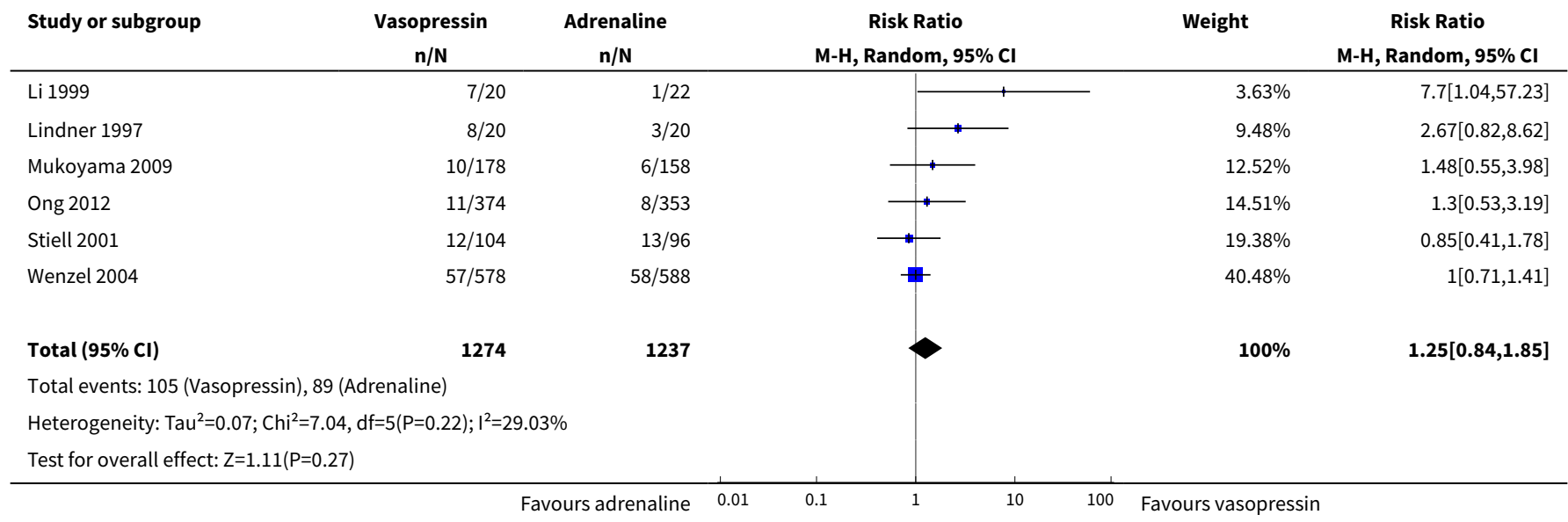


Analysis 3.2. Comparison 3 Standard dose adrenaline (SDA) versus vasopressin, Outcome 2 Survival to hospital discharge (OHCA vs IHCA).

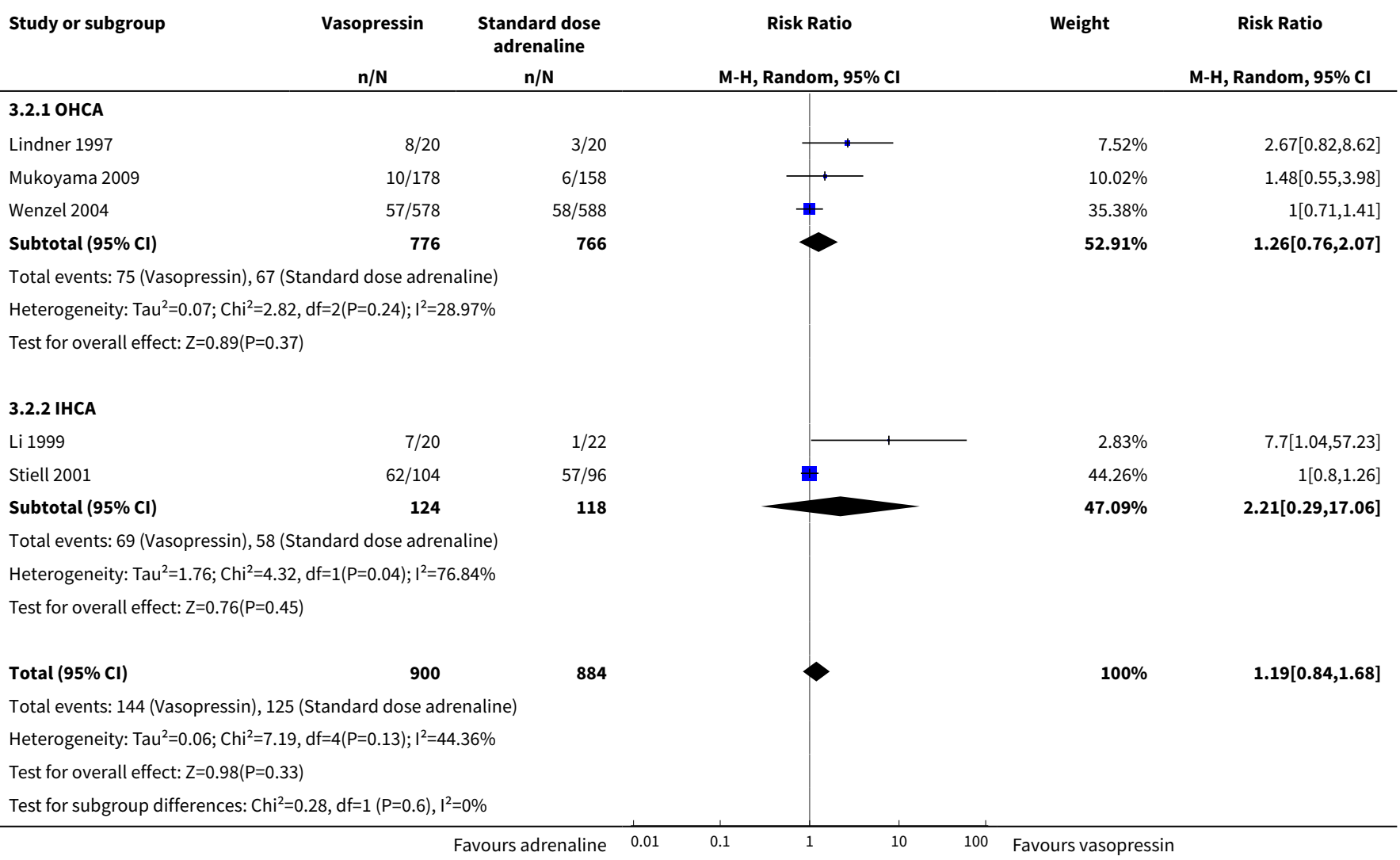

Analysis 3.3. Comparison 3 Standard dose adrenaline (SDA) versus vasopressin, Outcome 3 Survival to hospital admission.

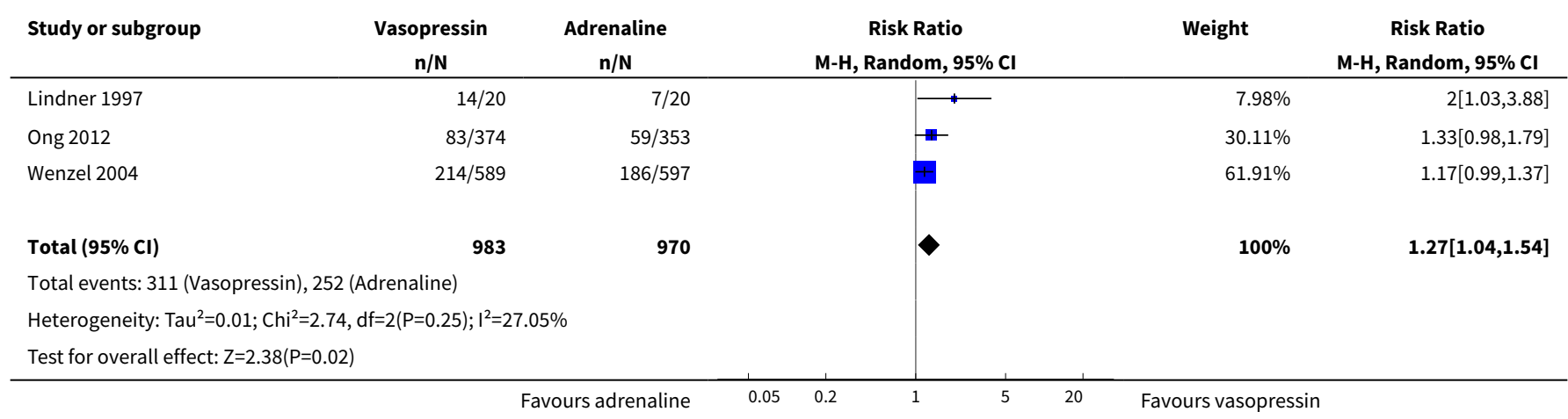


Analysis 3.4. Comparison 3 Standard dose adrenaline (SDA) versus vasopressin, Outcome 4 Neurological Outcome.

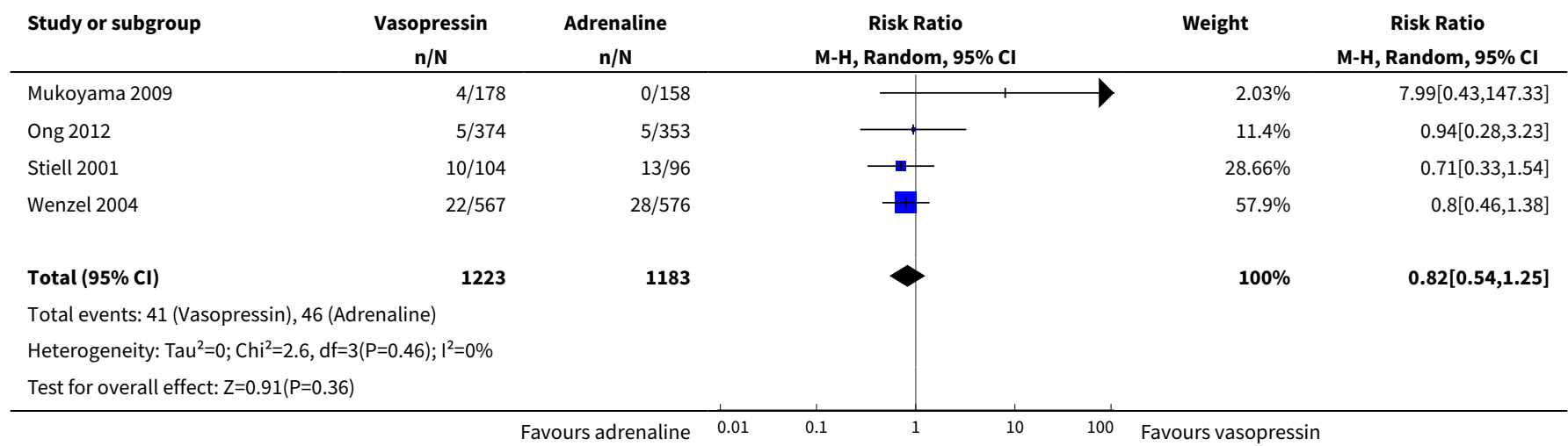

Analysis 3.5. Comparison 3 Standard dose adrenaline (SDA) versus vasopressin, Outcome 5 ROSC.

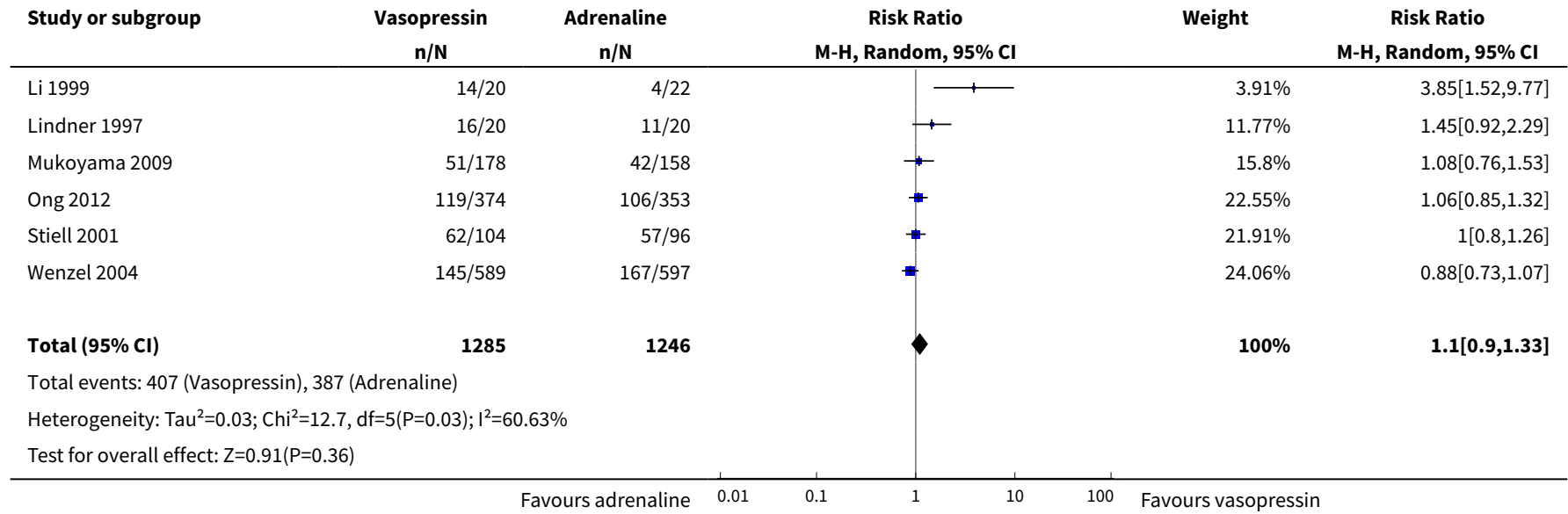

Analysis 3.6. Comparison 3 Standard dose adrenaline (SDA) versus vasopressin, Outcome 6 ROSC (OHCA vs IHCA).

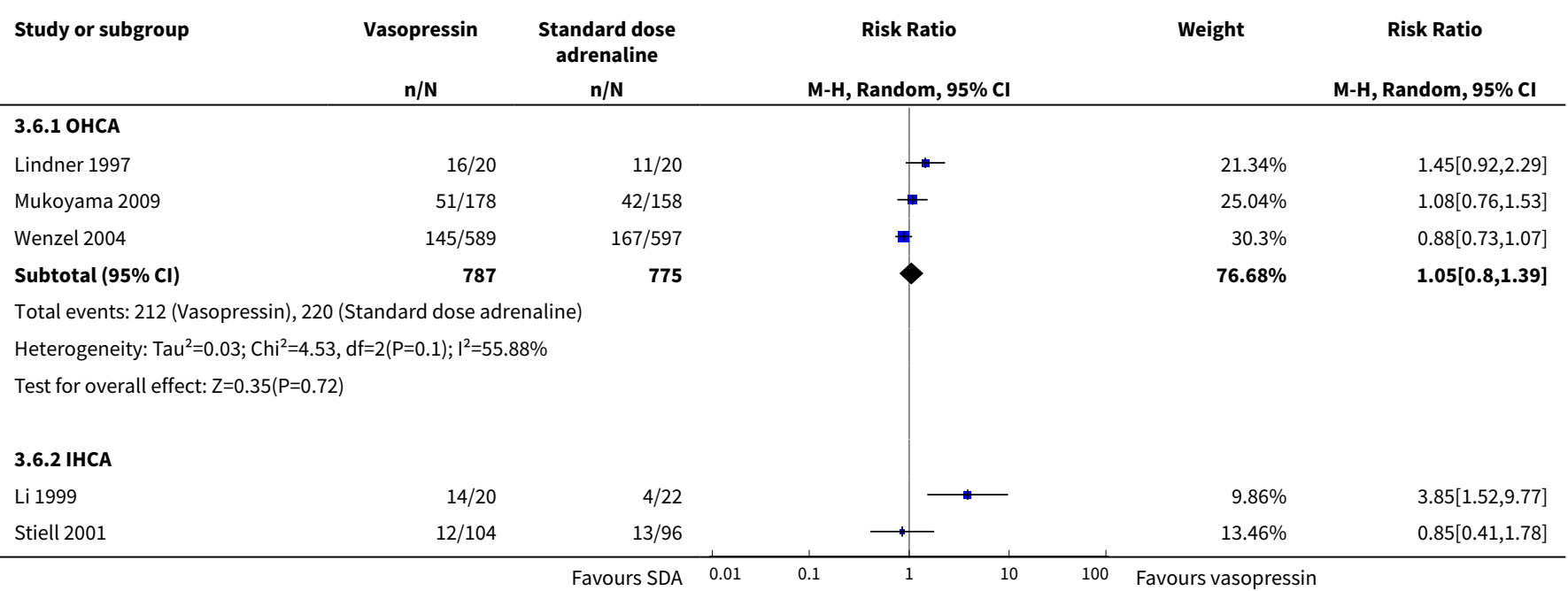




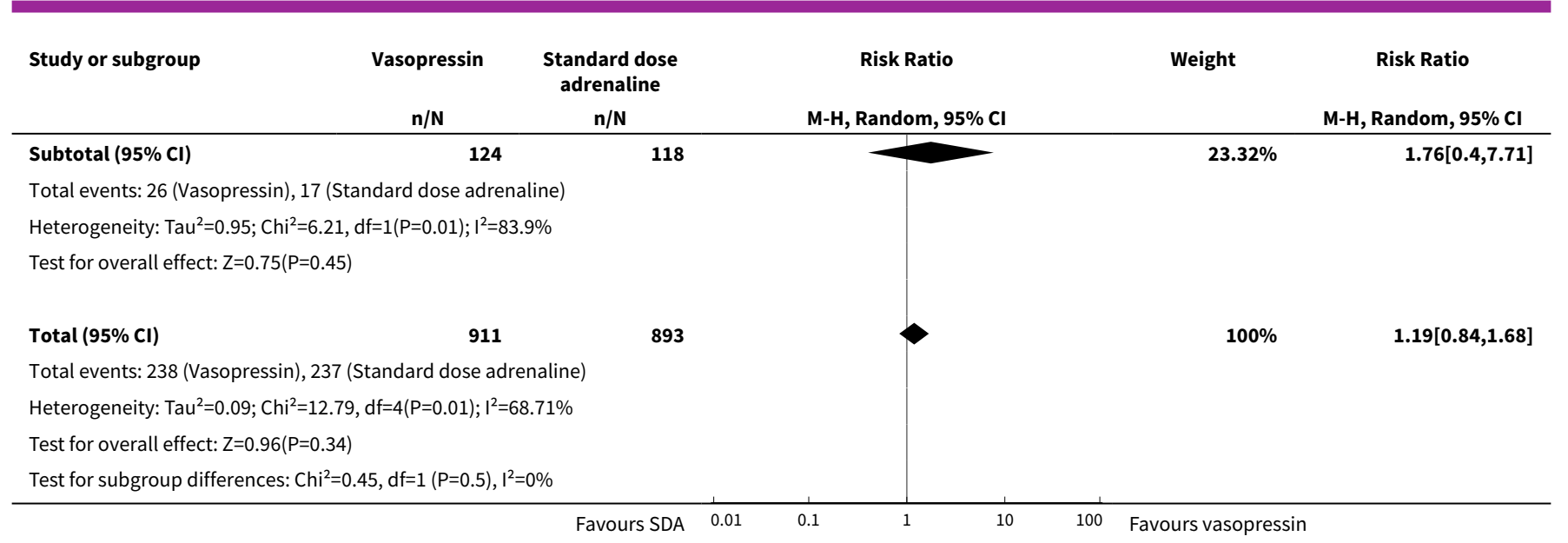

\section{Comparison 4. Standard dose adrenaline (SDA) versus [adrenaline and vasopressin]}

\begin{tabular}{lllll}
\hline Outcome or subgroup title & No. of studies & $\begin{array}{l}\text { No. of partici- } \\
\text { pants }\end{array}$ & Statistical method & Effect size \\
\hline $\begin{array}{l}\text { 1 Survival to hospital dis- } \\
\text { charge }\end{array}$ & 3 & 3242 & Risk Ratio (M-H, Random, 95\% Cl) & $0.76[0.47,1.22]$ \\
\hline $\begin{array}{l}\text { 2 Survival to hospital admis- } \\
\text { sion }\end{array}$ & 3 & 3249 & Risk Ratio (M-H, Random, 95\% Cl) & $0.95[0.83,1.08]$ \\
\hline 3 Neurological Outcome & 1 & & Risk Ratio (M-H, Random, 95\% Cl) & Totals not selected \\
\hline 4 ROSC & 3 & 3249 & Risk Ratio (M-H, Random, 95\% Cl) & $0.97[0.87,1.08]$ \\
\hline
\end{tabular}

Analysis 4.1. Comparison 4 Standard dose adrenaline (SDA) versus [adrenaline and vasopressin], Outcome 1 Survival to hospital discharge.

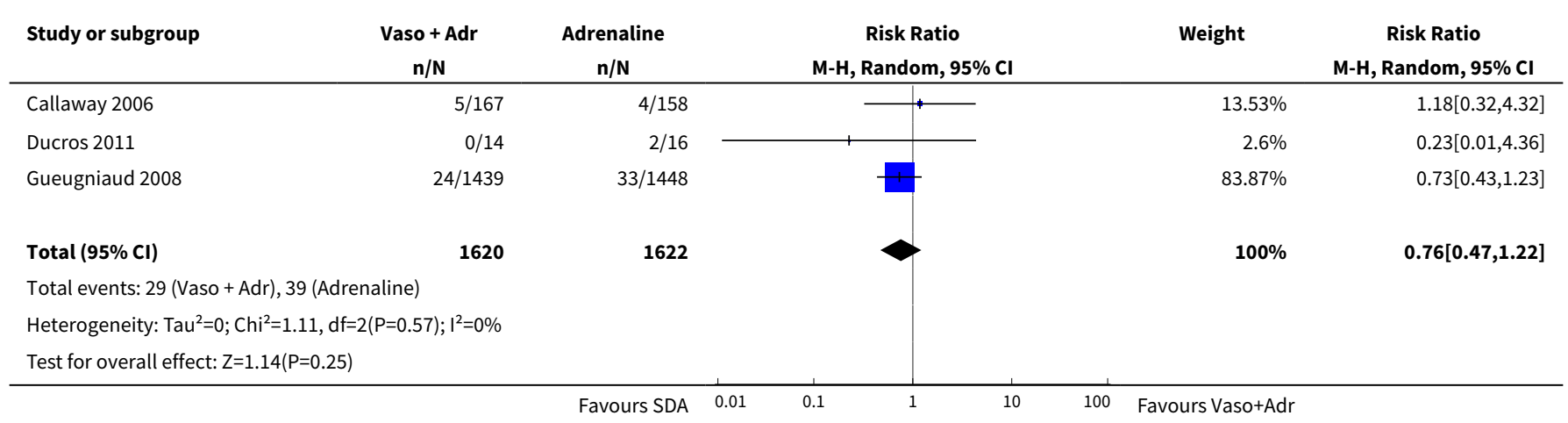


Analysis 4.2. Comparison 4 Standard dose adrenaline (SDA) versus [adrenaline and vasopressin], Outcome 2 Survival to hospital admission.

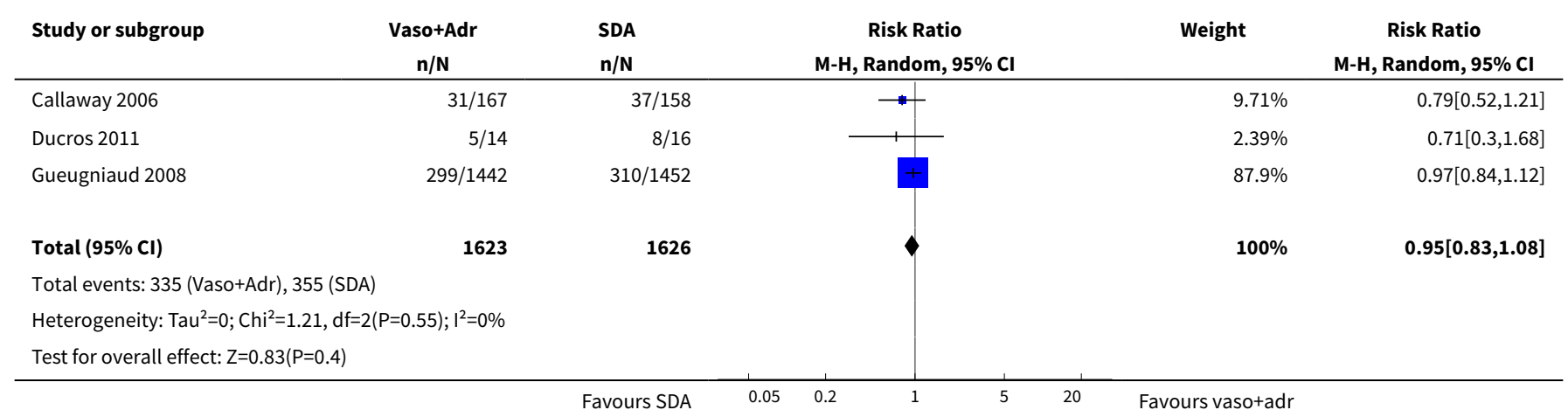

Analysis 4.3. Comparison 4 Standard dose adrenaline (SDA) versus [adrenaline and vasopressin], Outcome 3 Neurological Outcome.

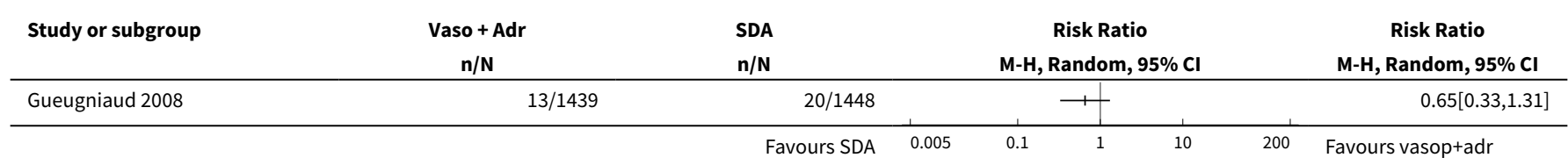

Analysis 4.4. Comparison 4 Standard dose adrenaline (SDA) versus [adrenaline and vasopressin], Outcome 4 ROSC.

\begin{tabular}{|c|c|c|c|c|c|}
\hline Study or subgroup & $\begin{array}{c}\text { Vaso + Adr } \\
\text { n/N }\end{array}$ & $\begin{array}{l}\text { SDA } \\
n / N\end{array}$ & $\begin{array}{c}\text { Risk Ratio } \\
\text { M-H, Random, } 95 \% \mathrm{CI}\end{array}$ & Weight & $\begin{array}{c}\text { Risk Ratio } \\
\text { M-H, Random, } 95 \% \text { CI }\end{array}$ \\
\hline Callaway 2006 & $52 / 167$ & $48 / 158$ & - & $10.61 \%$ & $1.02[0.74,1.42]$ \\
\hline Ducros 2011 & $6 / 14$ & $10 / 16$ & 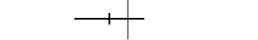 & $2.22 \%$ & $0.69[0.34,1.4]$ \\
\hline Gueugniaud 2008 & $413 / 1442$ & $428 / 1452$ & & $87.18 \%$ & $0.97[0.87,1.09]$ \\
\hline Total $(95 \% \mathrm{Cl})$ & 1623 & 1626 & 4 & $100 \%$ & $0.97[0.87,1.08]$ \\
\hline \multicolumn{6}{|c|}{ Heterogeneity: $\mathrm{Tau}^{2}=0 ; \mathrm{Chi}^{2}=1.02, \mathrm{df}=2(\mathrm{P}=0.6) ; \mathrm{I}^{2}=0 \%$} \\
\hline \multicolumn{6}{|c|}{ Test for overall effect: $\mathrm{Z}=0.57(\mathrm{P}=0.57)$} \\
\hline
\end{tabular}

\section{APPENDICES}

\section{Appendix 1. Search strategy}

\section{CENTRAL \& DARE}

\#1 MeSH descriptor Epinephrine explode all trees

\#2 (adrenalin*)

\#3 (epinephrin ${ }^{*}$ )

\#4 MeSH descriptor Vasopressins explode all trees 
\#5 (vasopressin ${ }^{\star}$ )

\#6 terlipressin

\#7 (antidiuretic hormone* or anti diuretic hormone ${ }^{\star}$ )

\#8 (argipressin)

\#9 (pitressin)

\#10 pressyn

$\# 11$ (petresin)

\#12 (glypressin)

\#13 (\#1 OR \#2 OR \#3 OR \#4 OR \#5 OR \#6 OR \#7 OR \#8 OR \#9 OR \#10 OR \#11 OR \#12)

\#14 MeSH descriptor Heart Arrest explode all trees

\#15 MeSH descriptor Ventricular Fibrillation, this term only

\#16 MeSH descriptor Cardiopulmonary Resuscitation explode all trees

\#17 (cardiac arrest)

$\# 18$ (heart arrest ${ }^{\star}$ )

\#19 (ventricular fibrillation*)

\#20 (acls or als)

\#21 resuscitation

\#22 (advanced near3 support* ${ }^{\star}$ )

\#23 (\#14 OR \#15 OR \#16 OR \#17 OR \#18 OR \#19 OR \#20 OR \#21 OR \#22)

\#24 (\#13 AND \#23)

\section{MEDLINE Ovid}

1 exp Epinephrine/

2 adrenalin\$.tw.

3 epinephrin\$.tw.

4 exp Vasopressins/

5 vasopressin $\$ . t w$.

6 terlipressin.tw.

7 (antidiuretic hormone\$ or anti diuretic hormone\$).tw.

8 argipressin.tw.

9 pitressin.tw.

10 pressyn.tw.

11 petresin.tw.

12 glypressin.tw.

13 or $/ 1-12$

14 exp Heart Arrest/

Adrenaline and vasopressin for cardiac arrest (Review) 
15 Ventricular Fibrillation/

16 exp Cardiopulmonary Resuscitation/

17 cardiac arrest\$.tw.

18 heart arrest\$.tw.

19 ventricular fibrillation\$.tw.

20 (acls or als).tw.

21 resuscitation.tw.

22 (advanced adj3 support\$).tw.

23 or $/ 14-22$

24 randomized controlled trial.pt.

25 controlled clinical trial.pt.

26 randomized.ab.

27 placebo.ab.

28 drug therapy.fs.

29 randomly.ab.

30 trial.ab.

31 groups.ab.

3224 or 25 or 26 or 27 or 28 or 29 or 30 or 31

33 exp animals/ not humans.sh.

3432 not 33

3513 and 23 and 34

\section{Embase Ovid}

1 exp Epinephrine/

2 adrenalin\$.tw.

3 epinephrin\$s.tw.

4 exp Vasopressins/

5 vasopressin\$.tw.

6 terlipressin.tw.

7 (antidiuretic hormone\$ or anti diuretic hormone\$).tw.

8 argipressin.tw.

9 pitressin.tw.

10 pressyn.tw.

11 petresin.tw.

12 glypressin.tw.

13 or/1-12

Adrenaline and vasopressin for cardiac arrest (Review) 
14 exp Heart Arrest/

15 Ventricular Fibrillation/

16 exp Cardiopulmonary Resuscitation/

17 cardiac arrest\$.tw.

18 heart arrest\$.tw.

19 ventricular fibrillation\$.tw.

20 (acls or als).tw.

21 resuscitation.tw.

22 (advanced adj3 support\$).tw.

23 or/14-22

24 random\$.tw.

25 factorial\$.tw.

26 crossover\$.tw.

27 cross over\$.tw.

28 cross-over\$.tw.

29 placebo\$.tw.

30 (doubl\$ adj blind\$).tw.

31 (singl\$ adj blind\$).tw.

32 assign\$.tw.

33 allocat\$.tw.

34 volunteer\$.tw.

35 crossover procedure/

36 double blind procedure/

37 randomized controlled trial/

38 single blind procedure/

3924 or 25 or 26 or 27 or 28 or 29 or 30 or 31 or 32 or 33 or 34 or 35 or 36 or 37 or 38

40 (animal/ or nonhuman/) not human/

4139 not 40

4213 and 23 and 41

\section{Appendix 2. Summary of study characteristics}

Presenting rhythm, witnessed cardiac arrests and bystander CPR for the control group (placebo or standard-dose adrenaline or standard-dose adrenaline and placebo) compared to experimental group (high-dose adrenaline or vasopressin) 


\begin{tabular}{|c|c|c|c|c|c|c|c|c|c|c|c|c|}
\hline \multirow[t]{2}{*}{ Study } & \multicolumn{2}{|c|}{$\begin{array}{l}\text { Number of partici- } \\
\text { pants }\end{array}$} & \multicolumn{2}{|l|}{ VF $\%$} & \multicolumn{2}{|c|}{ Asystole \% } & \multicolumn{2}{|c|}{ PEA \% } & \multicolumn{2}{|c|}{$\begin{array}{l}\text { Bystander } \\
\text { Witnessed arrest \% }\end{array}$} & \multicolumn{2}{|c|}{ Bystander CPR \% } \\
\hline & C & Exp & C & Exp & C & Exp & C & Exp & C & Exp & C & Exp \\
\hline Brown 1992 & 632 & 648 & 49.5 & 45.1 & 31.7 & 33.6 & 18.4 & 20.5 & 39 & 36 & 24 & 23 \\
\hline Callaham 1992 & 260 & 286 & 21 & 26 & 48 & 47 & 31 & 26 & 63 & 63 & 22 & 29 \\
\hline Callaway 2006 & 158 & 167 & 17 & 14 & 51 & 50 & 23 & 22 & 47 & 43 & 35 & 31 \\
\hline Choux 1995 & 265 & 271 & 16 & 18 & 75 & 72 & 9 & 10 & - & - & - & - \\
\hline Ducros 2011 & 16 & 14 & 0 & 14.3 & 50 & 21.4 & 50 & 64.3 & - & - & - & - \\
\hline Gueugniaud 1998 & 1650 & 1667 & 15.9 & 18 & 74.6 & 72.5 & 9.5 & 9.5 & 78.6 & 79.1 & 9.3 & 10.3 \\
\hline Gueugniaud 2008 & 1452 & 1442 & 9.3 & 9.2 & 82.4 & 83.1 & 8.3 & 7.7 & 76.1 & 74.3 & 26 & 27.7 \\
\hline Jacobs 2011 & 262 & 272 & 48.1 & 43.8 & 25.2 & 22.8 & 26.7 & 33.5 & 52.7 & 44.1 & 49.2 & 52.9 \\
\hline Li 1999a & 22 & 21 & - & - & - & - & - & - & - & - & - & - \\
\hline Li 1999 Lo Vaspn & 22 & 20 & - & - & - & - & - & - & - & - & - & - \\
\hline Li 1999 Hi Vaspn & 22 & 20 & - & - & - & - & - & - & - & - & - & - \\
\hline Lindner 1991a & 40 & 28 & - & - & 65 & 68 & 35 & 32 & 60 & 57 & - & - \\
\hline Lindner 1997 & 20 & 20 & 100 & 100 & -- & - & - & & 60 & 65 & 25 & 20 \\
\hline Lipman 1993 & 16 & 19 & & & 100 & 100 & & & & & & \\
\hline Mukoyama 2009 & 158 & 178 & 23 & 25 & 62 & 61 & 15 & 14 & 45.6 & 43.3 & 16.5 & 14 \\
\hline Ong 2012 & 353 & 374 & 7.9 & 5.9 & 67.4 & 70.9 & 20.4 & 17.6 & 75.1 & 70.9 & 14.2 & 16.6 \\
\hline Patterson 2005 & 59 & 95 & & & & & & & 24 & 23 & 37 & 33 \\
\hline Perkins 2018 & 3999 & 4015 & 17.1 & 17.8 & 54.9 & 53.2 & 23.4 & 23.8 & 49.2 & 50.1 & 58.7 & 59.3 \\
\hline
\end{tabular}




\begin{tabular}{|c|c|c|c|c|c|c|c|c|c|c|c|c|c|c|}
\hline 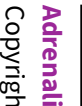 & $\begin{array}{l}\text { (Continued) } \\
\text { Perondi } 2004\end{array}$ & 34 & 34 & 0 & 12 & 82 & 62 & 18 & 26 & - & - & - & - & $0.1,11$ \\
\hline Noّ & Polglase $1994 \mathbf{a}$ & 41 & 30 & - & - & - & - & - & - & - & - & - & - & \\
\hline $\begin{array}{ll}-7 \\
\overline{0} \\
\end{array}$ & Polglase $1994 \mathbf{b}$ & 41 & 34 & - & - & - & - & - & - & - & - & - & - & \\
\hline 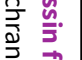 & Sanchez-Mendiola 1998 & 16 & 20 & - & & 100 & 100 & - & & - & - & - & - & \\
\hline$\frac{\varrho}{\overline{2}} \frac{0}{3}$ & Schmidbauer 2000 & 32 & 25 & 44 & 60 & 56 & 40 & - & & - & - & - & - & \\
\hline 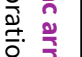 & Sherman 1997 & 62 & 78 & 16 & 31 & 84 & 69 & - & & 74 & 59 & - & - & \\
\hline 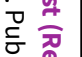 & Stiell 1992 & 333 & 317 & 40 & 43 & 41 & 41 & 16 & 20 & 69 & 69 & 27 & 34 & \\
\hline 尊总 & Stiell 2001 & 96 & 104 & 16 & 20 & 27 & 34 & 54 & 41 & 84 & 78 & - & - & \\
\hline$\frac{0}{\gamma}$ & Wenzel 2004 & 597 & 589 & 42 & 38 & 45 & 44 & 14 & 18 & - & - & 18 & 19 & \\
\hline 啇 & Woodhouse 1995 & 100 & 94 & 37 & 41 & 63 & 59 & - & - & - & - & 33 & 32 & \\
\hline 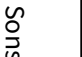 & Zhu 2000 & 20 & 23 & - & - & - & - & - & - & - & - & - & - & \\
\hline
\end{tabular}




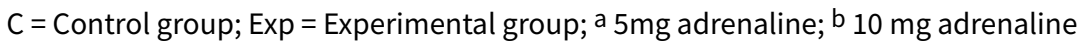

\section{CONTRIBUTIONSOF AUTHORS}

IJ and JF contributed equally to the protocol development.

IJ, JF, TW and GP selected studies for inclusion.

IJ, JF and TW extracted data from the studies and entered data into RevMan.

SG provided statistical advice.

IJ, JF, TW and GP drafted the review text.

JF and GP responded to reviewer feedback and amended review text accordingly.

JF, TW, GP and SG approved the final review.

\section{DECLARATIONS OF INTEREST}

GP is the lead investigator (and JF and SG are co-investigators) on the recent RCT of adrenaline versus placebo in OHCA in the UK, the Paramedic 2 trial (Perkins 2018).

GP has received reimbursement of expenses to attend and speak at CPR conferences and to develop national and international CPR guidelines. He has received payment from Elsevier Publishing for his role as an editor for the journal Resuscitation. He led a trial of adrenaline in out of hospital cardiac arrest, for which his employer received funding from the National Institute for Health Research.

IJ and JF were co-authors on another included study (Jacobs 2011).

TW - none known.

\section{SOURCES OF SUPPORT}

\section{Internal sources}

- Department of Emergency Medicine, University of Western Australia, Australia.

Previous employment (IJ, JF, TW)

- Curtin University, Australia.

Employment - (IJ, JF, TW)

- National Institute for Health Research, UK.

NIHR Senior Investigator

- Intensive Care Foundation, UK.

\section{External sources}

- Australian Resuscitation Council (Western Australian Branch), Australia.

\section{DIFFERENCES BETWEEN PROTOCOL AND REVIEW}

During the conduct of the review the lead author (IJ) passed away suddenly. Study selection, data extraction, quality assessment undertaken by IJ were checked by TW, who then acted as the 2nd review author for the completion of the review. We updated the search strategy to reflect changes in the search terms used in the online databases during the conduct of the review.

Update to protocol: Issue 2, 2003

Vasopressin. Since the protocol, a number of RCTs have been published which compare adrenaline with vasopressin for the treatment of cardiac arrest. We therefore considered it prudent to include studies of vasopressin, in addition to placebo and high-dose adrenaline. This provides a more comprehensive review.

The protocol listed the following possible outcomes, that were not reported in the included studies: all-cause mortality; return of a nonperfusing cardiac rhythm; Presence of organised electrical activity in the heart but producing no cardiac output, also referred to as pulseless electrical activity (PEA); admission to Intensive Care.

In the Methods section of the protocol it states: "Neurological outcome as assessed using either the Glasgow Outcome Scale (Teasdale 1998, Jennett 1975) or Cerebral Performance Category (Jennett 1975)". Whilst CPC scores (and to a lesser extent the GOS) are the most commonly reported methods of reporting neurological outcomes in resuscitation research (because of the relative ease of collection through medical record review), our intention was not to limit neurological outcomes to only those assessed by CPC or GOS. Our definition of 'neurological outcome' in the protocol should have been stated as follows: Neurological outcome (e.g. as assessed using either the 
Glasgow Outcome Scale (Teasdale 1998, Jennett 1975) or Cerebral Performance Category (Jennett 1975). We have therefore also mentioned other neurological assessments (such as the mini-mental score) in the Results.

We have included GRADE 'Summary of findings' tables, although they were not planned, to meet the more recent methodological standards required by Cochrane.

\section{N DEX TERMS}

\section{Medical Subject Headings (MeSH)}

Blood Circulation [ ${ }^{*}$ drug effects] [physiology]; Epinephrine [ ${ }^{*}$ administration \& dosage]; Heart [drug effects]; Heart Arrest [ ${ }^{*}$ drug therapy] [mortality] [physiopathology]; Out-of-Hospital Cardiac Arrest [drug therapy] [mortality]; Patient Admission [*statistics \& numerical data]; Patient Discharge [*statistics \& numerical data]; Placebos [administration \& dosage]; Randomized Controlled Trials as Topic; Survival Analysis; Vasoconstrictor Agents [ ${ }^{\star}$ administration \& dosage]; Vasopressins [ ${ }^{\star}$ administration \& dosage]

\section{MeSH check words}

Adult; Aged; Child; Child, Preschool; Humans; Middle Aged 